\title{
Discharge and water level uncertainty in bifurcating rivers
}

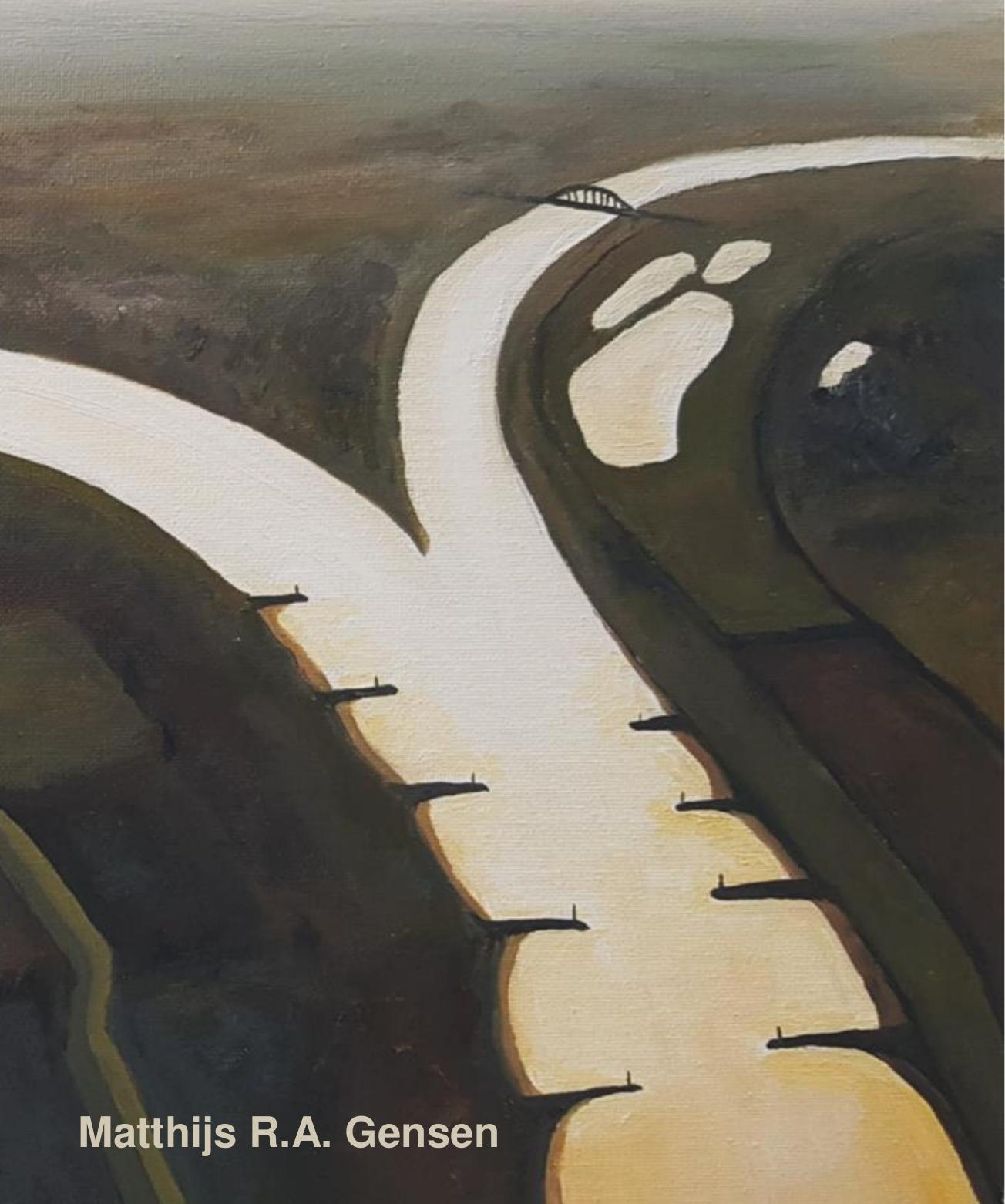




\section{Discharge and water level uncertainty in bifurcating rivers}

Matthijs Robert Alexander Gensen 


\section{This dissertation has been approved by:}

prof.dr. S.J.M.H. Hulscher University of Twente, supervisor

dr. J.J. Warmink University of Twente, co-supervisor

dr. F. Huthoff University of Twente, HKV, co-supervisor

The presented research in this thesis is carried out at the Water Engineering and Management (WEM) department, Civil Engineering, University of Twente, The Netherlands.

This work is part of the Perspective programme All-Risk with project number P15-21, which is (partly) financed by the Netherlands Organisation for Scientific Research (NWO) Domain Applied and Engineering Sciences, in collaboration with the following private and public partners: the Dutch Ministry of Infrastructure and Water Management (Rijkswaterstaat), Deltares, STOWA, HKV consultants, Natuurmonumenten and the regional water authorities Noorderzijlvest, Vechtstromen, it Fryske Gea, HHNK.

ISBN: $978-90-365-5305-6$

DOI: $10.3990 / 1.9789036553056$

Cover design: Matthijs Gensen

Printed by: Ipskamp Printing

Copyright (C) 2021 M.R.A. Gensen, The Netherlands. All rights reserved. No parts of this thesis may be reproduced, stored in a retrieval system or transmitted in any form or by any means without permission of the author. Alle rechten voorbehouden. Niets uit deze uitgave mag worden vermenigvuldigd, in enige vorm of op enige wijze, zonder voorafgaande schriftelijke toestemming van de auteur. 


\title{
DISCHARGE AND WATER LEVEL UNCERTAINTY IN BIFURCATING RIVERS
}

\section{DISSERTATION}

\author{
to obtain \\ the degree of doctor at the University of Twente, \\ on the authority of the Rector Magnificus \\ Prof.dr.ir. A. Veldkamp, \\ on account of the decision of the Doctorate Board, \\ to be publicly defended \\ on Thursday 2 December 2021 at 10.45 hours
}

by

Matthijs Robert Alexander Gensen

born on the $16^{\text {th }}$ of August, 1993

in Apeldoorn, The Netherlands 


\section{Graduation committee:}

prof.dr.ir. H.F.J.M. Koopman University of Twente, chairman and secretary

prof.dr. S.J.M.H. Hulscher

University of Twente, supervisor

dr. J.J. Warmink

University of Twente, co-supervisor

dr. F. Huthoff

University of Twente, HKV, co-supervisor

prof.dr. K.M. Wijnberg

University of Twente

prof.dr. A.A. Voinov

University of Twente

prof.dr. F. Klijn

Delft University of Technology

prof.dr. J.P. Martín-Vide

dr. B.G. van Vuren

Technical University of Catalonia

Rijkswaterstaat 
"To measure is to know"

Lord Kelvin 



\section{Contents}

$\begin{array}{lr}\text { Preface } & 9\end{array}$

$\begin{array}{ll}\text { Summary } & 11\end{array}$

$\begin{array}{lr}\text { Samenvatting } & 13\end{array}$

$\begin{array}{llr} & \text { Introduction } & 17\end{array}$

2 Feedback mechanism in bifurcating river systems: the effect on water level sensitivity $\quad 35$

3 Human interventions in a bifurcating river system: $\begin{array}{ll}\text { numerical investigation and uncertainty assessment } & 57\end{array}$

4 Improving rating curve accuracy by incorporating water balance closure at river bifurcations

$\begin{array}{lll}5 & \text { Discussion } & 101\end{array}$

6 Conclusions and recommendations $\quad \mathbf{1 2 5}$

$\begin{array}{ll}\text { List of references } & 131\end{array}$

$\begin{array}{lr}\text { List of publications } & 141\end{array}$

$\begin{array}{lr}\text { About the author } & 143\end{array}$ 



\section{Preface}

Time flies when you're having fun! But time still flies when you're having less fun. Each of the four years of my PhD flew by. In that time there were many, many ups. Unfortunately, Covid interrupted a lot; cancelled conferences, less discussion about content and fewer social events. In both the good and less good times, many people were there to support me and to keep a smile on my face (and hopefully vice versa)!

First, I would like to thank my promotor Suzanne Hulscher and supervisors Jord Warmink and Freek Huthoff. Suzanne, thank you for the opportunity you gave me. You know that time management wasn't always my strong point, but thank you for keeping me on track and creating the conditions for me to finish in (just over) four years. Jord, you were a great supervisor. You always took your time to give some good feedback on the content and on the process, while also having time for some chit chat. I also very much enjoyed our little competition in the Tubantia Tour de France pools; the final score was 3-1 for me! Freek, you joined a bit later, but helped me with words of encouragement, by asking practical questions and by always being very honest if you didn't like a piece of text I wrote.

Then, I would like to thank everyone within the AllRisk program and more specifically within sub-project B who I worked and spoken with. It were the interesting formal and informal meetings with other $\mathrm{PhDs}$ and end users that helped me shape my research and improve my (presentation) skills. Specifically, I would like to thank Juliette and Tjerk for the collaboration in writing a storyline.

I would also like to thank Koen Berends for our inspiring collaboration, which has led to two papers, one in your thesis and one in mine. Your enthusiasm for the topic of uncertainty has been a great encouragement for me. Furthermore, I would like to thank the many BSc and MSc students who I supervised throughout these years. It has been a great learning experience for me!

A huge thank you goes to all the people within the Water Engineering and Management department. I cannot imagine how boring the past four years would have been without all of you! First, I'd like to thank the secretaries, who always had an answer to even the slightest issues. Then, I want to thank the river-oriented researchers, who were with me in the sea of coastal and offshore oriented in our department. Also a thanks goes out to my roomies Geert, Leonardo, Wessel and Rutger for all the chats we had from behind and next to our screens as I and some of you were too short to look over them. A special mention goes to my AllRisk 
buddy Vera for all those coffee breaks over the years and for willing to be my paranymph. And also a thank you to all the others, with who I did so many fun things: coffee breaks, lunch walks, dinners and daghappen, futsal, running the Batavierenrace, political discussions, pub quizzing, partying, and so much more!

Het laatste dankwoord gaat naar m'n familie en vrienden. Bedankt voor het NIET praten over mijn werk of 'studie' zoals jullie het regelmatig noemden. Die kans kregen jullie ook niet echt van mij, omdat ik dat gesprek maar al te graag afkapte met een 'ja, prima!'. Juist het niet over het werk praten, maakte het werk leuker omdat ik 't nooit mee naar huis hoefde te nemen! In 't bijzonder bedank ik graag jullie: pap, mam, Carmen en Casper. Het laatste en beste dankwoord gaat natuurlijk naar jou Nico! Ik kijk uit naar de in door jullie omringde toekomst.

Bedankt allemaal!

Matthijs 


\section{Summary}

Accurate predictions of water levels, discharges and their uncertainties are essential for flood risk management of rivers. In river deltas, the river often splits into multiple branches. The discharge of the upstream river is distributed over the branches at the bifurcations. This discharge distribution is controlled by the conveyance capacity of the downstream branches. The conveyance capacity, amongst others determined by the hydraulic roughness and geometry of the branch, varies with the water level, giving rise to a feedback mechanism between water levels and discharge distribution. Therefore, the uncertainty in discharge distribution is one of the main drivers of water level uncertainty and associated flood risk.

Previous studies have shown that river water level uncertainties are dominated by discharge and hydraulic roughness uncertainty. Discharge uncertainty, i.e. the uncertain return period of a certain discharge, can mostly be attributed to statistical uncertainties in flood frequency analysis. For a given discharge, the hydraulic roughness of the river bed and of floodplains are the dominant sources of uncertainty for water level prediction. In previous studies, the water level uncertainty caused by these sources of uncertainty has been quantified for singlebranch rivers. The aim of this thesis is to quantify water level uncertainties in a bifurcating river system. The feedback mechanism between discharge distribution and water levels at the bifurcation is explicitly considered. The bifurcating Rhine river in the Netherlands is used as a case study.

In Chapter 2, it is assessed how sensitive water levels are to an uncertain main channel roughness. Main channel roughness in lowland rivers is dominated by the flow resistance caused by bedforms on the river bed. Scenarios for main channel roughness are set up based on available observations of bedforms. Next, the water levels under these roughness scenarios and under a large range of upstream discharge conditions are estimated using a one-dimensional hydraulic model of the Rhine branches. The results show that the feedback mechanism at bifurcations reduces the sensitivity of water levels in a branch to its own main channel roughness. In a single-branch river, a lower roughness significantly reduces water levels. However, a similar change in roughness in a bifurcating river reduces the water levels much less, as the branch with the lower roughness attracts additional discharge from the bifurcation. Consequently, water level uncertainties are reduced in a bifurcating river. The uncertainty in discharge distribution is predominantly caused by the roughness conditions in the largest branch. Therefore, water level uncertainties in the smaller branches, which are the most sensitive to discharge, are dominated by the uncertain roughness conditions in the largest branch. 
In Chapter 3, the impact of water-level-lowering human interventions on water levels and water level uncertainty in bifurcating rivers is investigated. Dike setback and a floodplain excavation are analysed, which are both typical types of interventions that increase conveyance capacity (i.e. Room for the River). An idealised one-dimensional model is set up, which roughly represents the Dutch Rhine river and its distributaries. The impact of the intervention is determined for a range of upstream discharges and considering an uncertain main channel and floodplain roughness. The results show that a single intervention causes a shift in discharge distribution, which subsequently increases water levels downstream of the intervention and decreases water levels in the other branches. The shift in discharge distribution can be counteracted by implementing a second intervention in the opposing branch. This second intervention should be designed to offset the change in discharge distribution caused by the first intervention. However, this can only be achieved for one specific discharge and for specific roughness conditions. Outside of these design conditions, unwanted water level increases will still occur. The results also show that implementing a single intervention or a set of compensating interventions only marginally influences water level uncertainty. Therefore, it is concluded that interventions impact water levels, but only marginally their uncertainties.

In Chapter 4, uncertainties in water levels and discharge distribution at two bifurcations of the Dutch Rhine are quantified by constructing rating curves based on the available discharge and water level gaugings. The results show that it is important to consider bed level degradation that occurs close to the bifurcations to obtain accurate rating curves. Also, the results show that these rating curves do not result in a closing water balance at the bifurcation, for which the inflowing discharge should equal the sum of discharges of the distributaries. Therefore, a bifurcation rating curve model is developed, which significantly improved water balance closure. When water balance closure is accounted for, rating curves are constrained in the extrapolation domain of the rating curves, thereby reducing the water level uncertainty in this domain.

In conclusion, this thesis has shown that the physics of a bifurcation, namely water balance closure and the feedback mechanism between water levels and discharge distribution, significantly affect system-wide water levels and water level uncertainties, and therefore need to be accounted for to accurately estimate the uncertainties in water levels and discharges. It is therefore recommended to consider these physics in flood risk analyses. Observations of discharges and water levels are required to construct rating curves and to calibrate hydraulic models, such that measurement errors may limit the accuracy of both hydraulic models and rating curves. Approaches in which hydraulic models and rating curves are combined may further increase the accuracy of water level predictions, and are therefore proposed for future research. It is also recommended to quantify the effect of the discharge distribution uncertainty on the flood risk along distributaries. 


\section{Samenvatting}

Nauwkeurige voorspellingen van waterstanden, afvoeren en hun onzekerheden zijn essentieel voor het beheren van overstromingsrisico's in rivieren. In rivierdelta's splitst de rivier zich vaak op in meerdere takken. Op de splitsingspunten wordt de bovenstroomse afvoer verdeeld over de riviertakken. Deze afvoerverdeling wordt bepaald door de afvoercapaciteit van de benedenstroomse takken. Deze capaciteit, die onder andere bepaald wordt door de hydraulische ruwheid en de geometrie van de takken, is afhankelijk van de waterstand. Dit zorgt voor een feedback mechanisme tussen de afvoerverdeling en waterstanden. De onzekerheid in afvoerverdeling stuurt daarom in belangrijke mate de onzekerheid in waterstanden en bijbehorende overstromingsrisico's.

Eerdere studies hebben laten zien dat onzekerheden in rivierwaterstanden worden gedomineerd door de onzekerheid in afvoer en ruwheid. Afvoeronzekerheid, oftewel de onzekerheid in de herhalingstijd van een bepaalde afvoer, wordt gedomineerd door de statistische onzekerheid die voortkomt uit afvoerfrequentieanalyses. Voor een gegeven afvoer is de hydraulische ruwheid van de rivierbodem en van uiterwaarden de dominante onzekerheid in waterstandsvoorspellingen. In eerdere studies is het effect van deze bronnen van onzekerheid op waterstanden gekwantificeerd voor losse takken. Het doel van dit onderzoek is om de onzekerheden in rivierwaterstanden te kwantificeren voor een rivier met splitsingspunten. Er wordt daarbij specifiek rekening gehouden met het feedback mechanisme tussen afvoerverdeling en waterstanden op splitsingspunten. Het studiegebied is het Nederlandse deel van de Rijn met haar twee splitsingspunten.

In Hoofdstuk 2 is bepaald hoe gevoelig waterstanden zijn voor een onzekere ruwheid in de hoofdgeul van een rivier. In laagland rivieren wordt de ruwheid van de hoofdgeul voornamelijk bepaald door bodemvormen. Ruwheidsscenario's zijn opgesteld middels beschikbare data van bodemvormen. Daarna zijn de waterstanden bepaald die horen bij deze scenario's en voor een groot afvoerbereik met behulp van een eendimensionaal hydraulisch model van de Rijntakken. De resultaten laten zien dat het feedback mechanisme op splitsingspunten de gevoeligheid van waterstanden voor lokale ruwheidsveranderingen vermindert. In een losse tak zorgt een lagere ruwheid voor een sterk lagere waterstand. Daarentegen zal dezelfde ruwheidsverandering in een tak met bovenstrooms een splitsingspunt extra afvoer gaan trekken, waardoor de waterstanden minder laag zullen zijn. Dit verlaagt de onzekerheid in waterstanden in splitsende rivieren. De onzekerheid in de afvoerverdeling wordt voornamelijk veroorzaakt door de ruwheid van de grootste riviertak. Als gevolg daarvan worden de waterstandsonzekerheden in de kleinere takken, die juist gevoelig zijn voor afvoer, ook voornamelijk bepaald 
door de onzekere ruwheid van de grootste tak.

In Hoofdstuk 3 is de impact van waterstandsverlagende menselijke ingrepen op waterstanden en waterstandsonzekerheden geanalyseerd voor een splitsende rivier. Dijkverlegging en uiterwaardvergraving, beide typische 'Ruimte voor de Rivier' ingrepen die de afvoercapaciteit van een rivier vergroten, zijn onderzocht. Hiervoor is een geïdealiseerd eendimensionaal model opgezet, dat ruwweg de Rijntakken in Nederland beschrijft. Er is rekening gehouden met een groot afvoerbereik en met onzekerheid in de ruwheid van de hoofdgeul en uiterwaarden. De resultaten laten zien dat een enkele ingreep extra afvoer naar de tak trekt, waardoor er benedenstrooms van de ingreep waterstandsverhogingen optreden, en juist waterstandsverlagingen optreden in de andere takken. Deze verandering van de afvoerverdeling kan worden tegengegaan met het implementeren van een compenserende maatregel in een tegenoverliggende tak. Deze tweede ingreep moet zo ontworpen worden dat de verandering van de afvoerverdeling waarvoor de eerste ingreep zorgt, wordt geminimaliseerd. Dit kan echter alleen worden bereikt voor een specifieke afvoer en voor specifieke ruwheden. Als deze precieze ontwerpcondities niet optreden, zal er toch ergens een waterstandsstijging optreden. Verder is ook laten zien dat ingrepen nauwelijks de waterstandsonzekerheid beïnvloeden en dus enkel zorgen voor een gemiddelde, maar onzekere, daling van de waterstand.

In Hoofdstuk 4 zijn de onzekerheden in waterstanden en afvoerverdeling van de Rijn ook bepaald middels het opstellen van afvoer-waterstandskrommes (Qhrelaties). Deze zijn opgesteld middels beschikbare waterstands- en afvoermetingen. De resultaten laten zien dat er rekening gehouden dient te worden met bodemdalingen die plaatsvinden rond de splitsingspunten om nauwkeurige Qhrelaties op te kunnen stellen. Verder laten de resultaten zien dat deze Qhrelaties een niet-sluitende waterbalans hebben. Een waterbalans is gesloten als de inkomende afvoer op een splitsingspunt gelijk is aan de som van de afvoeren van de benedenstroomse takken. Daarom is er een model voor Qh-relaties specifiek voor splitsingspunten opgesteld. Met dit model kan de waterbalans veel beter gesloten worden. Ook beheerst het model de Qh-relaties in het extrapolatiedomein, waardoor de waterstandsonzekerheid in dit domein gereduceerd wordt.

Concluderend, dit onderzoek heeft laten zien er rekening gehouden moet worden met de fysica rond splitsingspunten om nauwkeurige schattingen van waterstanden en afvoerverdeling te kunnen doen Deze fysica bestaat uit een sluitende waterbalans en het feedback mechanisme tussen afvoerverdeling en waterstanden. Daarom is het belangrijk om in riviermanagement altijd rekening te houden met deze fysica. Observaties van waterstanden en afvoeren zijn nodig voor zowel het afleiden van Qh-relaties als voor het kalibreren van hydraulische modellen, waardoor de nauwkeurigheid van beide wordt verminderd door meetfouten. Er worden methodes voorgesteld waarin Qh-relaties en modellen worden gecombineerd, waarbij vervolgonderzoek moet uitwijzen of met zulke 
methodes de nauwkeurigheid van waterstandsvoorspellingen verder kan worden vergroot. Verder wordt ook aanbevolen het effect van de onzekerheid in afvoerverdeling op overstromingsrisico's langs de takken te kwantificeren. 



\section{Chapter 1}

Introduction 
River flooding is one of the most harmful and most frequent natural hazards, causing considerable economic damage and loss of life (Dilley et al, 2005). In river deltas, where rivers split into multiple branches, areas exposed to potential flood risk expand. The joint river delta of the Rhine and Meuse rivers threatens around $30 \%$ of the area of the Netherlands, along with its 4 million inhabitants, with flooding (Deltares, 2018b). The flood risk along the rivers is mainly determined by the river water levels, which strongly depend on the discharge distribution over the distributaries. In such an area, a well-balanced and cost-effective flood risk management strategy is complex. This challenge may further be complicated under the influence of a changing climate, as higher river discharges are expected to occur (Sperna Weiland et al, 2015; Blöschl et al, 2019), thereby increasing flood risk.

Traditionally, flood risk is managed by constructing and raising flood defences, which are typically designed in balance with the value at risk behind the defences. Alternatively, flood risk may be reduced by increasing the conveyance capacity of rivers by making 'Room for the River' to reduce the water levels under extreme discharges (Dierauer et al, 2012; Zevenbergen et al, 2013; Klijn et al, 2018b). That way, both the probability of flooding and expected consequences once a flood occurs are lowered.

Effective flood risk management relies on accurate estimates of the discharges and water levels under the design conditions of the river system (Warmink et al, 2013a). Flood defences are often designed conservatively high to account for the uncertainties in the design conditions (Pahl-Wostl et al, 2011; Warmink et al, 2017), which could include increasing river discharges. By better quantifying the uncertainties associated with the design conditions, the need to design flood defences and interventions conservatively may diminish (Robinson et al, 2017).

\subsection{Bifurcating rivers}

Rivers are rarely a single branch for prolonged reaches, but instead join or split up between their origins and outflow points. In mountainous areas, rivers generally reconnect soon after splitting, forming vast networks of braided rivers. Further downstream, rivers also split and reconnect, creating anabranching river channels with mid-stream islands. In lowland areas, the channels do not necessarily reconnect, potentially forming large river deltas with multiple distributaries having outflow points into lakes, seas, or oceans. At each node where the river splits, i.e. the river bifurcation (Figure 1.1), the discharge and sediment that a river carries is divided over the downstream branches.

The distribution of upstream discharge over the distributaries is determined by the geometry and the water surface slopes of the distributaries (Kleinhans et al, 2011; 


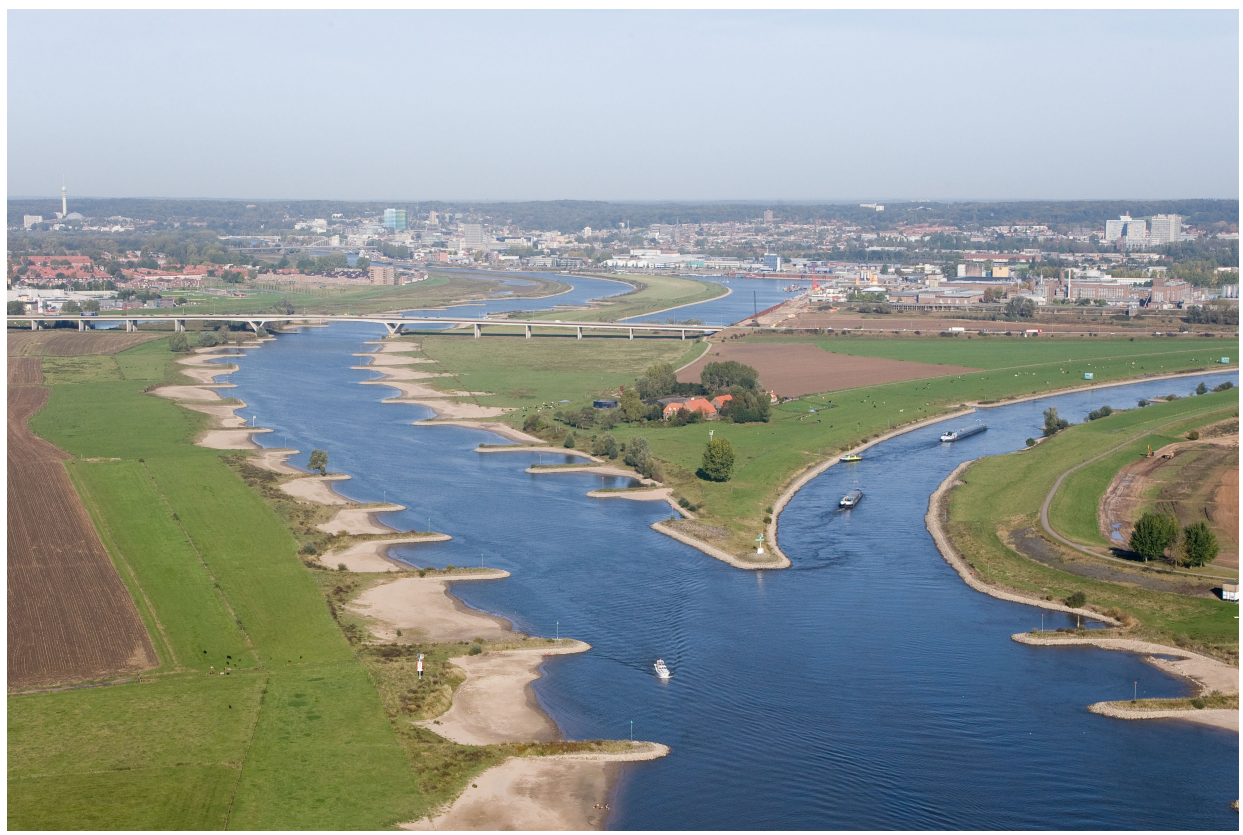

Figure 1.1: IJsselkop bifurcation: one of the two major bifurcations of the Rhine river in the Netherlands (Source: Rijkswaterstaat, 2009). The flow is from the foreground to the background.

Edmonds, 2012). The larger the cross-sectional area of the branch and the higher the water surface slope, the more discharge a distributary will receive (Jansen et al, 1979, i.e. the slope-area method). Naturally, discharges and water levels must be continuous at the bifurcation, where discharge continuity (i.e. a closed water balance) states that the discharge upstream of the bifurcation should equal the sum of discharges of the distributaries. Herein, the relative properties of the downstream branches determine how discharge is distributed, and how water levels both up- and downstream of the bifurcation respond. This apparently simple process leads to non-straightforward impacts when it comes to uncertainties of water levels.

If a bifurcation occurs close to the outflow point of the river into a lake, sea or ocean, water levels along the distributaries are dominated by the downstream water level. The passing of a tidal wave in a sea or ocean is often a main driver of fluctuations in discharge distribution (Buschman et al, 2010; Zhang et al, 2017; Feng et al, 2020). In such tidal rivers, flood risk is nearly unaffected by the discharge distribution as the amount of river discharge has a minimal influence on the water levels along them (Buschman et al, 2010; Feng et al, 2020). In contrast, if a bifurcation occurs further upstream, the discharge distribution dominates the water levels along the distributaries. In turn, the discharge distribution is 
determined by the downstream water levels (Edmonds, 2012). This feedback mechanism between discharge distribution and water levels strongly affects the flood risk along the distributaries.

River deltas are often very populated and therefore, consequences of flooding can be particularly high (Edmonds et al, 2020). River deltas thus experience large flood risks. Because bifurcations implicitly distribute flood risk, as they distribute the discharge over the distributaries, they are sometimes strictly managed. For instance, the Mississippi-Atchafalaya bifurcation is fully controlled by the weirs of the Old River Control System, with which the US Army Corps of Engineers can change the distribution of discharge over the Mississippi and Atchafalaya rivers under both low and high flow conditions. The discharge distribution would strongly change without the control structure (Edmonds, 2012).

In contrast to the fully controlled Mississippi-Atchafalaya bifurcation, the discharge distributions at bifurcations of the Rhine river in the Netherlands are not actively controlled. Instead, the river reaches close to the bifurcations are designed and maintained such that the distribution follows design values that are set by policy (Ten Brinke and Van Zetten, 2020). However, active steering is not possible if the discharge distribution deviates from these design values. Consequently, discharges and water levels along the distributaries may exceed the anticipated design conditions. Therefore, it is important to consider the uncertainty in water levels and discharges and the feedback mechanism between them in the design and assessment of the flood defences along the distributaries.

\subsection{Water level uncertainty for flood risk management purposes}

Accurate water level estimation under flood conditions in rivers is crucial for several flood risk management purposes: design of flood protection systems (Apel et al, 2006; Merz and Thieken, 2009), flood early warning systems (Habert et al, 2016; Ocio et al, 2017), and impact analyses of water-level-lowering human interventions (Berends et al, 2019). Many operational flood risk frameworks around the world, e.g. in the USA (U.S. Army Corps of Engineers, 2017), the UK (Robinson et al, 2017), and the Netherlands (Kok et al, 2017), acknowledge the importance of uncertainty in flood risk management and therefore require the assessment of uncertainties. Herein, uncertainty can be defined as "any deviation of the unachievable ideal of complete deterministic knowledge of the relevant system" (Walker et al, 2003). Information on the uncertainty can influence the decisionmaking process (Downton et al, 2005; Berends et al, 2019). See for example Hall and Solomatine (2008), who argue that with knowledge on the uncertainty, the preference order for measures to reduce flood risk may change or a choice can be 
made for a design that meets the reduction goals under a large range of conditions (i.e. a robust choice).

To assess the uncertainty in river water levels, the most important sources of uncertainty must be identified. Generally, discharge uncertainty (Pappenberger et al, 2006; Warmink et al, 2011; Bozzi et al, 2015) and hydraulic roughness uncertainty (Pappenberger et al, 2006; Warmink et al, 2013b) are seen as the dominant sources of uncertainty in river water level estimation. How these uncertainties arise is described in sections 1.2 .1 and 1.2 .2 , respectively.

\subsubsection{Discharge uncertainty}

Discharge uncertainty in a stretch of river is caused by the uncertain estimate of the return period of the (upstream) discharge and in case the branch is downstream of a bifurcation, also discharge distribution uncertainty. The uncertain return period of upstream discharges is caused by, for example, statistical uncertainty in flood frequency analysis, long-term non-stationarity and errors in discharge observations. The uncertain discharge distribution over distributaries determines the discharge uncertainty for a given upstream discharge in a stretch of river downstream of a bifurcation. Discharge distribution uncertainty is linked to the uncertainties in downstream water levels through the feedback mechanism between water levels and discharge distribution at the bifurcation. The uncertainty in downstream water levels can in turn be attributed to other sources of uncertainty, e.g. hydraulic roughness uncertainty, such that the discharge distribution uncertainty is also dependent on those sources of uncertainty.

The uncertainty in the return period of upstream discharges is mostly the result of statistical uncertainties when estimating the return period, especially for very high discharges (Di Baldassarre et al, 2009; Merz and Thieken, 2009; Bomers et al, 2019a). Return periods of discharges are generally estimated using flood frequency analyses, in which a probability distribution is fitted to a set of observed discharge extremes. However, this observational record is often limited, resulting in large uncertainties in the estimation of return periods of high discharges (Bomers et al, 2019a). Although several methods are available to reduce the uncertainty in flood frequency analysis (see for example Hegnauer et al, 2014; Bomers et al, 2019a), the uncertainty of the return period associated with very high discharges remains large. On top of statistical uncertainties, estimates of the return period of upstream discharges may also be uncertain due to long-term changes in the return periods. Such long-term changes can be the result of climate change and variability (Toonen et al, 2016; Winsemius et al, 2016; Blöschl et al, 2019) and land-use changes (Pinter et al, 2006). Both past (Pinter et al, 2006) as future (Blöschl et al, 2019) changes may influence the estimation of return periods of high discharges. 
Errors in discharge observations introduce additional uncertainty in flood frequency analysis. Discharge observation errors may also introduce uncertainty in hydraulic model results when the observations are used in the calibration of hydraulic models (Domeneghetti et al, 2012). Direct measurement errors are generally in the order of 5\% (ISO 1100-2, 2010; Di Baldassarre and Montanari, 2009). However, if discharges are obtained via rating curves (i.e. relations between discharge and water level used to estimate discharges), errors can increase to up to 30\% (Kuczera, 1996; Di Baldassarre et al, 2012). In flood frequency analyses, such errors can result in very large uncertainties in design flood estimation, sometimes even exceeding the statistical uncertainties that are the result of the limited length of the observational record (Steinbakk et al, 2016).

\subsubsection{Hydraulic roughness uncertainty}

Flow resistance and its representation in models are the most dominant sources of uncertainty for water level predictions for a given discharge in a stretch of river (Warmink et al, 2011). Being a dominant source of water level uncertainty, hydraulic roughness uncertainty also has a dominant influence on discharge distribution uncertainty. Both the hydraulic roughness caused by the occurrence of bedforms in the main channel (Warmink et al, 2013a) and the hydraulic roughness caused by vegetation on floodplains are significant sources of uncertainty (Straatsma and Huthoff, 2011).

Most flow resistance in the main channel is caused by the occurrence of bedforms on the river bed. However, the processes of bedform growth and decay (Best, 2005), the spatial variability in bedform dimensions (Frings and Kleinhans, 2008) the flow resistance they cause (Naqshband et al, 2017), and the potential flattening in Upper Stage Plane Bed (Naqshband et al, 2014; Van Duin et al, 2017), are not well understood in natural rivers. Furthermore, roughness in hydraulic models often represents other energy losses as well (Pappenberger et al, 2005). This is one of the reasons that the main channel roughness is often used as a calibration parameter in hydraulic models. However, using the model outside of the calibrated conditions may cause significant errors in the model predictions (Horritt et al, 2007).

Most flow resistance on floodplains can be attributed to the presence of vegetation. Often, the vegetation shows large spatial variability, which can result in a large source of uncertainty in water levels if patches of vegetation are observed, classified, or discretised onto a model grid incorrectly (Straatsma and Huthoff, 2011). Furthermore, uncertainty in river water level estimations arises in the estimation of roughness via vegetation formulas (Warmink et al, 2013b; Berends et al, 2020) and due to seasonal variation in the vegetation cover (Makaske et al, 2011; Perret et al, 2021). 


\subsection{Quantifying water level and discharge uncertainty}

Several techniques can be used to qualify or quantify uncertainties in water levels for flood risk management purposes: expert elicitation (Warmink et al, 2011), data analysis (Okoli et al, 2019) and hydraulic modelling (e.g. Warmink et al, 2013b; Bozzi et al, 2015).

Experts are often elicited if data or models are scarce or absent (Refsgaard et al, 2007). The advantage of expert elicitation is that expert knowledge that has not been or cannot be captured in data or models can still be used in uncertainty analysis (Refsgaard et al, 2010). Warmink et al (2011) have elicited experts to identify and quantify the most important sources of uncertainty for modelled water levels in the Dutch river Waal. Results obtained via expert elicitation may be prone to bias from several sources (Refsgaard et al, 2007; Warmink et al, 2011). For example, experts often base their estimates on earlier studies or conventional values instead of basing them on their own expertise. Furthermore, they may under- or overestimate their capability to accurately estimate the uncertainty. While the most important sources of uncertainty may be correctly identified, it may prove difficult to quantify the uncertainties, especially if the estimates of the experts are very different (Refsgaard et al, 2007).

For observed conditions, data analysis can be used to quantify water level and discharge uncertainty (Okoli et al, 2019). The relationship between them can be established using a best-fit technique on available pairs of discharge and water level gaugings. This relationship, i.e. a rating curve, is often applied to predict the river's discharge from a water level gauging. These discharge predictions are used for a wide range of flood risk management purposes, such as flood frequency analysis (Steinbakk et al, 2016), hydraulic model calibration and validation (Domeneghetti et al, 2012), and flood forecasting (Ocio et al, 2017). A rating curve can be a deterministic function, but can also be a probabilistic function. The advantage of a probabilistic rating curve is that it uses direct observations to obtain insight into water levels, discharges and their uncertainties in the observed discharge domain and beyond this domain. Rating curves are often extrapolated beyond the observed domain to evaluate water levels and discharges under flood conditions (Pappenberger et al, 2006). This extrapolation is the largest source of uncertainty in discharge and water level estimates when using rating curves (Domeneghetti et al, 2012). Furthermore, rating curve uncertainty also arises when a river system changes over time, through, e.g. morphological development Mansanarez et al (2019a), hydraulic roughness changes Perret et al (2021) or human interventions Berends et al (2021).

For unobserved conditions, hydraulic modelling can be used to predict water levels for unrecorded higher discharges or to predict the effects of changes to the 
river system. The advantage of hydraulic modelling is that physics are included, especially in the unobserved domain in which knowledge on the geometry and hydraulic roughness can be included when predicting water levels. Furthermore, hydraulic models may be used to assess the sensitivity of water levels to changes in such physical parameters, e.g. a change in hydraulic roughness or geometry. The accuracy of an uncertainty analysis using hydraulic models highly depends on the quantification of the uncertainty sources (Pianosi et al, 2016). This quantification can be in the form of physically realistic limits, scenarios or probability distributions. These can subsequently be propagated through a hydraulic model to find the effect of the uncertain parameters on water levels. Here, correlations between sources of uncertainty should be taken into account to acquire accurate uncertainty estimates (Pappenberger et al, 2008), but which in practice is often not done.

\subsection{Knowledge gap}

Accurate water level predictions for a range of discharge conditions are essential for flood risk management of river systems. Discharge and roughness uncertainty have proved to be dominant sources of uncertainty in water level predictions. Many studies have been conducted to assess the effect of these uncertainties on water levels in a single-channel river, e.g. for the Waal river (Warmink et al, 2013a), the Po river (Bozzi et al, 2015), and the Alzette river (Pappenberger et al, 2008).

However, in bifurcating rivers, the role of the bifurcations in the uncertainty of flood water levels is not yet known. In bifurcating rivers, water levels along the distributaries and the discharge distribution at the bifurcation are interdependent. This feedback mechanism between discharge and water levels is expected to impact the response of water levels to the most important sources of uncertainty, thereby not knowing whether water level uncertainty will increase or decrease as a result.

Furthermore, the implementation of human interventions may introduce uncertainty in water levels. Hydraulic models are generally used to assess the effect of interventions, but this analysis is prone to significant uncertainty (Berends et al, 2019). The impact of interventions and its uncertainty has been assessed for a single-branch river (Berends et al, 2019), but has not yet been assessed for a bifurcating river. It can be expected that the feedback mechanism at the bifurcation affects the uncertain impact of the intervention on water levels, but it is unknown how much it affects the local water-level-lowering impact and whether and how much water levels are affected system-wide. Furthermore, it is not known whether implementing an intervention affects water level and discharge distribution uncertainties in a bifurcating river.

For observed conditions, water level and discharge gaugings may be used to assess 
water level and discharge uncertainty through the construction of probabilistic rating curves. In a bifurcating river, a non-closing water balance between the rating curves suggests they are erroneous, but it is not clear what causes these errors (Twijnstra et al, 2020). To date, no research has been conducted on how probabilistic rating curves can accurately be constructed, specifically taking into account the water balance at the bifurcation. Subsequently, it is unknown to what extent accounting for water balance closure affects discharge distribution and water level uncertainty. Such probabilistic rating curve results may also show how well hydraulic model results compare with the gaugings.

\subsection{Aim and research questions}

The aim of this research is:

to quantify water level uncertainties in a bifurcating river system

The following research questions, also schematised in Figure 1.2, are formulated:

- RQ1: What is the sensitivity of water levels in a bifurcating river system to an uncertain main channel roughness?

- RQ2: What is the water-level-lowering impact of interventions in a bifurcating river system under discharge and roughness uncertainty?

- RQ3: To what extent does incorporating water balance closure at river bifurcations affect the rating curves and subsequent discharge and water level uncertainty?

\subsection{Methodology}

Water level uncertainty, thereby considering its interdependency with the discharge distribution, is quantified for a bifurcating river system using hydraulic models (RQ1 and RQ2) and data analysis (RQ3). The bifurcating Rhine river is used as a case study. In the Netherlands, the Rhine has two major bifurcation points, of which the discharge distribution is not actively steered for high discharges. Furthermore, the bifurcations are located sufficiently far away from the outflow points for the discharge distribution to not be significantly influenced by the sea and lake water levels. At these two bifurcation points, the feedback mechanism between discharge distribution and water levels may have an important effect on 


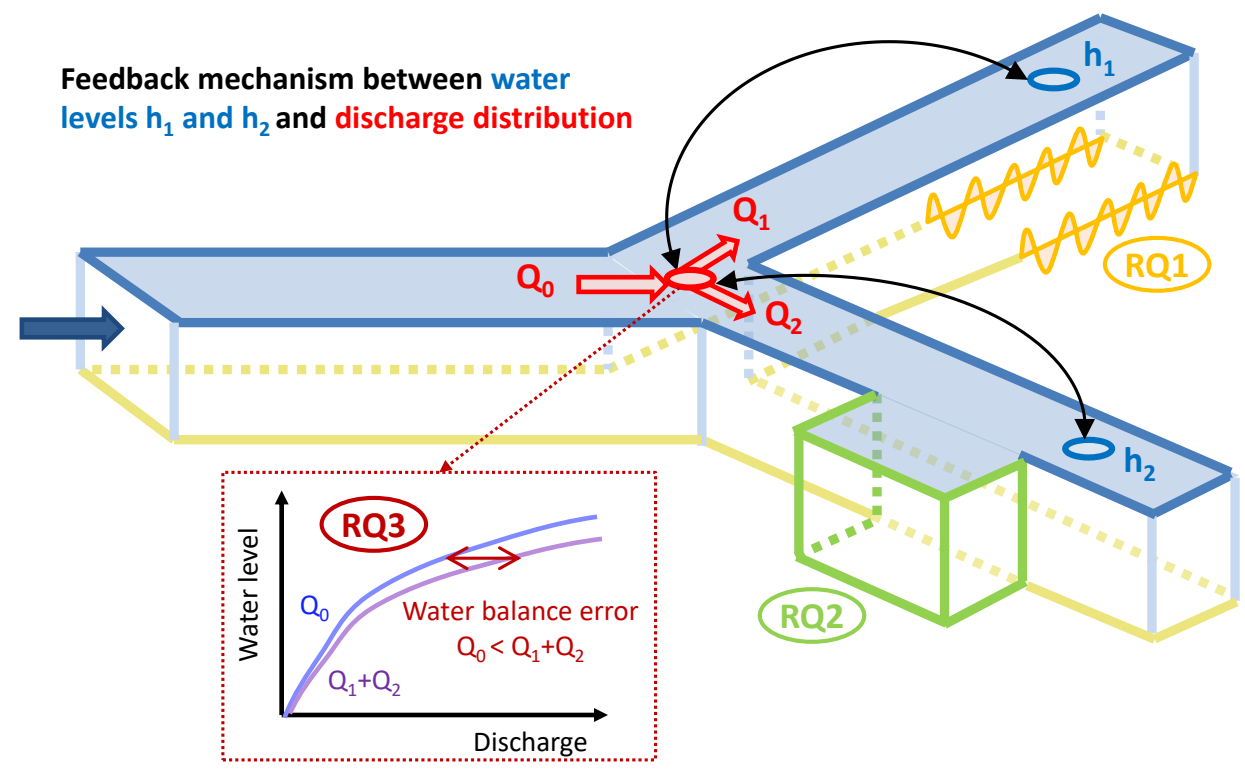

Figure 1.2: Schematisation of the research questions and of the feedback mechanism between discharge $(Q)$ distribution at the bifurcation and the water levels in the two downstream branches $\left(h_{1}\right.$ and $\left.h_{2}\right)$.

system-wide water level uncertainty. The study area is discussed in section 1.7. Below, the methodology for each research question is described:

RQ1: The sensitivity of water levels to variations in main channel roughness is quantified for a single-branch river and for a bifurcating river system. Singlebranch rivers and bifurcating rivers are analysed separately to assess the role of the feedback mechanism between water levels and discharge distribution on the sensitivity of water levels to roughness variations. Using available measurements of bedform dimensions in the Rhine branches, realistic upper and lower limits of the main channel roughness are estimated. These are combined to obtain a total of 16 roughness scenarios. The sensitivity analysis is performed using a realistic one-dimensional hydraulic model of the Rhine branches. Discharge uncertainty is accounted for by considering the entire range of possible discharges at the upstream boundary. The results show the impact of the feedback mechanism at river bifurcations on water level uncertainties.

RQ2: The impact of water-level-lowering interventions in the vicinity of a bifurcation is quantified using an idealised 1D hydraulic model roughly representing the Rhine branches. The idealised model has a constant bed slope and a uniform cross-section along each branch. Typical water-level-lowering interventions such as dike set-backs and floodplain excavations are studied. 
Firstly, a single intervention is assessed. Secondly, an additional intervention is implemented in the model which aims at compensating for the change in discharge distribution that a single intervention causes. Three combinations of intervention types that compensate for each other are assessed. The impact of the interventions is quantified for a wide range of discharge and roughness conditions.

RQ3: To quantify water level and discharge uncertainty, probabilistic rating curves are constructed for each of the branches at the two bifurcations of the Dutch Rhine. A 31-year record of discharge and water level gaugings is used. First, rating curves are constructed independently for each of the locations by Bayesian inference and Markov Chain Monte Carlo sampling. Secondly, bed level degradation, which was shown to cause a linear decrease in water levels over time, is accounted for in the rating curve model. Thirdly, water balance closure (i.e. discharge continuity) is considered in the construction of the rating curves at a bifurcation.

\subsection{Case: the bifurcating Dutch Rhine river}

The watershed of the river Rhine stretches over five countries before it enters the Netherlands. In the Netherlands, the Rhine discharge is divided over three distributaries (Figure 1.3). First, a few kilometers after entering the Netherlands at Lobith, the Bovenrijn (upper part of the Rhine) bifurcates into the Waal and Pannerdensch Kanaal at the Pannerdensche Kop bifurcation. The Pannerdensch Kanaal is a six-kilometer-long channel that connects the first bifurcation to the second bifurcation: the IJsselkop. At this second bifurcation, the water is divided over the Nederrijn (Lower Rhine) and the IJssel. The discharge distribution over the distributaries is approximately: $2 / 3^{\text {rd }}$ to the Waal, $2 / 9^{\text {th }}$ to the Nederrijn and $1 / 9^{\text {th }}$ to the IJssel. This discharge has been fixed by policy. The three distributaries have a length of approximately 100 kilometers.

\subsubsection{Human interventions in the Dutch Rhine}

Before human intervention, the Rhine branches consisted of many shallow channels and had large meander bends (Ten Brinke and Van Zetten, 2020). At that time, avulsions were frequent (Stouthamer and Berendsen, 2001). Once a new and often shorter route to the sea was formed due to flooding, this branch quickly became the dominant discharge distributary. Since the avulsion occurred that formed the IJssel river (Dierx et al, 2021), the Rhine discharge is conveyed to the sea in both westward and northward directions. Both directions were important distributaries of the discharges. The Sint-Elisabeth flood events in the $15^{\text {th }}$ century shortened the western route towards the sea, which therefore became the dominant distributary. 


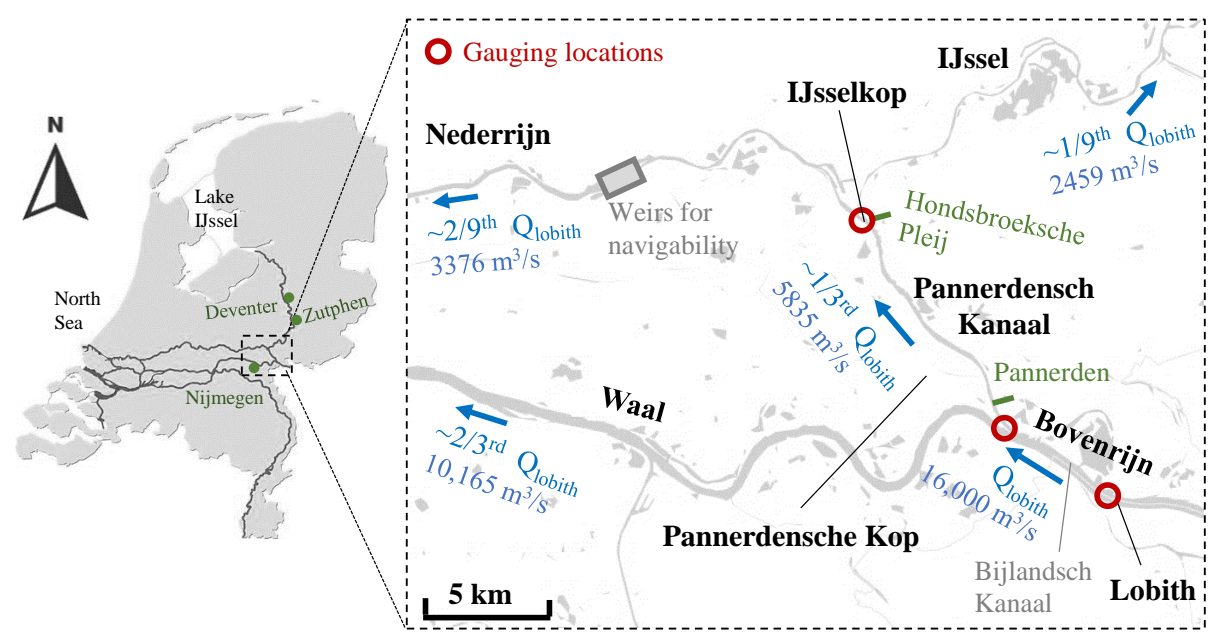

Figure 1.3: Map of the Rhine distributaries in the Netherlands, the approximate discharge distribution over the distributaries and the exact design distribution for a Rhine discharge at Lobith of $16,000 \mathrm{~m}^{3} / \mathrm{s}$. The outflow points of the Waal and Nederrijn is the North Sea, while the IJssel discharges into Lake IJssel.

As a result, sedimentation occurred in the Nederrijn and IJssel (Ten Brinke and Van Zetten, 2020). To avoid full closure of these branches and to create a more direct route towards them (Kleinhans et al, 2011), the Pannerdensch Kanaal was dug and was opened in 1707.

Decades later, a meander bend upstream of the newly formed bifurcation threatened to cut off the bifurcation what would lead to an exceedingly large discharge diverted towards the north (Kleinhans et al, 2013). To increase flood safety and ensure good navigability of the Bovenrijn, the three-kilometer long Bijlandsch Kanaal was dug and was opened in 1776. It is situated just downstream of Lobith, where it cuts off the meander bend that is still a body of water nowadays. In the same period, the IJsselkop bifurcation was altered (Ten Brinke and Van Zetten, 2020), as the original planform had a sharp take-off angle, which caused sedimentation in the IJssel and hindered navigation as a result. Ever since, the planform of the bifurcations has been roughly the same (Kleinhans et al, 2013), as well as the approximate distribution of Rhine discharge over the distributaries: $2 / 3^{\text {rd }}, 2 / 9^{\text {th }}$ and $1 / 9^{\text {th }}$ to the Waal, Nederrijn, and IJssel, respectively.

In the $19^{\text {th }}$ and beginning of the $20^{\text {th }}$ century, the rivers were normalised to a single and narrow channel (Ten Brinke and Van Zetten, 2020). This improved the conveyance capacity of the rivers to carry the discharge towards the sea safely and at the same time improved the navigability of the rivers. However, due to this narrowing, possibly together with a decreased sediment supply from upstream 
(Middelkoop et al, 2010), large-scale channel erosion occurred. This erosion is still ongoing nowadays (Ylla Arbós et al, 2020b).

With the normalisation of the rivers, the floodplain area of the Rhine distributaries decreased strongly (Middelkoop et al, 2010), resulting in higher flood water levels (Klijn et al, 2013). With the recently constructed projects under the Room for the River program, the floodplain area has increased slightly again (Klijn et al, 2018b). The Room for the River projects aimed at increasing the conveyance capacity of the river branches without raising dikes. Typical projects were dike set-backs, side-channels, and floodplain excavations. Based on model evaluations, the interventions reduce the design water levels under flood conditions at several crucial locations along the Rhine branches (Berends et al, 2021).

Within the scope of the Room for the River projects, regulation structures (Figure 1.4) were built near the bifurcation points to have more control options over the discharge distribution (Ten Brinke and Van Zetten, 2020). These structures allow alteration of the discharge distribution to meet the discharge distribution set in the policy. The regulation structures, named Pannerden and Hondsbroeksche Pleij, are located in the floodplain of the Pannerdensch Kanaal and the IJssel, respectively (Figure 1.3). They are divided into several weirs of which the height can be changed by adding or removing beams that make up the weir. The smaller the flow area through the weirs, the more discharge is steered towards the opposing branch, i.e. towards the Waal for Pannerden and towards the Nederrijn for Hondsbroeksche Pleij. The structures thus allow for alteration of the discharge distribution, even though at the moment active steering during the flood season is not possible.

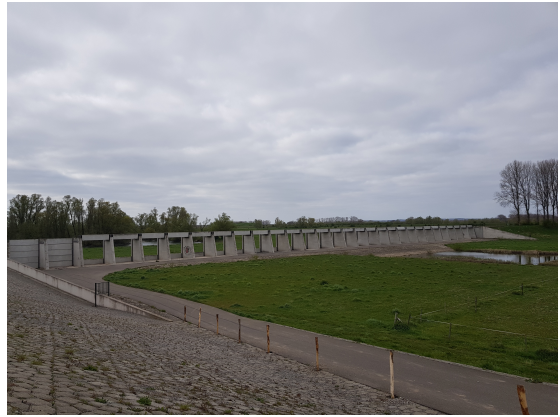

(a) Pannerden, located in the floodplain of the Pannerdensch Kanaal just downstream of the Pannerdensche Kop bifurcation. The picture shows the structure with nearly all beams removed. Photo: Matthijs Gensen

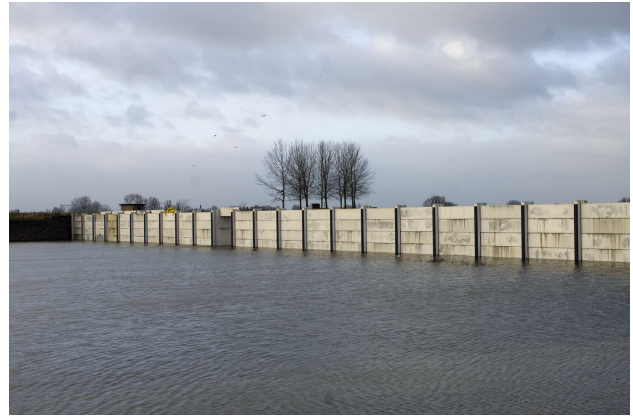

(b) Hondsbroeksche Pleij, located in the floodplain of the IJssel just downstream of the IJsselkop bifurcaiton. The picture shows the inundated floodplain and the structure almost fully. Photo: Rijkswaterstaat (2012)

Figure 1.4: Regulation structures at the bifurcations of the Dutch Rhine 


\subsubsection{Main characteristics of the Rhine branches}

The Rhine river and its distributaries are lowland rivers with a compound cross-section and a low gradient bed slope (Reeze et al, 2017). The three distributaries have approximately similar characteristics, with some slight but important differences in relative floodplain width and bed sediment characteristics.

The average discharge of the Rhine river at Lobith is around $2200 \mathrm{~m}^{3} / \mathrm{s}$. For lower discharges, weirs in the Nederrijn at Driel (Figure 1.3) increase the water levels to ensure navigability of the Rhine branches. For these low discharges, over $80 \%$ of the Rhine discharge is carried by the Waal branch and the remainder is mainly carried by the IJssel branch. For Rhine discharges over $2600 \mathrm{~m}^{3} / \mathrm{s}$ the weirs are fully opened and the Nederrijn is a free-flowing river.

A typical cross-section of the Rhine distributaries has a single, deep main channel ( $\sim 8 \mathrm{~m}$ up to the floodplain level) and wide, vegetated floodplains bounded by dikes. Often, the main channel has groynes on either or both sides to confine the flow area and improve the navigability for low discharges. Mostly, the floodplains are demarcated from the main channel by minor embankments (Dutch: zomerdijk) to avoid flooding of the floodplains in the summer for moderately high discharges (Middelkoop et al, 2010). These embankments are overtopped, and discharge is conveyed over the floodplains for discharges higher than the bankfull discharge of approximately $5000 \mathrm{~m}^{3} / \mathrm{s}$ at Lobith (Reeze et al, 2017). The width of the floodplains varies over the length of the branches and also between the branches (Ten Brinke and Van Zetten, 2020). Restricted floodplain widths are mainly found around cities (e.g. Nijmegen, Zutphen and Deventer). Floodplains are as wide as $3 \mathrm{~km}$ at locations along the IJssel river, where large meander bends are cut off with flow passing over the floodplains. Compared to the fraction of discharge the branches carry, the Waal has relatively narrow floodplains (Klijn et al, 2018a) with an average width of approximately $550 \mathrm{~m}$ (Reeze et al, 2017).

The distributaries have different morphological characteristics. While the average bed slopes of the branches are all in the order of $10 \mathrm{~cm} / \mathrm{km}$ (Reeze et al, 2017), the Pannerdensch Kanaal and the most upstream reaches of the Nederrijn and IJssel have slightly higher bed slopes of around $12 \mathrm{~cm} / \mathrm{km}$. The bed sediment in the Pannerdensch Kanaal is coarser than the Waal due to bend sorting in the upstream river bend (Frings and Kleinhans, 2008). The river beds in the upstream reaches of the Nederrijn and IJssel consist of coarse sands and fine gravels (1-5mm), whereas more downstream, the river beds are mostly sand and silt-dominated. Recent measurement campaigns have shown that the bed composition of the Waal branch is becoming coarser as the sandy top layers are eroded (Ten Brinke and Van Zetten, 2020). The pace of bed level erosion differs per river branch, with the river bed of the Waal bed eroding faster than that of the Pannerdensch Kanaal. As a result, the discharge distribution at the Pannerdensche Kop changes over time, with more discharge diverted towards the Waal. 


\subsubsection{Flood risk policy}

In 2017, the flood risk framework in the Netherlands has undergone a major change: from flood risk fully dependent on the exceedance probability of a single water level to a probabilistic approach based on both flooding probabilities and associated consequences (Kok et al, 2017). Under the old framework, the Rhine branches had to be designed such that they had sufficient conveyance capacity for a design discharge of $16,000 \mathrm{~m}^{3}$ that has an estimated return period of 1250 years. Herein, the heights of the dikes were determined by the water levels that correspond to the design discharge and a safety margin. With the Room for the River program, the dikes met the safety requirements under this old framework. Under the new flood risk framework (Kok et al, 2017), actual flood risk is considered, which includes flooding probabilities under different flooding scenarios and consequences of flooding. Safety standards for the flood protection system are also based on this new framework. Calculations show that currently the dikes are not strong enough and could fail as a result of geotechnical failure mechanisms such as macro-stability or piping at discharges much lower than the design discharge. Dike reinforcements are thus required to meet the new safety standards. Dike reinforcements are planned under the Flood Protection Program (Dutch: Hoogwaterbeschermingsprogramma). As flooding may occur during all bankfull-exceeding discharges, the flooding probabilities depend on all discharges exceeding the bankfull level. Accurate estimates of water levels for all return periods are thus required for accurate flood risk management.

As the discharge distribution over the distributaries is crucial for the downstream flood risk, the discharge distribution is part of the flood risk policy. The policy discharge distribution sets the design distribution for the former design discharge of $16,000 \mathrm{~m}^{3} / \mathrm{s}$. Under the new flood risk approach, the policy discharge distribution was maintained. Consequently, the discharge distribution for Rhine discharges other than $16,000 \mathrm{~m}^{3} / \mathrm{s}$ have become relevant in flood risk management. For extremely high discharges, the policy aims at having the Nederrijn discharge not exceed $3376 \mathrm{~m}^{3} / \mathrm{s}$, which corresponds to the design discharge at a Bovenrijn discharge of $16,000 \mathrm{~m}^{3} / \mathrm{s}$. Along the Nederrijn, dike reinforcements are more expensive than along the other branches. For such extreme discharges, additional discharge is therefore preferred to be divided over the other distributaries. Any additional discharge should be distributed over the Waal and IJssel branch instead. This policy is currently not met in practice (Ten Brinke and Van Zetten, 2020). With a focus on the long term, the year 2050 and further, a different discharge distribution could increase flood safety and cost efficiency (Deltares, 2018a). Dikes are designed for a period of 50 years, so future changes to the flood risk should already be accounted for in the current design of dikes. It is likely that the policy aimed at a certain maximum discharge towards the Nederrijn will remain in place. Therefore, research is being performed on what the discharge distribution should be for extreme discharges and how this should be achieved. For instance, the potential for more discharge towards the IJssel is investigated, as this branch is 
able to carry relatively more discharge because of its relatively wide floodplains in comparison to the Waal branch (Klijn et al, 2018a)

\subsection{Outline}

The structure of this thesis is as follows (Figure 1.5). In Chapter 2, RQ1 is answered by hydraulically modelling the water level changes that occur in singlechannel and bifurcating rivers under various roughness conditions. In Chapter 3, RQ2 is addressed by estimating the water-level-lowering impact of typical interventions such as dike set-back and floodplain excavations and to assess the effect of the feedback mechanism at the bifurcation on this. In Chapter 4, RQ3 is answered by constructing rating curves at the bifurcations of the Dutch Rhine using the available 31-year long observational record. Chapter 5 provides a discussion of the main results and links the results from the three research questions in the context of flood risk management. Finally, Chapter 6 gives the conclusions and recommendations.

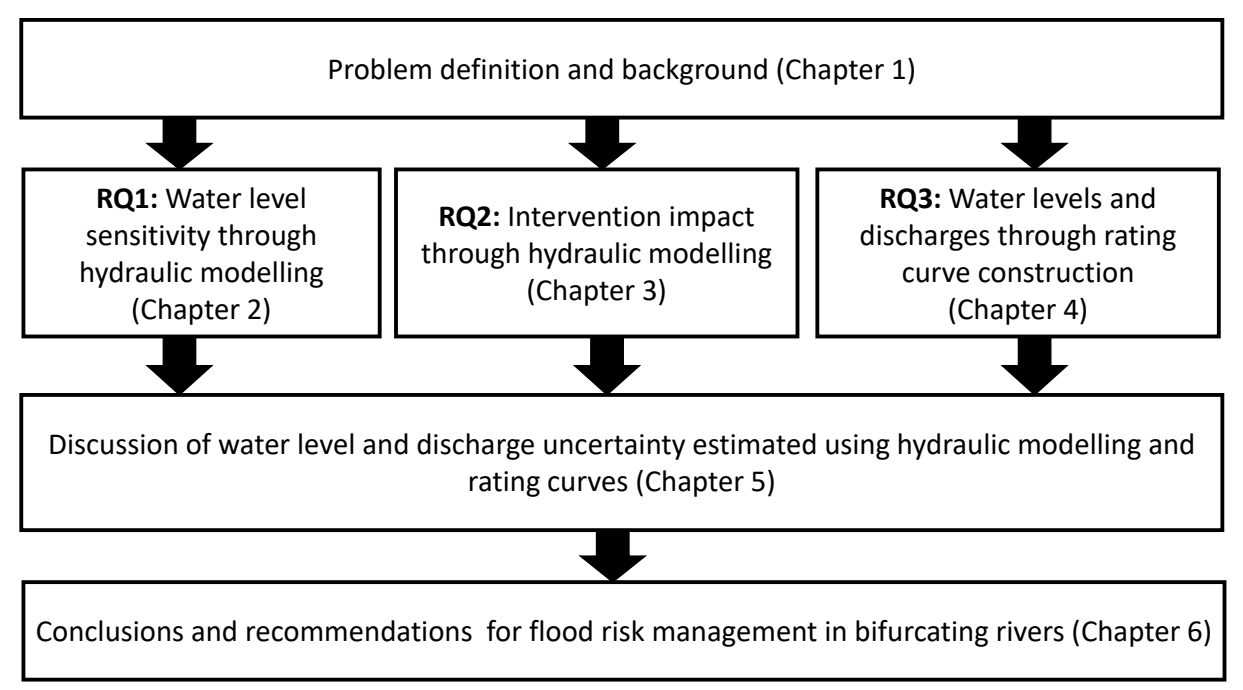

Figure 1.5: Thesis outline 




\title{
Chapter 2
}

\section{Feedback mechanism in bifurcating river systems: the effect on water level sensitivity}

\begin{abstract}
Accurate and reliable estimates of water levels are essential to assess flood risk in river systems. In current practice, uncertainties involved and the sensitivity of water levels to these uncertainties are studied in single-branch rivers, while many rivers in deltas consist of multiple distributaries. In a bifurcating river, a feedback mechanism exists between the downstream water levels and the discharge distribution at the bifurcation. This chapter aims to quantify the sensitivity of water levels to main channel roughness in a bifurcating river system. Water levels are modelled for various roughness scenarios under a wide range of discharge conditions using a one-dimensional hydraulic model. The results show that the feedback mechanism reduces the sensitivity of water levels to local changes of roughness in comparison to the single-branch river. However, in the smaller branches of the system, water-level variations induced by the changes in discharge distribution can exceed the water-level variations of the single-branch river. Therefore, water levels throughout the entire system are dominated by the conditions in the largest branch. As the feedback mechanism is important, the river system should be considered as one interconnected system in maintenance of rivers, flood-risk analyses, and future planning of river engineering works.
\end{abstract}

This chapter is published as M.R.A. Gensen, J.J. Warmink, F. Huthoff and S.J.M.H. Hulscher (2020). Feedback mechanism in bifurcating river systems: the effect on water level sensitivity, Water, 12(7), 1915. DOI: 10.3390/w12071915 


\subsection{Introduction}

Around the world, river flooding is one of the largest natural hazards, causing large economic damage and loss of life (Dilley et al, 2005). Risks of flooding are especially high in river deltas. Under the influence of a changing climate, higher river discharges are expected to occur, thereby increasing flood risk. Deltaic rivers split into multiple branches, with every branch carrying a certain fraction of the upstream discharge. The distribution of this upstream over the branches has a major influence on the flood risks over the downstream branches (Bomers et al, 2019c). Assessing the sensitivities of water levels for bifurcating rivers is essential for accurate flood-risk management.

Accurate and reliable estimates of water levels at extreme conditions are essential to assess flood risk and to design flood protection measures (Warmink et al, 2013a). Hydrodynamic models are increasingly being used for the purpose of water-level estimates. Water-level estimates using models are inherently uncertain for conditions that have never occurred. These uncertainties in estimates of flood water levels can influence the decision process (Apel et al, 2008; Berends et al, 2019). The design water levels (DWLs) that underlie the design of flood protection systems are higher if accounting for these uncertainties (Berends et al, 2019). Performing an uncertainty analysis is thus a crucial aspect in flood risk analyses (Pappenberger et al, 2006).

An important component of uncertainty analyses is to assess to what extent water levels are sensitive to the sources of uncertainty (Pappenberger et al, 2008). Analyses of sensitivity and uncertainty have been performed for several singlebranch rivers around the world, generally agreeing that the upstream discharge (Merz and Thieken, 2009; Warmink et al, 2011; Bozzi et al, 2015) and the main channel roughness (Warmink et al, 2013a; Pappenberger et al, 2008; Warmink et al, 2011; Bozzi et al, 2015) influence water-level prediction the most. Discharge uncertainty for a river stretch includes the inability to accurately estimate return periods of very high discharges (Merz and Thieken, 2009; Bomers et al, 2019b) and the uncertain distribution of discharge over branches (Van Vuren et al, 2005; Klijn et al, 2018a). When looking at uncertain water-level predictions at a given discharge, the most important source of uncertainty is the roughness of the main channel. Estimating roughness values in natural channels is a challenge, but is crucial for attaining accurate water levels in model studies (Ardıçlıoğlu and Kuriqi, 2019). In low-land, alluvial rivers, bedforms often develop in the river bed, thereby creating a large flow resistance (Van Rijn, 1993; Julien and Klaassen, 1995; Best, 2005). The process of the generation, evolution and possible flattening of river bedforms and the flow resistance they cause is not fully understood. In particular, if bedforms flatten out in a condition of upper stage plane bed, a large spatial variation in roughness is possible (Nelson et al, 2011; Hulscher et al, 2017). The sensitivity of water levels to these sources of uncertainty has not yet been 
assessed in a bifurcating river system. This in contrast with single-branch river segments, for which quantitative analyses have been performed, e.g. the Waal river (Warmink et al, 2013a) the Po river (Bozzi et al, 2015) and the Alzette river (Pappenberger et al, 2008). The larger modelling domain for a bifurcating river system increases the computational demand. The high computational demand is often a limiting factor for performing uncertainty analyses (Berends et al, 2018), which might explain why sensitivities of water levels have not been assessed for full bifurcating river systems. It has long been established that in a bifurcating river system a feedback mechanism exists between the downstream water levels and the discharge distribution (Jansen et al, 1979). Such hydraulic interactions are important to consider, as demonstrated for the interaction that occurs when dike heightening causes an increase in downstream flood water levels (Ciullo et al, 2019). It may thus be expected that in a bifurcating river system the feedback mechanism between water levels and discharge distribution affects the sensitivity of water levels to roughness uncertainty and consequently the design water levels. However, to what extent this feedback mechanism affects sensitivities of water levels is unknown.

In a bifurcating river system, the sensitivity of the water levels in the branches is influenced by the feedback mechanism between discharge distribution and water levels. The aim of this study is to quantify the sensitivity of water levels in a bifurcating river system to variations in main channel roughness to support flood-risk management. Thereby, the focus is on to what extent this sensitivity is different than in a single-branch river. A hydraulic model of the Rhine river system in the Netherlands is used as a case study to quantify the effects of main channel roughness on water levels in the Rhine river system. The outline of this chapter is as follows. Section 2.2 introduces the study area and its characteristics and gives an overview of the available bedform measurements. Section 2.3 presents the methodology for deriving the roughness scenarios (Section 2.3.1) that are propagated through the 1D hydraulic model (Section 2.3.2) and for obtaining the return periods of the water levels in each of the branches (Section 2.3.3). Section 2.4 shows the result in the effects on the design water levels and the stage-discharge relationships by comparing the results for the single-branch river (Section 2.4.1) and for the bifurcating river (Section 2.4.2). Finally, the results are discussed in Section 2.5 and conclusions are drawn in Section 2.6.

\subsection{Domain description}

\subsubsection{Study area}

The river Rhine bifurcates into three distributaries: the river Waal, river Nederrijn and river IJssel (Figure 2.1). The river Waal has the largest discharge conveyance 
and the largest main channel (Table 2.1). The two major bifurcation points are the Pannerdensche Kop and the IJsselkop, connected to each other by a six-kilometre long channel, the 'Pannerdensch Kanaal'. The river Rhine enters the Netherlands at Lobith with a yearly average discharge of approximately $2,200 \mathrm{~m}^{3} / \mathrm{s}$. The bankfull discharge of the Rhine distributaries correspond to a discharge at Lobith of approximately $5,000 \mathrm{~m}^{3} / \mathrm{s}$ (Reeze et al, 2017). The maximum attainable Rhine discharge is estimated to be around 18,000 $\mathrm{m}^{3} / \mathrm{s}$ (Bomers et al, 2019c). The current plan form of the Rhine branches, with its two bifurcation points, exists since the 18th century. Ever since, the discharge distribution over the distributaries has been relatively stable at about: $2 / 3^{\text {rd }}$ towards the Waal, $2 / 9^{\text {th }}$ towards the Nederrijn and $1 / 9^{\text {th }}$ towards the IJssel.

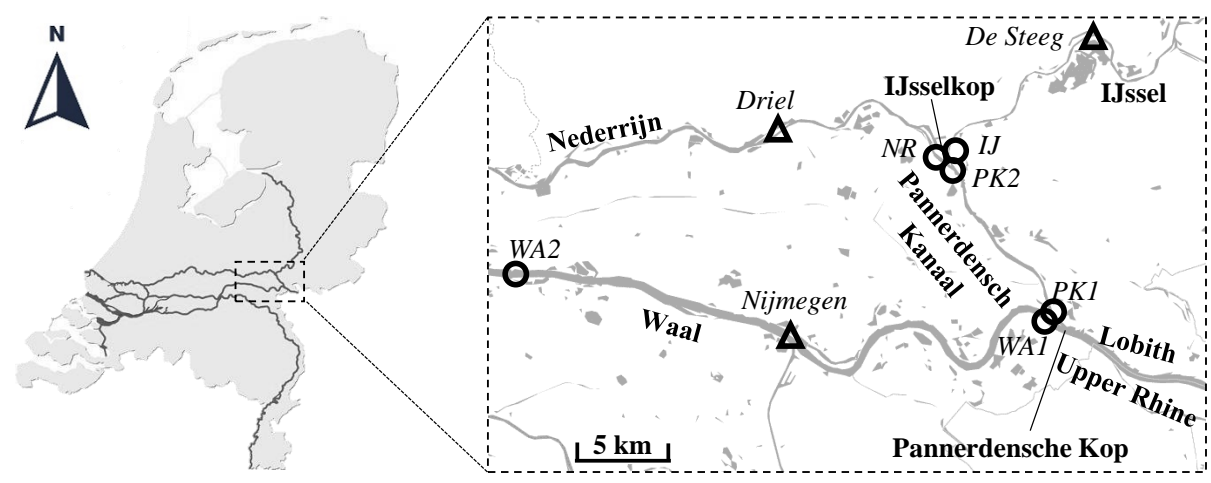

Figure 2.1: Map of the study area in the Netherlands. The three triangles indicate the representative locations for the water levels in the three downstream branches under consideration in this study. The six circles indicate the locations at which measurements of bedform dimensions are available

Table 2.1: Characteristics of the Dutch Rhine distributaries, based on Van Vuren et al (2005), Reeze et al (2017), and Brilhuis (1988).

\begin{tabular}{lllll}
\hline River branch & $\begin{array}{l}\text { Bankfull } \\
\text { discharge }\end{array}$ & $\begin{array}{l}\text { Width main } \\
\text { channel }\end{array}$ & $\begin{array}{l}\text { Mean width } \\
\text { floodplains }\end{array}$ & $\begin{array}{l}\text { Median } \\
\text { grain size }\end{array}$ \\
\hline Bovenrijn & $5000 \mathrm{~m}^{3} / \mathrm{s}$ & $330-440 \mathrm{~m}$ & $850 \mathrm{~m}$ & $3-4 \mathrm{~mm}$ \\
Waal & $3400 \mathrm{~m}^{3} / \mathrm{s}$ & $260-370 \mathrm{~m}$ & $550 \mathrm{~m}$ & $1-2 \mathrm{~mm}$ \\
Pan. Kanaal & $1600 \mathrm{~m}^{3} / \mathrm{s}$ & $130-200 \mathrm{~m}$ & $400 \mathrm{~m}$ & $3-5 \mathrm{~mm}$ \\
Nederrijn & $900 \mathrm{~m}^{3} / \mathrm{s}$ & $130-200 \mathrm{~m}$ & $400 \mathrm{~m}$ & $1-2 \mathrm{~mm}$ \\
IJssel & $700 \mathrm{~m}^{3} / \mathrm{s}$ & $80-120 \mathrm{~m}$ & $500 \mathrm{~m}$ & $2-5 \mathrm{~mm}$ \\
\hline
\end{tabular}

\subsubsection{Available bedform measurements}

Bedform measurements for various periods of time and under different flow conditions are available (Table 2.2). The majority of these data are obtained 
from Wilbers and Ten Brinke (2003), who have used single-beam and multibeam (mostly since 1997) measurements of the river bed at the Pannerdensche Kop to derive bedform dimensions during large flood events. This data set includes records taken during the discharge wave with the highest recorded discharge in the river Rhine in 1995 as well as from flood waves in 1997 and 1998. Additionally, Frings and Kleinhans (2008) have analysed the bedforms around the IJsselkop during a moderate flood event in 2004. Finally, Sieben (2008) provides data under moderate discharges along the Waal branch. Data points from every source at least contain a bedform height and a bedform length estimate as well as the local water depth, depth-averaged flow velocity and discharge estimate.

Table 2.2: Characteristics of the available bedform measurements of Wilbers and Ten Brinke (2003) (WB03), Sieben (2008) (SI08), and Frings and Kleinhans (2008) (FR08). The measurement locations are shown in Figure 2.1. For location WA2, measurements were taken for the northern (WA2a) and southern (WA2b) half of the main channel.

\begin{tabular}{|c|c|c|c|c|}
\hline Source & \# Data points & Location & Period & Flow regime(s) \\
\hline WB03 & 38 & WA1 & 1997-1998 & Flood waves '97 and '98 \\
\hline WB03 & 84 & WA2a & 1989-1998 & $\begin{array}{l}\text { Moderate flows \& flood waves } \\
\text { ' } 95 \text {, ' } 97 \text { and ' } 98\end{array}$ \\
\hline WB03 & 49 & WA2b & 1994-1998 & Flood waves '95, '97 and '98 \\
\hline WB03 & 31 & PK1 & 1997-1998 & Flood waves '97 and '98 \\
\hline SI08 & 94 & WA3 & $2002-2003$ & Moderate flows \\
\hline FR08 & 5 & PK2 & Jan. 2004 & Moderate flows \\
\hline FR08 & 5 & IJ & Jan. 2004 & Moderate flows \\
\hline
\end{tabular}

\subsection{Methodology}

The sensitivity of water levels to variations in roughness is quantified for a singlebranch river and for a bifurcating river system by modelling the water levels under various roughness scenarios (Figure 2.2). Therefore, in each of the four Rhine branches, a realistic upper and lower value of the roughness is estimated (Section 2.3.1). This results in 16 possible combinations of system roughness consisting of a high or a low roughness value for each of the branches. The sensitivity analysis is performed using the one-dimensional hydraulic model of the Rhine branches (Section 2.3.2). A one-dimensional model allows for fast computations, while it is sufficiently accurate for the purpose of this study. Sensitivity is defined as the difference in water levels between the scenarios in which the local branch experiences a high and a low roughness. The single-branch river and the bifurcating river are differentiated by comparing the water levels at equal local branch discharge or at equal upstream discharge, respectively. Finally, the simulated water levels are linked to return periods to obtain design water levels (Section 2.3.3). This shows the impact of the water-level variations in the context 
of flood management.
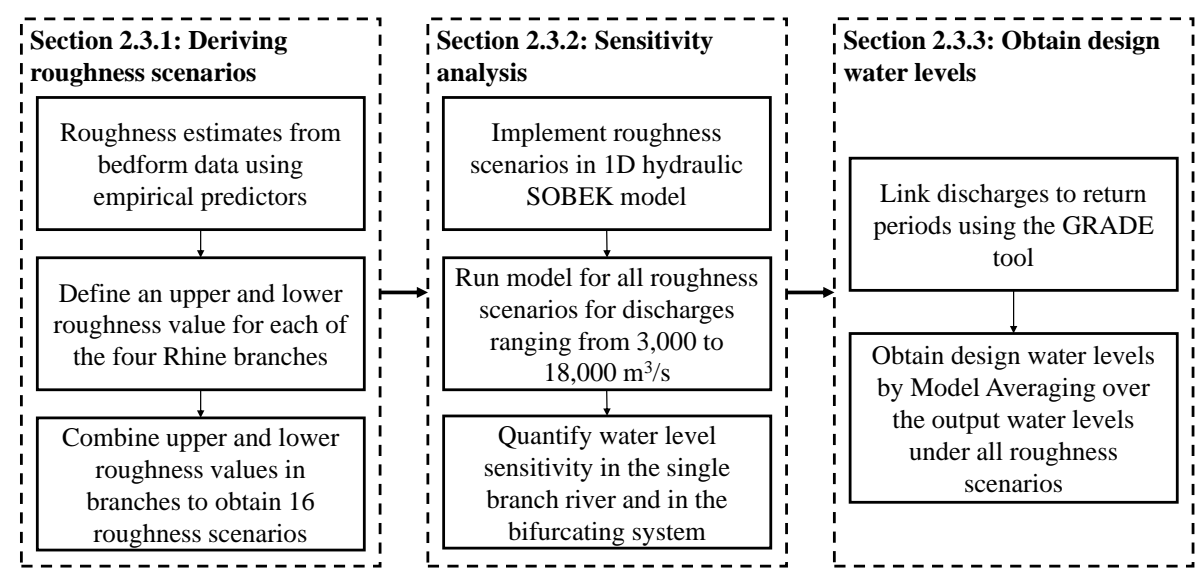

Figure 2.2: Overview of the methodology.

\subsubsection{Deriving roughness scenarios from the available bedform dimension data}

Sixteen roughness scenarios are defined that consist of combinations of an upper and a lower roughness value for each branch. These 16 scenarios represent the variability in main channel roughness in the river system. The high and low roughness value should be seen as an extreme, but realistic spread in roughness that could occur in each branch. It is not intended to give accurate predictions of roughness, given the large spread in the bedform observations, but merely to show the sensitivity of the water levels to variations in roughness. The assumptions that underlie the derivation of these roughness scenarios are discussed in Section 2.5.1.

The available bedform measurements are transformed into roughness values using empirical roughness predictors. The predictors of Van Rijn (1993) and Vanoni and Hwang (1967) are selected for this study as those showed the best performance for the Upper Rhine reach (Warmink et al, 2013a)). For every data sample, two roughness values are obtained, one for each of the two predictors.

The predictor of Van Rijn (1993) is a function of the grain size and the bedform height and length:

$$
k_{N}=k_{N ; \text { grains }}+k_{N ; \text { forms }}=3 D_{90}+1.1 * 0.7 * \Delta\left(1-e^{-25 \Delta / \lambda}\right)
$$

In addition to the bedform dimensions, the Vanoni and Hwang (1967) predictor 
requires the magnitude of mean water levels and flow velocities:

$$
c_{f}=\frac{1}{8}\left(1.8 \log \left(\frac{4 u R}{7 \nu}\right)\right)^{-2}+\frac{1}{8}\left(3.3 \log \left(\frac{\lambda R}{\Delta^{2}}\right)-2.3\right)^{-2}
$$

The friction coefficient $\mathrm{c}_{f}[-]$ can be transformed into a Nikuradse roughness height as follows:

$$
k_{N}=\frac{12.2 h}{10^{(1 / 2.03) \sqrt{1 /\left(8 c_{f}\right)}}}
$$

In these predictors, $\mathrm{k}_{N}$ is the Nikuradse roughness height $[\mathrm{m}], \mathrm{D}_{90}$ is the $90^{t h}$ percentile grain diameter $[\mathrm{m}], \Delta$ and $\lambda$ are the mean dune height and mean dune length $[\mathrm{m}], \mathrm{R}$ is the hydraulic radius $[\mathrm{m}], \mathrm{h}$ is the water depth $[\mathrm{m}], \mathrm{u}$ is the depthaveraged velocity $[\mathrm{m} / \mathrm{s}]$ and $\nu$ is the kinematic viscosity $\left[\mathrm{m}^{2} / \mathrm{s}\right]$.

The predicted roughness values that correspond to the data of the Waal branch show a large variation (Figure 2.3). This scatter is a result of the variation in underlying bedform dimensions and variations in the flow parameters. Generally, the Van Rijn predictor results in higher roughness values than the Vanoni-Hwang predictor. This is consistent with earlier findings of Warmink et al (2013a). No distinct discharge-dependency of the roughness is observed in the data at Waal discharges higher than $2000 \mathrm{~m}^{3} / \mathrm{s}$. This is not consistent with the literature (e.g. Julien et al, 2002; Paarlberg et al, 2010) as a larger discharge is generally accompanied by larger bedform dimensions.

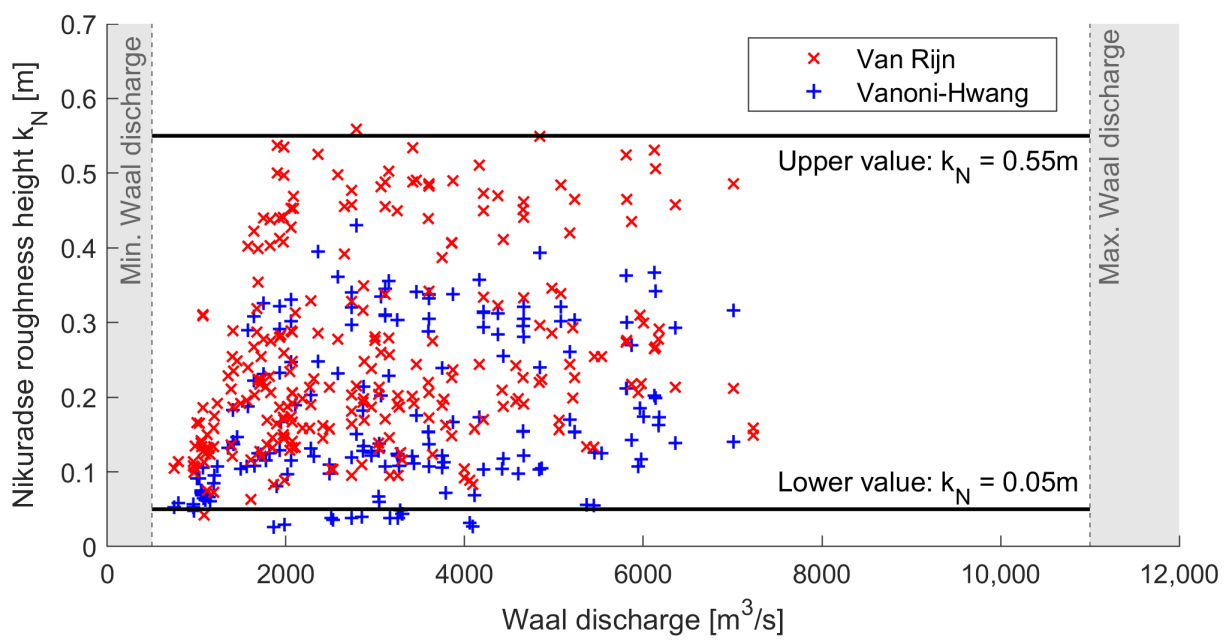

Figure 2.3: Nikuradse roughness values calculated with the Van Rijn (1993) and Vanoni and Hwang (1967) roughness predictors for the available data in the Waal branch. The black lines indicate the defined range of roughness with an upper value and a lower value.

The same analysis is carried out for the three other Rhine river distributaries (not shown here). The predicted roughness values of the Pannerdensch Kanaal 
(PK) observations show a slightly lower spread in roughness values $\left(\mathrm{k}_{N}=0.05\right.$ $\mathrm{m}$ up to $\mathrm{k}_{N}=0.35 \mathrm{~m}$ ). However, discharge-dependency is more pronounced with the highest roughness values occurring at the highest observed discharges. This indicates that for higher discharges, higher roughness induced by bedforms may also occur, because of the larger grain size in the PK (Table 2.1). For both the Nederrijn and IJssel, only 5 observations are available, all recorded in a single flood wave with moderate flows. For these observations, roughness estimates are all in the order of $\mathrm{k}_{N}=0.1 \mathrm{~m}$.

After visual inspection of the roughness predictions, an upper and a lower roughness value is chosen for each branch. For the Waal branch, the lower and upper value are set to $\mathrm{k}_{N}=0.05 \mathrm{~m}$ and $\mathrm{k}_{N}=0.55 \mathrm{~m}$, respectively (Figure 2.3). In the measured discharge range, only a few predicted roughness values fall outside of these values. The chosen upper value does not account for higher roughness values outside of the measured discharge domain, because in the measured domain the roughness does not show a clear discharge-dependency. For the other branches, the lower and upper value are set to $\mathrm{k}_{N}=0.05 \mathrm{~m}$ and $\mathrm{k}_{N}=0.55 \mathrm{~m}$ as well, for consistency with the Waal branch. For these branches, fewer observations are available. As the bed material and flow conditions are fairly similar in all branches (see Table 2.1), there is no reason to expect very different roughness values in the other branches. Additionally, the literature indicates that the bedform variability in these branches is also significant (Frings and Kleinhans, 2008; Sieben, 2008). Therefore, the same roughness values as for the Waal and Pannerdensch Kanaal are applied.

\subsubsection{Sensitivity analysis using the hydraulic SOBEK model of the Rhine branches}

The SOBEK modelling environment is selected to perform the sensitivity analysis. In this environment, a detailed schematization is available for the study area. This official schematization 'Rijn-j16_5_v1' is used by the Dutch Ministry of Infrastructure and Water Management for operational uses. SOBEK is a modelling environment for 1D hydraulic computations (Deltares, 2020), numerically solving the 1D Saint-Venant equations. The river is schematized by a 1D network in which the other dimensions are assigned by imposing cross-sections. Cross-sections are divided into different parts, e.g., left and right floodplains and the main channel. Furthermore, the presence of minor embankments on the floodplains is accounted for by the addition of flow area in the floodplain area (Figure 2.4). The governing equations are solved for the different parts separately and, after iteration, the division of discharge between the different parts of the cross-section is found. This allows for different flow velocities in the floodplains and the main channel.

The model schematization has cross-sections with a longitudinal spacing of 


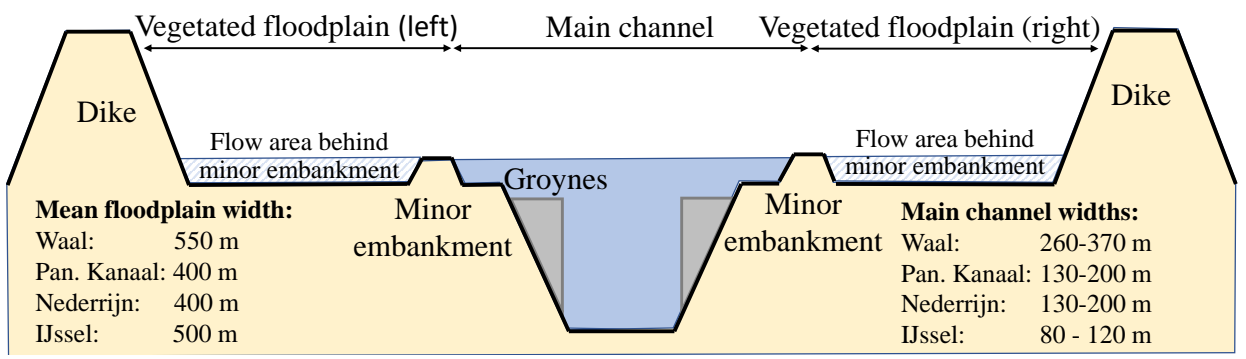

Figure 2.4: Schematisation of a typical cross-section of the Rhine branches.

approximately $500 \mathrm{~m}$. A schematization of a typical cross-section is shown in Figure 4. In an earlier study (Becker et al, 2014), the cross-sections were extracted from a 2D model, which is based on digital elevation maps constructed from echosounds in the main channel and Lidar measurements in the floodplains. After extracting the cross-sections from the $2 \mathrm{D}$ model, the cross-sectional dimensions were modified, such that such that modelled stage-discharge relationships match those of the 2D model (Becker et al, 2014). Each cross-section is associated with discharge-dependent Chezy roughness values for the floodplains. The floodplains of the Rhine distributaries are vegetated, mostly with grass, but also with higher and denser vegetation. They are mainly used for agriculture and nature conservation and are regularly managed for those purposes. The roughness values are based on vegetation maps, vegetation roughness descriptions and two-dimensional model simulations (Warmink et al, 2013a; Straatsma and Huthoff, 2011). In an earlier study, the 2D model simulations were used as reference case for the calibration of the floodplain roughness in the 1D SOBEK model (Becker et al, 2014). Generally, Chezy values roughness are around $40 \mathrm{~m}^{1 / 2} / \mathrm{s}$ at lower discharges and $50 \mathrm{~m}^{1 / 2} / \mathrm{s}$ at higher discharges.

The upstream boundary of the model is located just upstream of Lobith in the Upper Rhine (Figure 2.1). The downstream boundary of each branch consists of a stage-discharge relation based on measurements. These boundaries are located more than $60 \mathrm{~km}$ downstream of the area of interest, which is sufficiently far away to not influence the water levels in the area of interest (Figure 2.1).

The roughness scenarios are implemented in the original schematization of the Rhine branches. In the original schematization, the main channel roughness is calibrated to attain measured water levels for a measured discharge distribution over the branches. The defined main channel roughness scenarios replace these calibrated values of main channel roughness. The roughness of the floodplains are kept at their calibrated values. Because the main channel roughness values are adapted in the scenario runs, they no longer correspond to their calibrated values. This caused shifts in the stage-discharge relationships. To attain values for water levels and bankfull discharges that are in the same order as the values from the 
calibrated model, a constant additional roughness was added in all branches. This additional roughness accounts for all roughness inducing processes that are not accounted for in the model schematization, such as the flow resistance caused by groynes. A value of $\mathrm{k}_{N \text {,rest }}=0.3 \mathrm{~m}$ for all branches gives the best match with results from the original, calibrated model schematization (i.e., 'Rijn-j16_5_v1'). To find this best match, the water levels averaged over all scenarios were compared with the results from the calibrated model. This value is added to the roughness of the main channel on top of the adopted roughness scenarios. This gives a constant low roughness value of $\mathrm{k}_{N}=0.35 \mathrm{~m}$ and a constant high roughness value of $\mathrm{k}_{N}=0.85 \mathrm{~m}$ for all branches. In summary, the floodplain roughness values remain at their calibrated values, while the main channel roughness values under the roughness scenarios are realistic compared to the fully calibrated model by the addition of a constant roughness.

The model is run for every of the 16 roughness scenarios. To assess the sensitivity of the water levels to discharge, the model is run for every scenario with constant discharges ranging from $3000 \mathrm{~m}^{3} / \mathrm{s}$ (above yearly-averaged discharge) up to 18,000 $\mathrm{m}^{3} / \mathrm{s}$ (maximum discharge at Lobith; see Bomers et al, 2019c) with steps of $500 \mathrm{~m}^{3} / \mathrm{s}$. This gives a total amount of model runs of 496 (31 discharges and 16 roughness scenarios). The sensitivity to roughness at a certain discharge is defined as the mean difference in water levels between the scenarios in which the local branch experiences a high roughness $(\mathrm{H})$ and a low roughness $(\mathrm{L})$, respectively:

$$
\operatorname{Sensitivity}(Q)=\overline{H_{W a a l}(Q)-L_{W a a l}(Q)}
$$

Here, the differentiation is made between a single-branch river and a bifurcating river system. In the single-branch river system, the sensitivity to roughness is assessed at equal discharge inside the branch. In contrast, in the bifurcating river system, the sensitivity is assessed at equal upstream Lobith discharge, thereby allowing for variations in the discharge distribution under the various roughness scenarios.

\subsubsection{Obtaining Design Water Levels (DWLs) using Model Averaging}

The return periods of modelled water levels are determined for the three locations of interest (Figure 2.1) for the single-branch river and for the bifurcating river system. Model averaging (MA) is applied to combine the model results under the various scenarios into a single new model result. MA has been widely used in the field of hydrology (Parrish et al, 2012) and recently MA has been used in river flood modelling as well (Liu and Merwade, 2018). Furthermore, it is common practice under the Dutch flood risk framework to apply MA to account for uncertainties, while still having a single model prediction (Diermanse, 2017). MA is used to determine the probability of occurrence of a water level $\mathrm{p}(\mathrm{h})$ averaged over all 16 
scenarios:

$$
p(h)=\sum_{m_{i}} p\left(m_{i}\right) p\left(h \mid m_{i}\right)
$$

Here, $\mathrm{p}\left(\mathrm{m}_{i}\right)$ is the probability of occurrence of a roughness scenario and $\mathrm{p}\left(\mathrm{h} \mid \mathrm{m}_{i}\right)$ is the probability of water level $h$ occurring under roughness scenario $m_{i}$. It is assumed that every roughness scenario is equally likely to occur, so:

For the single-branch river: $p\left(m_{i}\right)=0.5$; for $\mathrm{i}=1: 2$

For the bifurcating river: $p\left(m_{i}\right)=0.0625$; for $\mathrm{i}=1: 16$

The return periods from the modelling tool 'Generator of Rainfall and Discharge Extremes' (GRADE) are used for this analysis (Prinsen et al, 2015). In the Netherlands, this tool is used in operational practices by the Dutch Ministry of Infrastructure and Water Management. Using these data, the return periods of input upstream discharges ranging from 3000 to $18,000 \mathrm{~m}^{3} / \mathrm{s}$ are obtained. For the single-branch river system, branch discharges are coupled to the upstream discharge and their return periods by taking the mean discharge distribution over all 16 scenarios.

\subsection{Results}

\subsubsection{Sensitivity to roughness in a single-branch river}

The results show that the imposed roughness scenarios induce large changes to the local stage-discharge relationships at the two locations in the Waal and IJssel branches (Figure 2.5), representing the sensitivity of single-branch rivers for roughness variations. Averaged over all discharges, water levels under the high roughness estimates are $0.4 \mathrm{~m}$ higher at Nijmegen (Waal) and $0 . .3 \mathrm{~m}$ higher at De Steeg (IJssel), compared to the low roughness estimates. Similar sensitivities to the roughness are found for the location of Driel (Nederrijn). These values are in the same order of magnitude as values of water-level uncertainties caused by roughness uncertainty that were previously found in literature, e.g., a $95 \%$ confidence interval of $0.53 \mathrm{~m}$ at the design discharge in the Waal river (Warmink et al, 2013a) and $95 \%$ confidence intervals of $0.3-1.0 \mathrm{~m}$ in the Po and Garonne river (Bozzi et al, 2015).

The modelled shapes of the stage-discharge relationships are typical for a lowland river with floodplains (see schematized cross-section in Figure 2.4). Under bankfull stages, marked in Figure 2.5, the stage-discharge relationship is steep. Once the water level exceeds the height of the minor embankments, the floodplains start accommodating discharge, causing flattening of the stage-discharge relationship. 

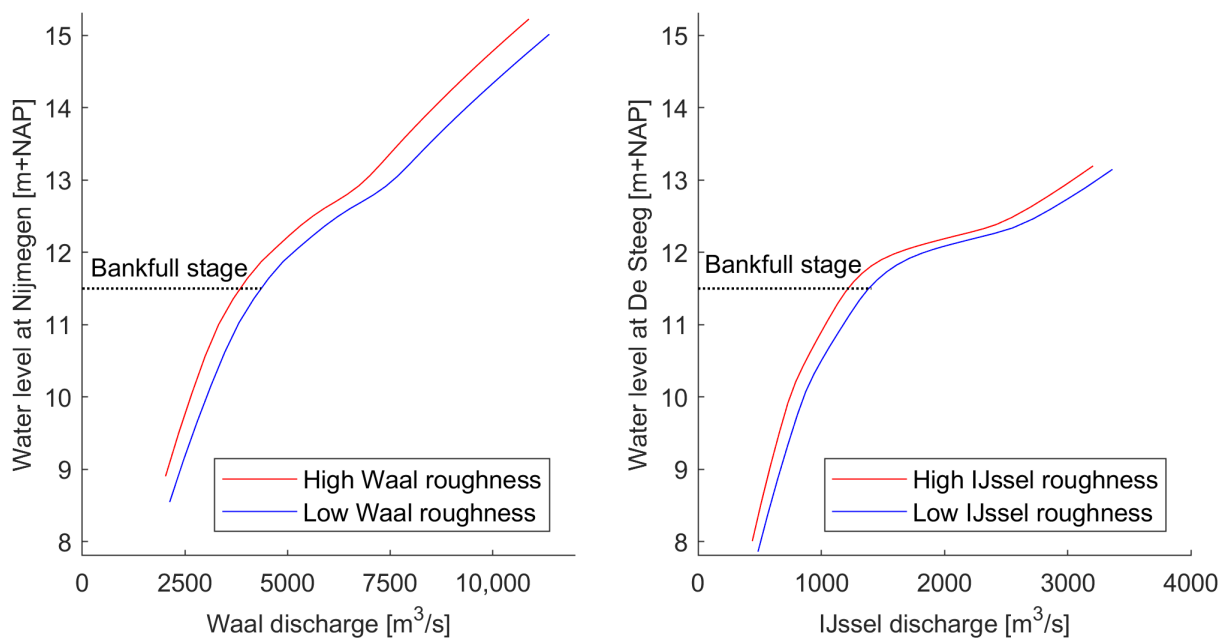

Figure 2.5: Modelled stage-discharge relations, with water levels relative to the Dutch Ordnance Datum (NAP), at Nijmegen (left) and De Steeg (right) under the imposed main channel roughness scenarios. Averaged over all discharges, a high local roughness compared to a low local roughness results in $0.4 \mathrm{~m}$ higher water level at Nijmegen (Waal) and $0.3 \mathrm{~m}$ higher water levels at De Steeg (IJssel).

The flattening of the stage-discharge relationship is more pronounced for the IJssel than for the Waal branch, as the floodplains of the IJssel branches are relatively wider than those of the Waal branch (Table 2.1).

\subsubsection{Sensitivity to roughness in a bifurcating river system}

In a bifurcating river system, the model results show that changes in the discharge distribution at the Pannerdensche Kop, indirectly induced by the roughness variations in all branches, have a strong effect on the water levels at Nijmegen (Figure 2.6). Averaged over all discharges, the sensitivity of the water levels at Nijmegen to Waal roughness is $0.2 \mathrm{~m}$ in this bifurcating river system, while it was $0.4 \mathrm{~m}$ in the single-branch river. Minimum and maximum sensitivities are $0.09 \mathrm{~m}$ and $0.40 \mathrm{~m}$, which occur at discharges that correspond to the same branch discharges as in the single-branch river, but in this single-branch river the minimum and maximum values were $0.22 \mathrm{~m}$ and $0.61 \mathrm{~m}$. At higher discharges, the sensitivity is relatively constant at $0.21 \mathrm{~m}$, while this was $0.45 \mathrm{~m}$ in the single-branch river. So, at all discharges, the sensitivity of the water levels to Waal roughness has been reduced, in comparison to the single-branch river, with approximately $0.2 \mathrm{~m}$.

The reduced sensitivity in the bifurcating system compared to the single-branch river is associated with approximately $3 \%$ differences in Lobith discharge diverted 

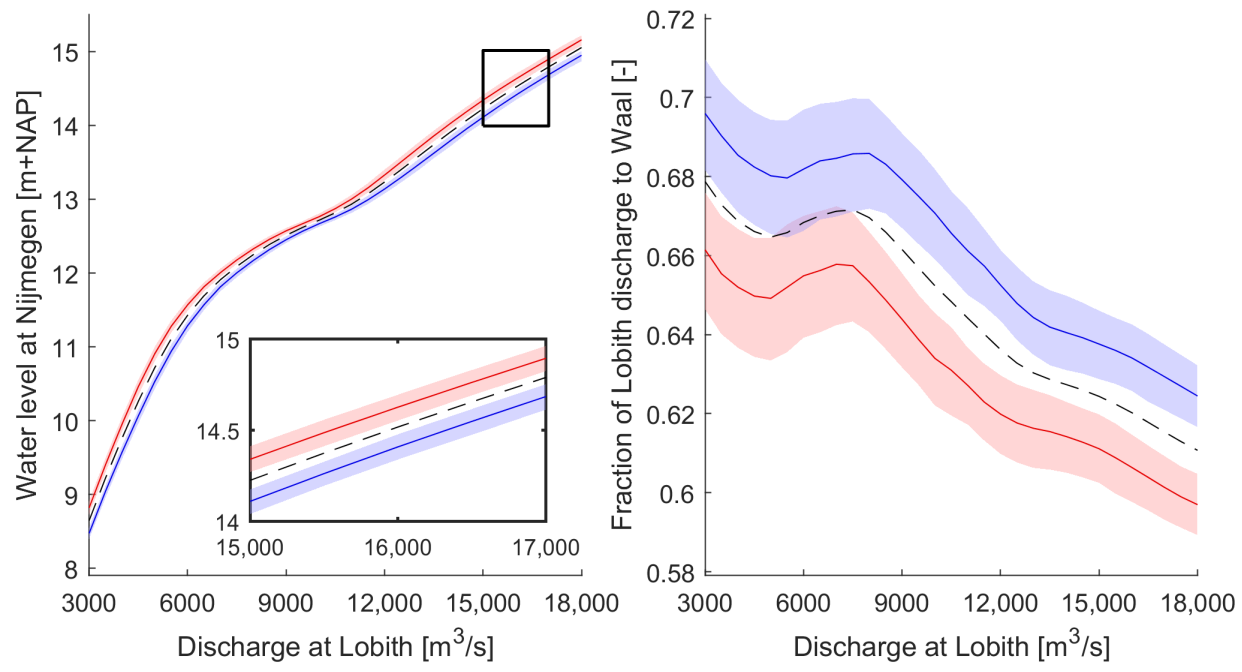

\begin{tabular}{lll}
\hline & $\mathrm{H}_{\text {Waal }} \longrightarrow$ Mean $\mathrm{H}_{\text {Waal }} \quad \mathrm{L}_{\text {Waal }} \quad$ Mean $\mathrm{L}_{\text {Waal }} \quad---$ Mean all \\
\hline
\end{tabular}

Figure 2.6: Modelled water levels at Nijmegen in the Waal branch (a) and the fraction of upstream discharge towards the Waal (b) under the 16 roughness scenarios as a function of (upstream) Lobith discharge. Scenarios with low Waal roughness (blue shaded) cause relatively low water levels and high Waal discharges, while scenarios with high Waal roughness (red shaded) cause relatively high water levels and low Waal discharges.

towards the Waal (right panel of Figure 2.6). The effect of roughness variations on the ratio of the discharge distribution between the branches is nearly equal for all Lobith discharges. This implies that absolute discharge variations linearly increase with upstream discharge, e.g., on average a difference of $155 \mathrm{~m}^{3} / \mathrm{s}$ and $440 \mathrm{~m}^{3} / \mathrm{s}$ at upstream discharges of $5000 \mathrm{~m}^{3} / \mathrm{s}$ and $16,000 \mathrm{~m}^{3} / \mathrm{s}$, respectively.

At De Steeg in the IJssel branch, the difference in response of water levels to roughness variations between the bifurcating river and the single-branch river are even more pronounced. In the bifurcating system, water levels at De Steeg are insensitive to the local (IJssel) roughness (Figure 2.7). The sensitivity to IJssel roughness varies between $0.03 \mathrm{~m}\left(\right.$ at $\left.Q_{\text {Lob }}=18,000 \mathrm{~m}^{3} / \mathrm{s}\right)$ and $0.16 \mathrm{~m}\left(\right.$ at $Q_{\text {Lob }}=$ $5000 \mathrm{~m}^{3} / \mathrm{s}$ ), while the sensitivity varied between $0.10 \mathrm{~m}$ and $0.58 \mathrm{~m}$ in the singlebranch river. Still, looking at the overall water-level variations, these exceed the variations in the single-branch river. The difference between the best and worst case roughness scenarios ranges reaches a maximum value of $0.88 \mathrm{~m}$ (at $\mathrm{Q}_{\mathrm{Lob}}=$ $4500 \mathrm{~m}^{3} / \mathrm{s}$ ), while it also exceeds $0.5 \mathrm{~m}$ at extremely high discharges $(>16,000$ $\mathrm{m}^{3} / \mathrm{s}$ ). These large water-level variations are induced by the deviations in the discharge distribution (right panel of Figure 2.7).

The response of water levels to changes in roughness in a bifurcating river system 

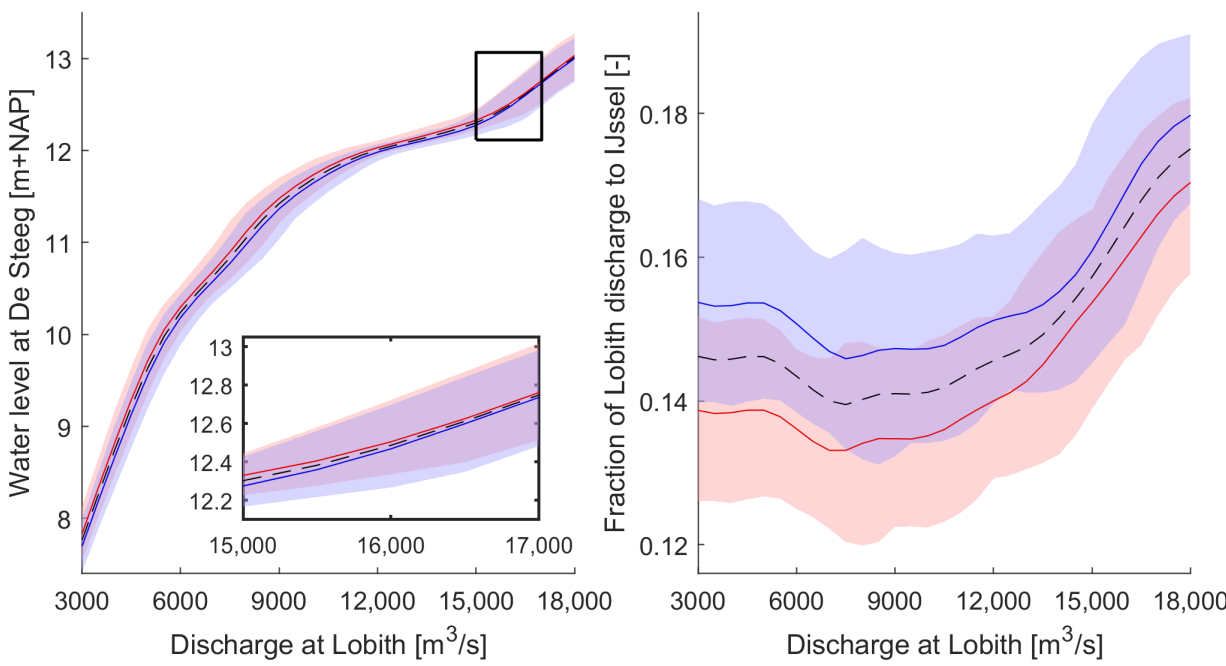

\begin{tabular}{lll}
\hline $\mathrm{H}_{\text {IJssel }} \longrightarrow$ Mean $\mathrm{H}_{\text {IJssel }} \quad \mathrm{L}_{\text {IJssel }} \quad$ Mean $\mathrm{L}_{\text {IJssel }} \quad---$ Mean all \\
\hline
\end{tabular}

Figure 2.7: Modelled water levels at De Steeg in the IJssel branch (a) and the fraction of upstream discharge diverted towards the IJssel (b) under the 16 roughness scenarios as a function of (upstream) Lobith discharge. The IJssel roughness has a small effect on both the water levels and the amount of discharge diverted towards the IJssel branch.

is thus different from a single-branch river (Figure 2.8). As seen in Figures 2.5-2.7, sensitivity to roughness is higher around the bankfull discharge $\left(5000 \mathrm{~m}^{3} / \mathrm{s}\right)$ than at larger discharges, at which floodplains accommodate a portion of the discharge. In the bifurcating river, water levels are a function of the roughness of all branches. However, the contribution of the branches to the total water-level variation is not equal, illustrated by the unequal height of the bars in Figure 2.8. The water levels at every location are most sensitive to the roughness in the Waal branch, illustrated by the red bars being higher than the other bars of the bifurcating system. Oppositely, the roughness of the smaller branches has little influence on the water levels in the larger Waal branch, as expected. Notably, the maximum sensitivity in the bifurcating river system (total height of the bars) even exceeds the single-branch values (blue bars) for the smaller IJssel and Nederrijn branches. However, this is only reached under specific roughness conditions, e.g., a very high discharge in the IJssel occurs if the Waal has a high roughness, while the Pannerdensch Kanaal has a low roughness. A change in roughness in the Waal branch can almost offset the water-level variations caused by all other branches (equally high bars).

Concluding, the model results showed that the sensitivity of water levels to roughness is very different in a single-branch river than in a bifurcating river system. The sensitivity to local roughness is smaller in a bifurcating river system 


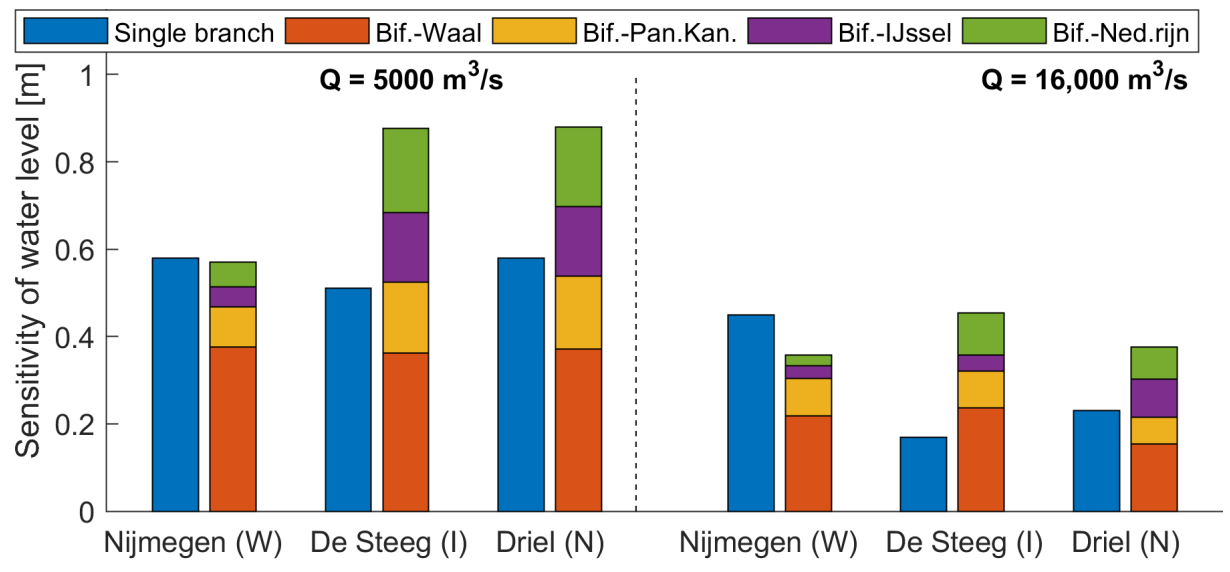

Figure 2.8: The sensitivity of water levels to main channel roughness in a single-branch river and in a bifurcating river system (Bif.) at upstream discharges at Lobith (Q) of 5000 and $16,000 \mathrm{~m}^{3} / \mathrm{s}$. The shown locations are Nijmegen (Waal), De Steeg (IJssel) and Driel (Nederrijn). For every location, the single-branch sensitivity is shown, as well as the sensitivity to the roughness of every branch in the bifurcating river system.

due to changes in the discharge distribution over the branches. However, the smaller branches of the system experience large water-level variations that are related to the variations in discharge distribution. These discharge effects can exceed the local effects of roughness. These differences in sensitivities between a single-branch river and a bifurcating river system are important for floodrisk assessments. Next, the impact of these differences on design water levels is assessed.

\subsubsection{Impact on Design Water Levels}

Using Model Averaging, Design Water Levels (DWLs) are determined at the three locations (Figure 2.1) for the single-branch river case and for the bifurcating river case. Due to different degrees of water-level uncertainty, the DWLs are different in a bifurcating river system than in a single-branch river (Table 2.3).

Table 2.3: Change in design water levels (DWL) at different return periods $(T)$ at the three locations if comparing the bifurcating river system (bif.) to the single-branch river cases.

\begin{tabular}{llll}
\hline$\Delta$ DWL (Bif.-Single) & Nijmegen (Waal) & De Steeg (IJssel) & Driel (Nederrijn) \\
\hline $\mathrm{T}=100$ years & $-3 \mathrm{~cm}$ & $-1 \mathrm{~cm}$ & $+1 \mathrm{~cm}$ \\
$\mathrm{~T}=1000$ years & $-6 \mathrm{~cm}$ & $+1 \mathrm{~cm}$ & $-2 \mathrm{~cm}$ \\
$\mathrm{~T}=10,000$ years & $-8 \mathrm{~cm}$ & $+5 \mathrm{~cm}$ & $-1 \mathrm{~cm}$ \\
\hline
\end{tabular}


In the Waal branch, DWLs are lower in a bifurcating river system than in the single-branch Waal river (Figure 2.9). Water-level uncertainties in this branch, are smaller in the bifurcating system than in the single-branch river (Figure 2.8). This can also be seen in Figure 2.9 as all blue dashed lines lie between the dashed red lines.

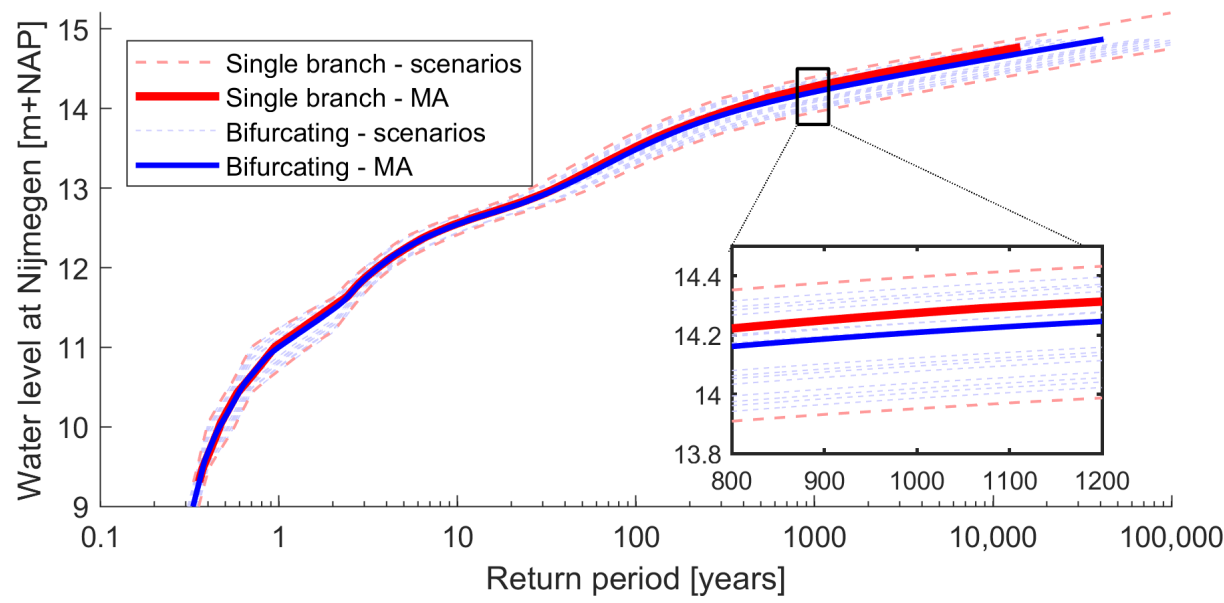

Figure 2.9: Water levels at Nijmegen (Waal) vs. Return period for the full bifurcating river system and for the single-branch Waal branch. The dashed lines show the individual scenarios, while the continuous lines are the model averaged (MA) lines over the single-branch scenarios (red) and over the bifurcating river system scenarios (blue).

Contrarily, for the IJssel branch, the DWLs are generally higher in the bifurcating river system than in the single-branch IJssel river (Figure 2.10). This is caused by the higher water-level uncertainties in the bifurcating river system than in the single-branch river (Figure 2.8). The small IJssel branch is more sensitive to the discharge variations than the larger Waal branch. In Figure 2.10, many of the roughness scenarios (blue dashed lines) now fall outside of the single-branch scenarios (red dashed lines).

\subsection{Discussion}

\subsubsection{Roughness scenarios}

In this study, roughness scenarios are defined on the basis of available data on observed bedform characteristics in the four Dutch Rhine branches. These scenarios represent a realistic estimate of variations in roughness, as roughness predictions from observations and values derived in the literature (Frings and 


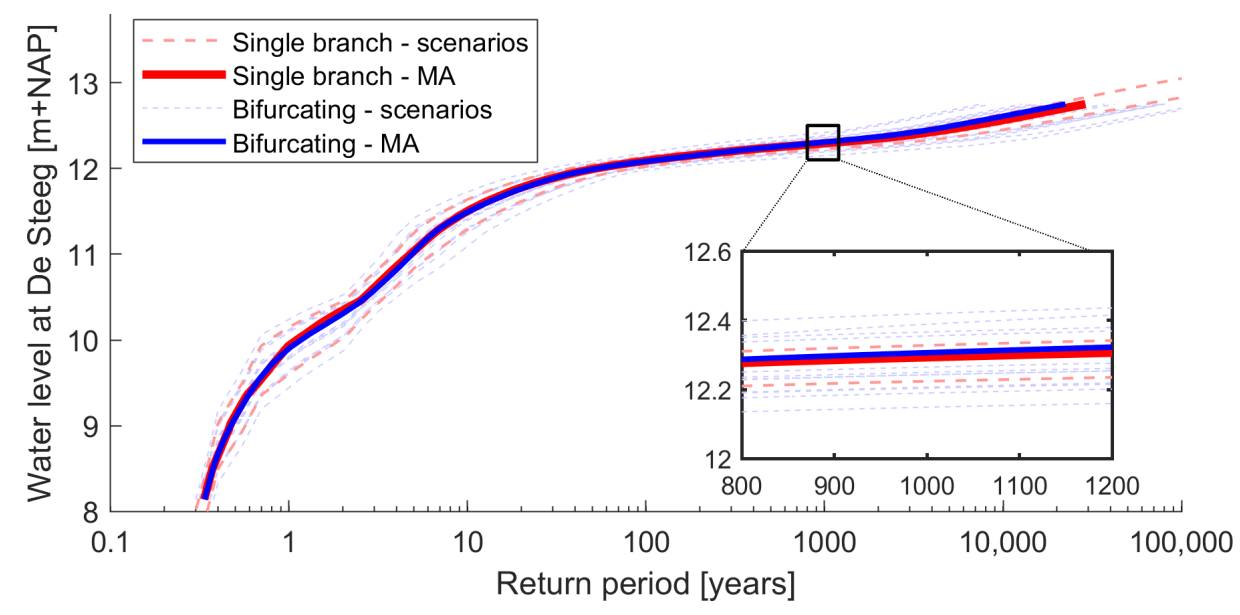

Figure 2.10: Water levels at De Steeg (IJssel) vs. Return period for the full bifurcating river system and for the single-branch IJssel branch. The dashed lines show the individual scenarios, while the continuous lines are the model averaged (MA) lines over the single-branch scenarios (red) and over the bifurcating river system scenarios (blue).

Kleinhans, 2008; Julien et al, 2002) fall within the defined roughness values. Due to limited data availability in the Pannerdensch Kanaal, IJssel and Nederrijn branches, it is assumed that the bedform dynamics in the Waal river are also a good representation of the bedform dynamics in the other branches. Additional measurements of bedform dimensions in mainly the Nederrijn and IJssel branch can show the validity of this assumption and may allow for an improvement of the roughness scenarios. These additional measurements could also show the presence of discharge-dependency, which is now not observed for the Waal branch data (Figure 2.3). Generally, bedforms grow with increasing discharge (Julien and Klaassen, 1995; Paarlberg et al, 2010). However, the relationship of form roughness with discharge is even more complex. Amongst other factors, the shape of the bedform and its lee-side angle (De Ruijsscher et al, 2020) as well as the water depth (Frings and Kleinhans, 2008) play an important role. While in the upper reach of the Dutch Rhine discharge-dependency is clearly present (Warmink et al, 2013a; Julien et al, 2002), this was not as pronounced not found for downstream locations in the Waal branch (Frings and Kleinhans, 2008; Julien et al, 2002).

Consequently, a higher than assumed spread of main channel roughness may occur at high discharges. Firstly, if the main channel roughness is more discharge dependent, higher roughness values at extremely high, unobserved discharges may be expected. However, secondly, flattening of bedforms in a condition of Upper Stage Plane Bed could also occur locally (Hulscher et al, 2017; Naqshband et al, 2014), leading to a significant decrease in roughness (Nelson et al, 2011). An increased spread in roughness at higher discharges is, therefore, possible. If the 
spread in roughness is larger than assumed, the bandwidth of modelled water levels will become slightly wider. However, the difference in water-level response to roughness variations between a single-branch river case and a bifurcating river can still be expected. Likely, this difference grows with a larger spread in roughness, which would also lead to larger differences in design water levels.

Another assumption in the roughness scenarios was that the main channel roughness between the branches could change independently of the other branches. However, correlation of the roughness between the branches may be expected. The primary source of possible correlation between the roughness of the branches is the history of the upstream discharge by which the bedforms have developed (Wilbers and Ten Brinke, 2003; De Ruijsscher et al, 2020). Other factors that can cause correlation between the roughness of the branches can be grain characteristics (Wilbers and Ten Brinke, 2003; Frings and Kleinhans, 2008), similar crosssectional shape (Wilbers and Ten Brinke, 2003) and the shape of the discharge wave (Warmink, 2014). However, differences in these factors are present in the Rhine system. For example, the Waal branch has much finer sediment than the IJssel branch and also in the Waal branch a smaller portion of the discharge is accommodated by the floodplains than in the IJssel branch. Strong correlation is, thus, not apparent.

To test the effect of correlation of roughness between the branches, results are shown for the case if full correlation of the roughness is assumed (Figure 2.11). This leaves two roughness scenarios: either a high roughness in every branch or a low roughness in every branch. Sensitivities of water levels to roughness would generally decrease compared to the uncorrelated case. In the bifurcating river system, correlation between the roughness of the branches means that relative roughness differences between the branches diminish. Therefore, the discharge distribution will show less variation. Due to less variation in the discharge distribution, sensitivity is much closer to the single-branch river (Figure 2.11). Furthermore, correlation causes the maximum water-level variation to decrease in the smaller branches of the system, which is dominated by the variations in the discharge distribution.

\subsubsection{Uncertainty analyses in bifurcating river systems}

In this study, the sensitivities of water levels to roughness have been quantified using a one-dimensional SOBEK model of the Rhine branches. The 1D model results are expected to be reasonably accurate in support of the aim of this study. A two-dimensional model is preferred over a one-dimensional model if more accurate predictions of absolute water levels are required (Berends et al, 2018). However, in this study, the focus is on differences in water levels between the scenarios. The 1D approach is expected to be able to predict these differences accurately, as the various roughness scenarios are treated similarly in the model schematization. 


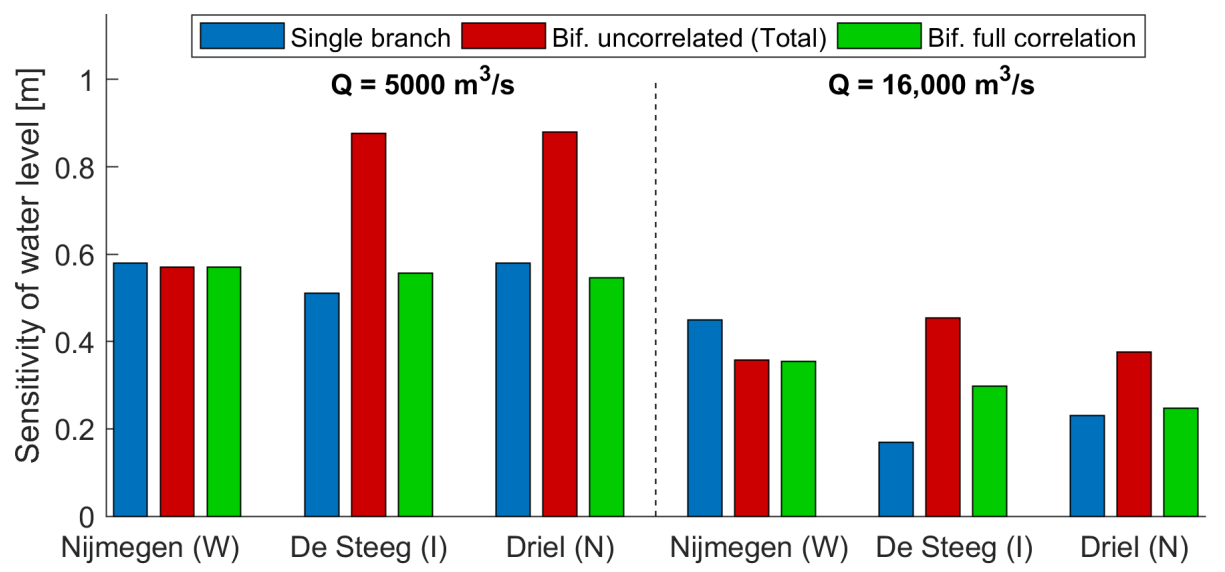

Figure 2.11: Sensitivities of water levels in a bifurcating river system if the main channel roughness were fully uncorrelated or fully correlated and in a single-branch river. The bar for the uncorrelated case is the sum of the individual components for each branch (total height in Figure 2.8).

A comparison with an earlier study of water-level sensitivity in the Waal branch (Warmink et al, 2013a) showed similar values of water-level sensitivity as were found in this study.

This chapter has considered variability in discharge and uncertainty in main channel roughness, being the most important sources of uncertainty. Besides these sources, several other sources of uncertainty, such as floodplain roughness (Straatsma and Huthoff, 2011) and geometry (Van Vuren et al, 2005) result in uncertain water-level estimates. If taking these sources of uncertainty into account, slightly larger water-level variability can be expected. Specifically at extreme discharges, uncertainty related to floodplain roughness and geometry will influence the water-level estimates. It can be expected that these sources of uncertainty show less correlation between the branches, as within a branch little correlation is observed e.g., (Straatsma and Huthoff, 2011) thereby inducing larger changes to the discharge distribution. Water levels modelled in a single-branch river will, therefore, increasingly be different from the water levels modelled in a bifurcating river system. This will especially be true for sources of uncertainty that may occur very locally and in the vicinity of the bifurcating point, e.g.,: breaching of a flood defense (Bomers et al, 2019c), Upper Stage Plane Bed (Hulscher et al, 2017) or erosion of the river bed (Kleinhans et al, 2008). Accounting for the feedback mechanism by modelling the full bifurcating river system is thus essential in uncertainty analyses of water levels for flood risk management. 


\subsection{Conclusions}

In this chapter, the sensitivity of water levels to main channel roughness is quantified for the bifurcating Dutch river Rhine system. In earlier studies, the effect of roughness uncertainty was evaluated for single-branch rivers. This study shows that the feedback mechanism between downstream water levels and discharge distribution at a river bifurcation strongly affects the sensitivity of water levels to roughness variations.

The results show that in a bifurcating river system water levels are less sensitive to changes of the local roughness than in a single-branch river. Changes in the discharge distribution counteract the effects of roughness on water levels. Comparing the bifurcating river with the single-branch rivers, sensitivity to local roughness at a very high upstream discharge of $16,000 \mathrm{~m}^{3} / \mathrm{s}$ reduced from $0.45 \mathrm{~m}$ to $0.22 \mathrm{~m}$, from $0.17 \mathrm{~m}$ to $0.04 \mathrm{~m}$ and from $0.23 \mathrm{~m}$ to $0.07 \mathrm{~m}$, in the Waal, IJssel and Nederrijn branches, respectively. In addition to sensitivity to local roughness, water levels in the bifurcating river system are also sensitive to the roughness of the other branches. Variations in roughness in the largest Waal branch lead to large variations in water levels throughout the entire system. In contrast, variations in roughness in the smallest branch lead to little change in water levels locally, and elsewhere in the system. In the smaller branches, the discharge variations that are governed by the larger branches, can exceed the sensitivity to roughness, thereby increasing the total variability of water levels in a bifurcating river system compared to a single-branch river. At an upstream discharge of $16,000 \mathrm{~m}^{3} / \mathrm{s}$, the total variability of water levels in the IJssel and Nederrijn branches is $0.45 \mathrm{~m}$ and $0.38 \mathrm{~m}$ respectively, clearly exceeding the single-branch values of $0.17 \mathrm{~m}$ and $0.23 \mathrm{~m}$. These principles are generally valid for lowland bifurcating river systems. Therefore, it implies that in these systems the water levels are dominated by waterlevel uncertainties in the largest downstream branch, if those uncertainties occur in the vicinity of the bifurcation point.

Design water levels are different in a bifurcating river system than in single-branch rivers. In the largest branch, design water levels are lower due to the lower waterlevel uncertainties, while in the smallest branch design, water levels increase. Therefore, it is essential that, in river management, the river system should be modelled as one interconnected system in the analysis of the water levels along the branches. This is important for the maintenance of rivers, the assessment of flood risks as well as for the future planning of river engineering works. 


\section{Acknowledgements}

This work is part of the Perspectief research programme All-Risk with project number P15-21, which is (partly) financed by NWO Domain Applied and Engineering Sciences, in collaboration with the following private and public partners: the Dutch Ministry of Infrastructure and Water Management (Rijkswaterstaat), Deltares, STOWA, HKV, Natuurmonumenten and the regional water authorities Noorderzijlvest, Vechtstromen, it Fryske Gea, HHNK.

The authors would like to thank the Dutch Ministry of Infrastructure and Water Management for providing the model. 



\title{
Chapter 3
}

\section{Human interventions in a bifurcating river system: numerical investigation and uncertainty assessment}

\begin{abstract}
In bifurcating rivers, an intervention aimed at flood risk reduction may trigger a change in discharge distribution and thus influence water levels throughout the entire river system. This chapter aims at assessing the impact of interventions on system-wide water levels, explicitly accounting for a range of discharges and model parameter uncertainty. An idealised 1D model with dimensions of the bifurcating Dutch Rhine river is used. The results show that an unwanted increase in water levels downstream of the intervention occurs due to an increased discharge if a single intervention is implemented in a distributary. This effect can be counteracted by implementing a second intervention that balances the hydraulic effect of the first intervention at the bifurcation. However, unwanted water level increases still occur at other discharges. Furthermore, while interventions may reduce local water-level-uncertainty, uncertainty in discharge distribution is not reduced. This implies that flooding probabilities cannot be reduced throughout the entire river system by the implementation of interventions in upstream reaches. Concluding, for intervention design in a bifurcating river, it is important to consider the entire river system and explicitly account for a range of discharge conditions to avoid unwanted water level increases throughout the river system.
\end{abstract}

This chapter is published as M.R.A. Gensen, J.J. Warmink, F. Huthoff and S.J.M.H. Hulscher (2021). Human interventions in a bifurcating river system: numerical investigation and uncertainty assessment. Journal of Flood Risk Management. e12762. DOI: 10.1111/jfr3.12762 


\subsection{Introduction}

Worldwide, investments are made to reduce flood risks in river systems, which could otherwise increase as a result of more frequent extreme hydrological events related to climate change, and due to increasing socio-economic value in floodprone areas (Winsemius et al, 2016). Traditionally, flood risk reduction strategies focused on increasing the height and strength of flood protection systems (Silva et al, 2004). The Netherlands largely abandoned this strategy in the recently completed 'Room for the River' program, which instead aims to reduce flood risk by creating more conveyance capacity in the river (Asselman and Klijn, 2016; Deltaprogramma Rivieren, 2014). Such strategies are also becoming more popular in other countries (Dierauer et al, 2012; Guida et al, 2015; Zevenbergen et al, 2013).

Creating more space in the river lowers water levels and flow velocities (Silva et al, 2004), thereby reducing flooding probabilities as well as the expected consequences if a flood occurs (Asselman and Klijn, 2016; Klijn et al, 2018b). Both of these aspects are considered in the new Dutch flood risk framework (Kok et al, 2017) for which the norms are set in the Dutch Water Act. Under this new framework, the system is designed based on minimizing the expected annual costs that are associated with flood risk, calculated as the product of flooding probabilities and its associated potential losses during occurrences of floods. This approach takes into account various failure mechanisms that can lead to flooding at a range of discharge conditions. Examples are dike breaching at medium-high discharges, and dike overtopping at extremely high discharges. That way, optimal flood protection is not related to a single reference discharge, but rather to a range of discharges where flood probabilities, failure mechanisms and the associated impacts are considered.

The downside of the Dutch flood risk framework is that it is mathematically demanding to explicitly calculate the net annual flood risk for all potential interventions. For that reason, the Netherlands has also defined simpler flood management rules that are meant to guide the design of acceptable river interventions (Rijkswaterstaat, 2019). The rationale behind these rules is that interventions are not allowed to increase the flood risk at any location in the river system. Under the first rule, interventions may not induce water level increases greater than $1 \mathrm{~mm}$ for a reference upstream discharge of $16,000 \mathrm{~m}^{3} / \mathrm{s}$. Under the second rule, the intervention is not allowed to affect the discharge distribution at either of the bifurcation points in the Rhine by more than $5 \mathrm{~m}^{3} / \mathrm{s}$. Again, this relates to the reference discharge level of $16,000 \mathrm{~m}^{3} / \mathrm{s}$. These imposed regulations are very strict and practically mean that no significant solitary interventions can be taken in the vicinity of the bifurcation points in the river Rhine.

An argument that solidifies these strict rules is that Deltares (2018a) showed that a change in the discharge distribution over the distributaries would require high 
costs of dike reinforcements in places where flood risk goes up, which almost always significantly outweighs the economic savings that are achieved by reduced costs in places where flood risk goes down. However, this "lock-in situation" and conservative strategy is also problematic, because changes may still occur in the river system naturally. Interventions may still be needed to restore or counteract such trends, which is typical for rivers in a lock-in situation (Di Baldassarre et al, 2018; Warmink et al, 2017). It is therefore important to look beyond the "lock-in" and the imposed strict design rules for river interventions, and to also improve our ability to anticipate the impacts that interventions near the bifurcation points may have. Moreover, even within the existing strict regulation rules, there is the possibility to consider combinations of interventions around the bifurcation points that compensate or counteract each other's effect. That way, strict regulation rules are respected while other benefits could be achieved.

The aim of this study is to assess the impact of river interventions on systemwide water levels in a bifurcating river system, with particular focus on the Rhine River in the Netherlands. A range of discharge conditions and uncertainties in the main channel and floodplain roughness are considered to determine the impact throughout the system. For this purpose, an idealised modelling approach is taken such that the effect of the interventions can be quantified.

\subsection{Methodology}

\subsubsection{Study area: Dutch Rhine branches}

The river Rhine in the Netherlands bifurcates into three main distributaries: the river Waal, river Nederrijn and river IJssel (Figure 3.1). The Rhine river enters the Netherlands at Lobith after which it reaches the first bifurcation point, the Pannerdensche Kop, after approximately $5 \mathrm{~km}$. The river Waal is the largest distributary and conveys approximately $2 / 3^{\text {rd }}$ of the Lobith discharge. The other $1 / 3^{\text {rd }}$ of the discharge is carried by the Pannerdensch Kanaal, which again bifurcates after 11 kilometers at the IJsselkop bifurcation. At the IJsselkop, the discharge distributes in a fraction of approximately $2 / 3^{\text {rd }}$ and $1 / 3^{\text {rd }}$ over the Nederrijn and IJssel rivers, respectively. The yearly average discharge of the Rhine at Lobith is approximately $2200 \mathrm{~m}^{3} / \mathrm{s}$. The bankfull discharges of all Rhine distributaries correspond to a Lobith discharge of around $5000 \mathrm{~m}^{3} / \mathrm{s}$. All branches are compound channels, with wide floodplains conveying significant discharge when the bankfull discharge is exceeded. The hinterland is protected by dikes, which are dimensioned to keep out water until discharges of $16,000 \mathrm{~m}^{3} / \mathrm{s}$, generally associated with a return period of 1250 years (Klijn et al, 2018a). More recent studies show that this discharge level is more likely associated with lower return periods, perhaps exceeding 10,000 years (Sperna Weiland et al, 2015). The maximum discharge that 
can reach Lobith is estimated at 18,000 $\mathrm{m}^{3} / \mathrm{s}$ (Bomers et al, 2019c).

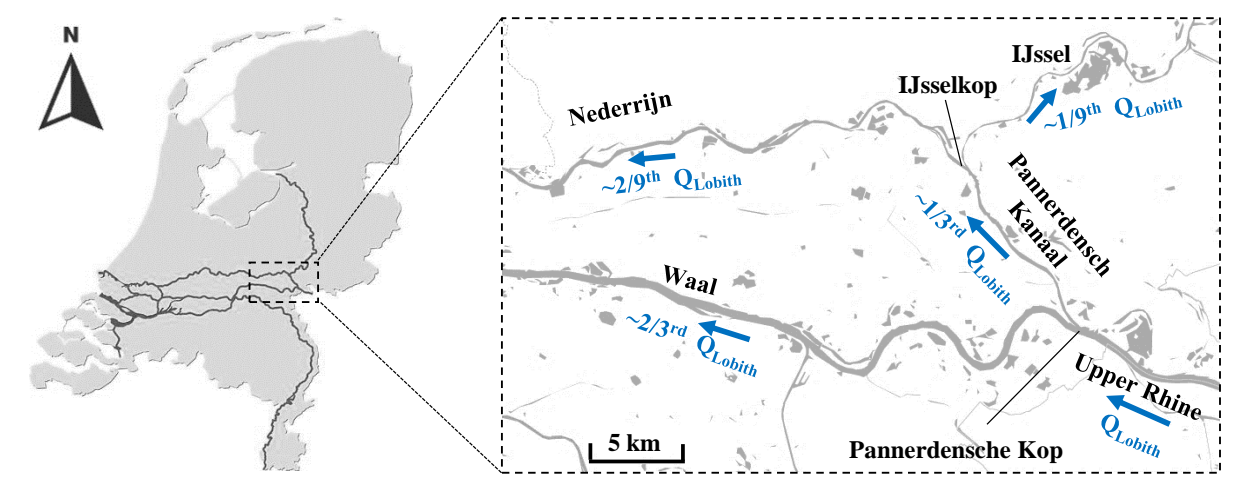

Figure 3.1: Study area: Rhine branches in the Netherlands

A one-dimensional, idealised network model of the Rhine branches is set up in the SOBEK modelling environment (Deltares, 2020). SOBEK numerically solves the 1D Saint-Venant equations on a staggered grid. The dimensions of the river network are assigned by cross-sections, which are divided into different sections to create a compound cross-section. The governing equations are solved for each of these sections separately, such that average flow velocities can differ within the cross-section, and that each of these sections is assigned its own hydraulic roughness. Computational grid points are spaced 250 meters apart and the maximum time step is set to 10 minutes, which is similar to other 1D model studies of the Rhine branches (e.g. Berends et al, 2018).

\subsubsection{Model schematization and configurations}

The schematized river network is based on the dimensions of the Rhine branches (Figure 3.2A). The three distributaries, the Waal, the Nederrijn and the IJssel have respective lengths of $93 \mathrm{~km}, 107 \mathrm{~km}$ and $113 \mathrm{~km}$. A uniform bed slope of $10^{-4}$ is assigned for each branch, averaging the actual bed slope of the Rhine branches which varies between $0.9^{*} 10^{-4}$ and $1.2^{*} 10^{-4}$ (Reeze et al, 2017). Every branch is assigned a uniform compound cross-section with of which the dimensions are based on the average geometries of Rhine branches. In every branch, the floodplain base level is located 8 meters above that of the main channel, which is the approximate water depth at which the banks that demarcate the main channel and floodplains are exceeded. Both the main channel and the floodplain roughness are defined by probability distributions of Manning roughness values (Figure 3.2B, see section 3.2.3). The upstream boundary of the model is a steady discharge $\mathrm{Q}_{\text {Lobith}}$, which can be varied between runs. Each distributary has a characteristic 
stage-discharge relationship at its downstream boundary, which is located far away from the bifurcation points, chosen such that under mean roughness values the flow will be uniform along the entire branch.
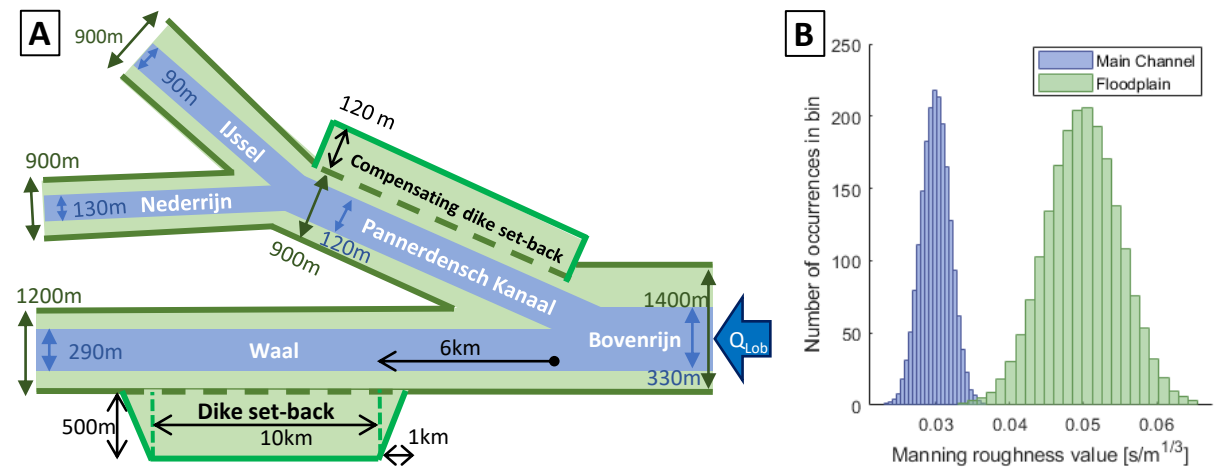

Figure 3.2: A) Schematization of the Rhine branches. B) Roughness samples of the Waal main channel (blue) and floodplains (green). The hydraulic roughness of the main channels and floodplains of the other branches follow the same distributions and are all independent.

In a bifurcating river system, changes in water levels downstream of the bifurcation create a feedback mechanism through the discharge distribution. If the water level goes down in one branch, then that branch will draw more discharge from the bifurcation, which, in turn, will increase the water level in that branch. This interaction between the water levels of downstream branches and discharge distribution at bifurcation points is known to affect the uncertainty of water levels compared to a single-branch river (Gensen et al, 2020; Straatsma et al, 2013). To single out effects that are caused by changing discharge distributions, an alternative "branch configuration" of the model is included in the analysis where only the Waal branch is modelled, such that the effects of the feedback mechanism at the bifurcation are absent. The model configuration with feedback at the bifurcation points is referred to as the "system configuration" (Table 3.1). For the branch configuration, the upstream boundary is located at the bifurcation point. The inflow discharge is steady and is equal to the discharge that is diverted into the Waal branch in the system configuration without any intervention under mean roughness conditions.

Typical 'Room for the River' type interventions, which enlarge the conveyance capacity of the floodplains, are studied. A dike set-back widens the floodplains and a floodplain excavation deepens a floodplain, thereby both reducing the water levels for given discharges. First, a single intervention (a dike set-back) is implemented in the Waal branch. As the Waal is the largest branch, it is expected that an intervention along this branch gives the largest change in discharge distribution (Gensen et al, 2020). The dike is set back by $500 \mathrm{~m}$ over a length of $10 \mathrm{~km}$ (Figure 3.2A). The upstream end is located at $6 \mathrm{~km}$ downstream 
from the bifurcation. This is close enough to the bifurcation to have a large impact on the discharge distribution, but it is far enough from the bifurcation to achieve a reduction of water levels in the Waal branch upstream of the intervention. The transition between the cross-section with the dike set-back and the original crosssection is smoothed out over $1 \mathrm{~km}$ both upstream and downstream to avoid abrupt changes in channel geometry. The hydraulic roughness of the widened section is equal to the roughness of the floodplains in the original Waal branch.

To compensate for the discharge shift at the bifurcation point due to the dike set-back in the Waal river, a second intervention is considered over the entire length of the Pannerdensch Kanaal $(11 \mathrm{~km})$. Three combinations of compensating interventions are assessed (Table 3.1): 1) two dike set-backs, 2) a dike setback in the Waal combined with a floodplain excavation in the Pannerdensch Kanaal and 3) a floodplain excavation in the Waal at the same location as the original dike set-back combined with a dike set-back in the Pannerdensch Kanaal. The dimensions of the compensating interventions (Table 3.1) are chosen such that the discharge distribution is exactly restored to that of the system without interventions at a reference discharge of $\mathrm{Q}_{\text {Lobith }}=16,000 \mathrm{~m}^{3} / \mathrm{s}$. Considering combinations of interventions, and using model settings with and without feedback at the bifurcation point, seven model configurations will be considered (Table 3.1).

Table 3.1: Model configurations

\begin{tabular}{|c|c|c|c|}
\hline Configuration & Intervention Waal & $\begin{array}{l}\text { Intervention } \\
\text { Pan. Kanaal }\end{array}$ & $\begin{array}{l}\text { Results in } \\
\text { section }\end{array}$ \\
\hline System, no intervention & None & None & 3.3 .1 \\
\hline Branch, no intervention & None & - & 3.3 .1 \\
\hline System, single intervention & $500 \mathrm{~m}$ dike set-back & None & 3.3 .2 \\
\hline Branch, single intervention & 500m dike set-back & - & 3.3 .2 \\
\hline Compensating system 1 & 500m dike set-back & 120m dike set-back & 3.3.3 \\
\hline Compensating system 2 & $500 \mathrm{~m}$ dike set-back & $\begin{array}{l}0.39 \mathrm{~m} \text { floodplain } \\
\text { excavation }\end{array}$ & 3.3 .4 \\
\hline Compensating system 3 & $\begin{array}{l}1.46 \mathrm{~m} \text { floodplain } \\
\text { excavation }\end{array}$ & $120 \mathrm{~m}$ dike set-back & 3.3 .4 \\
\hline
\end{tabular}

\subsubsection{Monte Carlo Simulation of uncertain intervention impact}

The effects of river interventions on water levels using model simulations are inherently uncertain (Berends et al, 2019). The uncertainty in the water levels is accounted for by setting the main channel roughness and floodplain roughness as stochastic parameters, both being major sources of uncertainty in hydraulic modelling (Bozzi et al, 2015; Pappenberger et al, 2008; Warmink et al, 2013b). A rather simple approach is adopted in which the main channel roughness and 
floodplain roughness are normally distributed (Figure 3.2B). The mean values of the Manning's roughness for the main channel and floodplain are 0.03 and 0.05 $\mathrm{m}^{1} / 2 / \mathrm{s}$ and the standard deviations are 0.002 and $0.005 \mathrm{~m}^{1} / 2 / \mathrm{s}$, respectively. The roughness of the main channel roughly represents a river bed covered with dunes (Julien et al, 2002), while the roughness of the floodplains roughly represents floodplains covered with bushes as vegetation (Chow, 1959). The roughness distributions are the same for every branch of the river system, and the roughness is assumed independent between the branches. While correlation is expected (e.g. Straatsma and Huthoff, 2011), the degree of correlation is difficult to determine. The significance of the assumption is addressed in section 3.4.1.

A Monte Carlo Simulation (MCS) is run 2000 times for every model configuration and for 18 discharge conditions, giving a total of 36,000 runs per model configuration. The upstream discharge is varied from $1000 \mathrm{~m}^{3} / \mathrm{s}$ to $18,000 \mathrm{~m}^{3} / \mathrm{s}$ in steps of $1000 \mathrm{~m}^{3} / \mathrm{s}$. A set of 2000 quasi-random samples is established using Sobol sequencing. One sample consists of 8 roughness values, being a main channel and floodplain roughness for each of the 4 branches. Sobol sequences ensure good coverage of the parameter domain and reproducibility (Saltelli et al, 2010). The same set of 2000 samples is used as input for every model configuration and for every discharge condition to allow direct comparison. Figure 3.3 shows that 2000 samples are sufficient to ensure convergence of the $90 \%$ confidence intervals of calculated water levels.

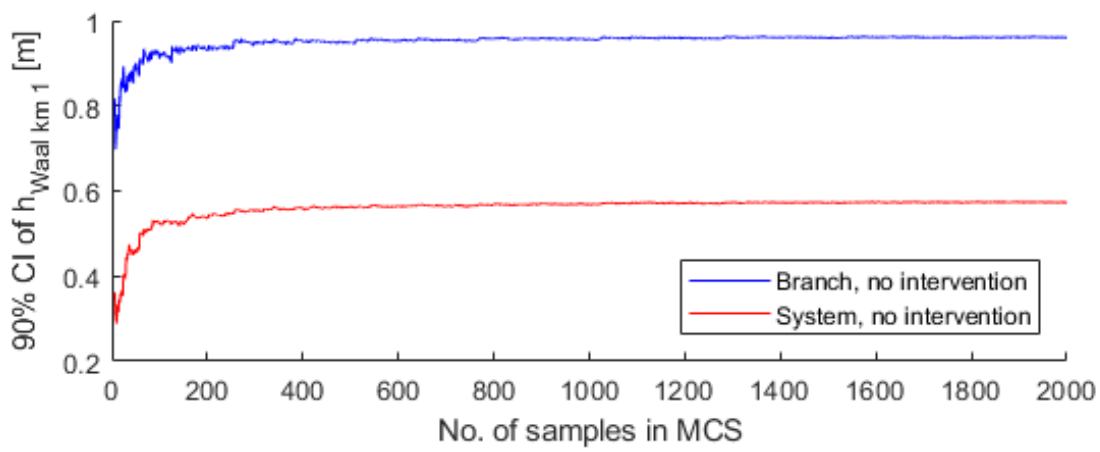

Figure 3.3: $90 \%$ confidence intervals $(\mathrm{Cl})$ of water levels at Waal river kilometer 1 for $Q_{\text {Lobith }}=16,000$ $\mathrm{m}^{3} / \mathrm{s}$ as function of the number of Sobol samples.

The intervention impact is quantified by two parameters: 1) mean effect on water levels at location ' $\mathrm{x}$ ' $\left(\overline{\Delta h_{x}}\right)$ and 2$)$ relative uncertainty of the effect on water levels, $R U 90_{x}$. Often the results are shown for the reference discharge $\mathrm{Q}_{\text {Lobith }}=16,000$ $\mathrm{m}^{3} / \mathrm{s}$, which is the discharge for which the dikes along the Rhine branches are currently designed.

Firstly, the mean effect on water levels $\left(\overline{\Delta h_{x}}\right)$ is quantified by determining the 
mean of the set of 2000 water level differences (Eq. 3.1). This set is obtained by subtracting the water levels in the configuration without interventions (system or branch) from the modelled water levels in the configuration with interventions. This subtraction is done for every roughness sample and for every location ' $\mathrm{x}$ ' separately.

Mean effect at location 'x': $\overline{\Delta h_{x}}=\overline{h_{\mathrm{s}, \mathrm{x}} \text { with intervention }-h_{\mathrm{s}, \mathrm{x} \text { no intervention }}}$

where, $\mathrm{h}$ is the water level, $\mathrm{x}$ is any location in the river system and $\mathrm{s}$ is the sample number.

Secondly, from the set of 2000 water level differences, the $90 \%$ confidence interval (CI) is quantified by using the $5^{\text {th }}$ percentile and $95^{\text {th }}$ percentile water level differences. Subsequently, this $90 \%$ confidence interval is divided by the mean change in water levels to obtain the relative uncertainty (Eq. 3.2). Relative uncertainty is a metric introduced by Berends et al (2019) that enables comparison between different types of interventions.

$$
\text { Relative uncertainty at location 'x': } R U 90_{x}=\frac{90 \% C I \text { of } \Delta h_{x}}{\overline{\left|\Delta h_{x}\right|}}
$$

\subsection{Results}

\subsubsection{Branch and system configurations without interventions}

Figure 3.4 shows the results of the branch and system configurations without applying any interventions. These configurations are comparable to Gensen et al (2020), extended here by including floodplain roughness uncertainty. The results show that mean water levels and the shape of the water depth-discharge relationship are the same between the branch and system configuration (Figure 3.4A). The depth-discharge relationship is steep below bankfull discharge ( $~ 5000$ $\mathrm{m}^{3} / \mathrm{s}$ ) and flattens above bankfull discharge as the floodplains start conveying discharge. Note that the confidence interval for the system model configuration is narrower than for the branch model configuration. This is the result of the feedback mechanism at the bifurcation which counteracts the highest perturbations in flow parameters and thereby distributes the uncertainty over downstream branches, as was also shown in Gensen et al (2020).

Figure $3.4 \mathrm{~B}$ shows the nearly normally distributed water depth in the two configurations for $\mathrm{Q}_{\text {Lobith }}=16,000 \mathrm{~m}^{3} / \mathrm{s}$. Both distributions have a slight skewness with a heavier left tail. As already pointed out for Figure $3.4 \mathrm{~A}$, the $90 \%$ confidence 

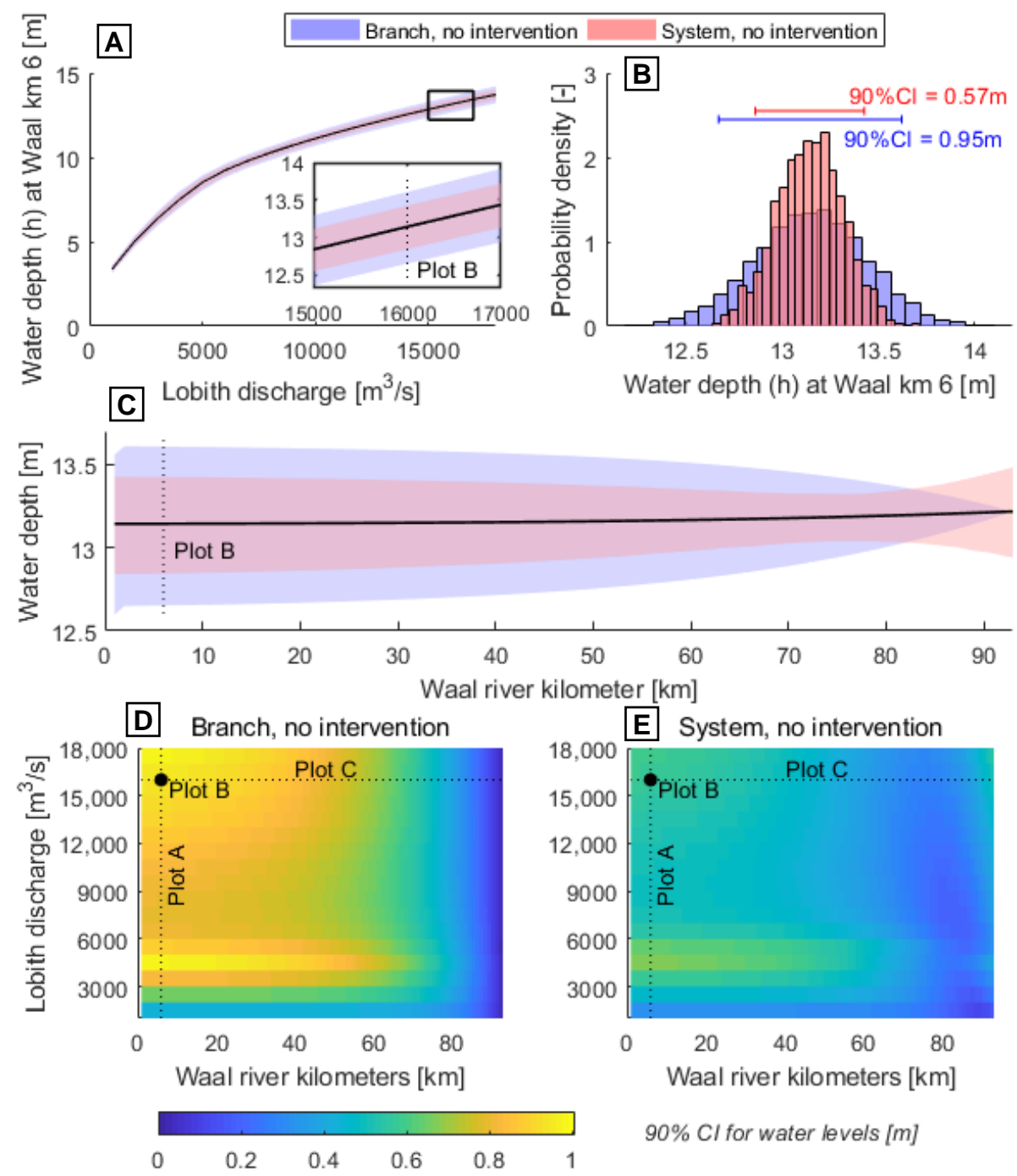

Figure 3.4: (A) Water depth in the main channel at Waal $\mathrm{km} 6$ (location of the highest expected effect of the intervention) as function of Lobith discharge in the branch (blue) and system (red) configurations without interventions. The shaded areas mark the $90 \%$ confidence intervals and the black line shows the mean water depths, which are equal in the two configurations. (B) Histograms of water depths for $\mathrm{Q}_{\text {Lobith }}=16,000 \mathrm{~m}^{3} / \mathrm{s}$ at Waal $\mathrm{km} 6$ and their $90 \%$ confidence intervals $(\mathrm{Cl})$. (C) Water depths along the Waal branch for $Q_{\text {Lobith }}=16,000 \mathrm{~m}^{3} / \mathrm{s}$. The shaded areas mark the $90 \%$ confidence intervals and the black line shows the mean water depths which are equal in the two configurations. (D\&E) $90 \%$ confidence intervals $(\mathrm{Cl})$ of water levels for varying Lobith discharges and for locations along the Waal branch in the branch (D) and system (E) configurations without interventions. 
interval in the system configuration is narrower than that of the branch. The $90 \%$ confidence interval in the branch configuration is $0.95 \mathrm{~m}$, which is in the same order of magnitude as Warmink et al (2013b) $(95 \% \mathrm{CI}=0.68 \mathrm{~m})$, who used a $2 \mathrm{D}$ model and considered the same Waal branch under the reference discharge of $16,000 \mathrm{~m}^{3} / \mathrm{s}$ and used uncertain main channel and floodplain roughness as well. This shows that the idealised 1D model reproduces results of more complex and more realistic model studies reasonably well.

Figure $3.4 \mathrm{C}$ shows that the $90 \%$ confidence interval in the system configuration is narrower than in the branch configuration along the largest part of the Waal branch. In the branch configuration, the width of the $90 \%$ confidence interval reduces to $0 \mathrm{~m}$ in downstream direction, as the downstream model boundary fixes the water level if the discharge is invariant. In the system configuration, waterlevel-uncertainty is still present $(0.54 \mathrm{~m})$ at the downstream boundary as the branch discharge varies.

Figures $3.4 \mathrm{D}$ and $3.4 \mathrm{E}$ show the width of the $90 \%$ confidence interval as function of discharge and location along the Waal branch in the branch and system configuration, respectively. In general, the confidence interval widens with increasing discharge. A sharp decrease in water-level-uncertainty is observed around and just above bankfull discharge $\left(\sim 5000 \mathrm{~m}^{3} / \mathrm{s}\right)$ as the conveyance capacity suddenly increases.

\subsubsection{Impact of a single intervention}

Figure 3.5 shows the results for a single intervention, a dike set-back, in the Waal branch for both the system configuration and the branch configuration. In both configurations, the impact is generated over the length of the intervention with a maximum water-level-reduction at the upstream end of the intervention at $\mathrm{km}$ 6. These are $\overline{\Delta h_{x=6}}=-0.14 \mathrm{~m}$ and $\overline{\Delta h_{x=6}}=-0.24 \mathrm{~m}$ in the system and branch configuration, respectively. Towards the bifurcation point at $\mathrm{km} 0$, the impact reduces following a backwater curve. The feedback mechanism at the bifurcation in the system configuration reduces the water-level-lowering effect of the intervention, and it creates an increase in water levels of about $9 \mathrm{~cm}$ downstream of the intervention location. This downstream water level rise is caused by an average increase in discharge towards the Waal branch of $164 \mathrm{~m}^{3} / \mathrm{s}$, which is a result of the feedback mechanism. 


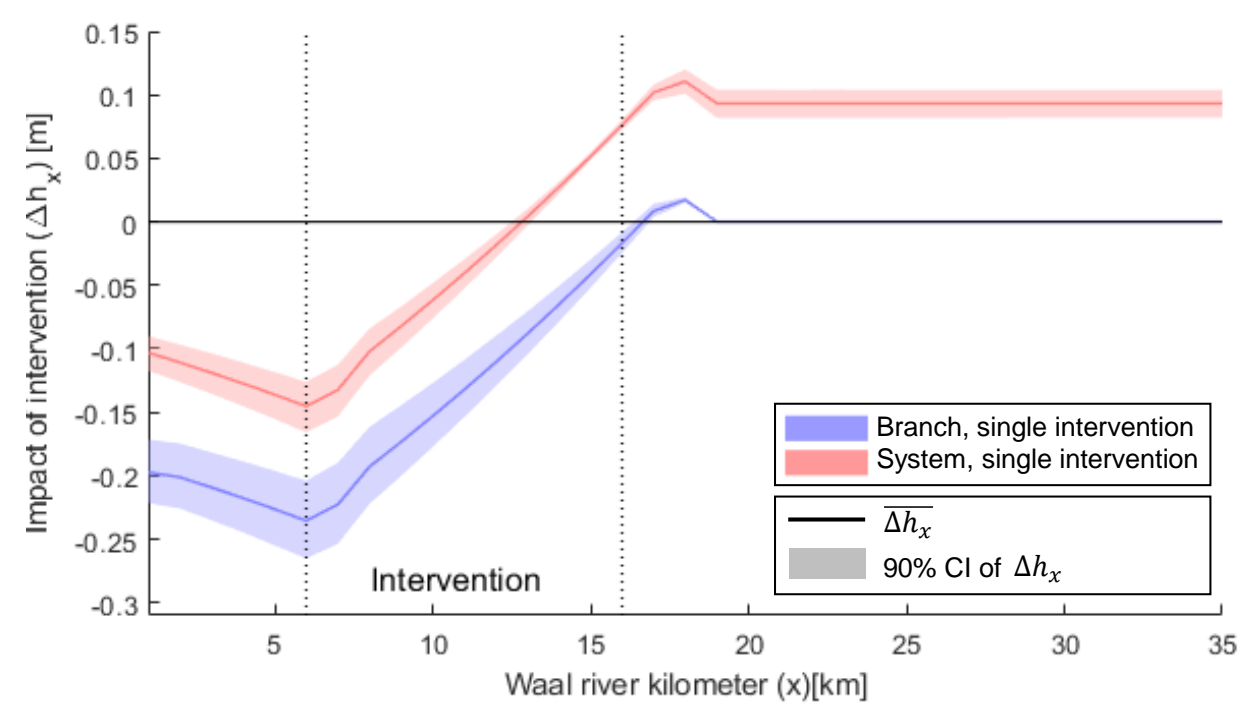

Figure 3.5: Impact of a single intervention in the Waal branch for $Q_{\text {Lobith }}=16,000 \mathrm{~m}^{3} / \mathrm{s}$ in the system (red) and branch (blue) configuration. The shaded area marks the $90 \%$ confidence interval $(90 \% \mathrm{Cl})$ of the set of 2000 water level differences $\left(\Delta h_{x=6}\right)$. The continuous line marks the mean effect of the intervention $\left(\overline{\Delta h_{x=6}}\right)$

\subsubsection{Impact of two compensating interventions of the same type}

Figure 3.6 shows that the implementation of a compensating intervention of the same type (a dike set-back) in the opposing branch removes unwanted water level increases throughout the river system that are caused by a single intervention. The mean effect on Waal water levels is equal in the branch and system configuration. This implies that the two dike set-backs result in the same mean discharge distribution as in the pre-intervention situation for $\mathrm{Q}_{\text {Lobith }}=16,000 \mathrm{~m}^{3} / \mathrm{s}$, which is where they were designed for. For other discharges than $16,000 \mathrm{~m}^{3} / \mathrm{s}$, the two compensating interventions do not have exactly equal effect, causing a small change in the discharge distribution in comparison to the situation without interventions. Still, the resulting water level increases throughout the system are very small, with a maximum of $0.8 \mathrm{~cm}$ in the Waal and $0.2 \mathrm{~cm}$ in the IJssel (see Figure 3.7 in section $3.3 .4)$. 


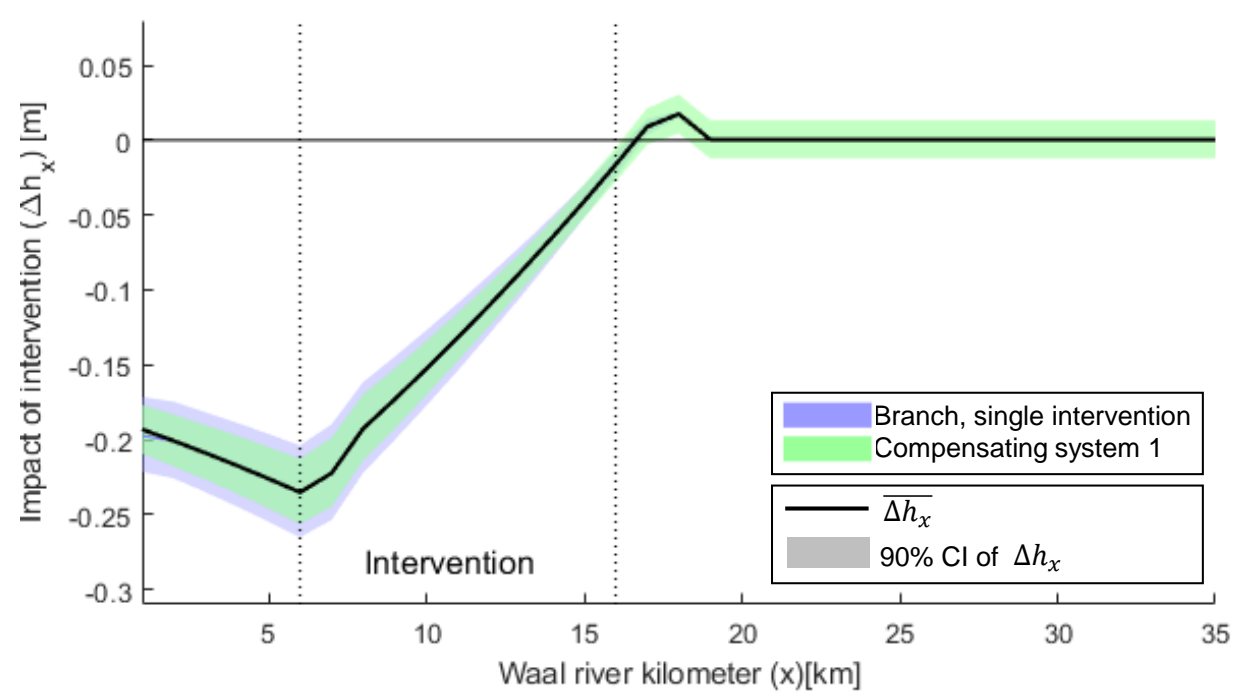

Figure 3.6: Impact on water levels for $Q_{\text {Lobith }}=16,000 \mathrm{~m}^{3} / \mathrm{s}$ of a single intervention in the branch configuration (blue) and of a set of compensating dike set-backs in the system configuration (compensating system 1; green). The shaded area marks the $90 \%$ confidence interval $(90 \% \mathrm{Cl})$ of the set of 2000 water level differences $\left(\Delta h_{x=6}\right)$. The thick, black line marks the mean effect $\left(\overline{\Delta h_{x=6}}\right)$ for both configurations.

\subsubsection{Impact of compensating interventions of different types as function of discharge}

Unwanted water level increases occur downstream of one of the compensating interventions if the compensating interventions are not of the same type (Figure 3.7 and Table 3.2). Figure 3.7 shows the impact on water levels $30 \mathrm{~km}$ into the Waal branch (left panel) and $30 \mathrm{~km}$ into the IJssel branch (right panel) of different combinations of interventions. At these locations, water level differences are governed by the changes in discharge distribution that are induced by the interventions. Therefore, an increase in water levels at this location in the Waal branch is always accompanied by a decrease in water levels in the IJssel branch and vice versa.

A system configuration with a single intervention in the Waal branch shows a steadily increasing impact on water levels with increasing discharge (Figure 3.7), causing increasing Waal water levels and decreasing IJssel water levels. The reduction of discharge towards the Pannerdensch Kanaal is attributed to both downstream branches (IJssel and Nederrijn), resulting in water level decreases here that are in the same order as the water level increase in the Waal. For two compensating dike set-backs, very little mean effects occur $\left(\overline{\Delta h_{x=\text { Waal30 }}} \sim 0\right.$ 
Table 3.2: Mean effects $\left(\overline{\Delta h_{x}}\right)$ and width of the $90 \%$ confidence interval of $\Delta h_{x}$ for $\mathrm{Q}_{\text {Lobith }}=6000$ $\mathrm{m}^{3} / \mathrm{s}$ (above bankfull discharge) and $Q_{\text {Lobith }}=18,000 \mathrm{~m}^{3} / \mathrm{s}$ (predicted maximum discharge in the Rhine system) for 4 intervention configurations in the Waal and Pannerdensch Kanaal (Pan.Kan.). Intervention types are either a dike set-back or a floodplain (fp.) excavation.

\begin{tabular}{|c|c|c|c|}
\hline \multicolumn{2}{|c|}{$\begin{array}{l}\text { Intervention types } \\
\text { (configurations) }\end{array}$} & \multicolumn{2}{|c|}{$\begin{array}{l}\overline{\Delta h_{x=6}} \text { and }\left(90 \% \mathrm{Cl} \text { of } \Delta h_{x=6}\right) \\
\text { for } Q_{\text {Lobith }}=6000 \mathrm{~m}^{3} / \mathrm{s}\end{array}$} \\
\hline Waal & Pan. Kanaal & $x=$ Waal $\mathbf{k m} 30$ & $x=\mid$ Jssel $\mathrm{km} 30$ \\
\hline $\begin{array}{l}\text { Dike set-back } \\
\text { Dike set-back } \\
\text { Dike set-back } \\
\text { Fp. excavation }\end{array}$ & $\begin{array}{l}\text { - } \\
\text { Dike set-back } \\
\text { Fp. excavation } \\
\text { Dike set-back }\end{array}$ & $\begin{array}{l}+1.5 \mathrm{~cm}(1.4 \mathrm{~cm}) \\
+1.0 \mathrm{~cm}(0.5 \mathrm{~cm}) \\
-4.7 \mathrm{~cm}(2.6 \mathrm{~cm}) \\
+6.4 \mathrm{~cm}(2.0 \mathrm{~cm})\end{array}$ & $\begin{array}{l}-3.4 \mathrm{~cm}(2.7 \mathrm{~cm}) \\
-1.0 \mathrm{~cm}(2.7 \mathrm{~cm}) \\
+11.0 \mathrm{~cm}(5.9 \mathrm{~cm}) \\
-13.3 \mathrm{~cm}(7.4 \mathrm{~cm})\end{array}$ \\
\hline \multicolumn{2}{|c|}{$\begin{array}{l}\text { Intervention types } \\
\text { (configurations) }\end{array}$} & \multicolumn{2}{|c|}{$\begin{array}{l}\overline{\Delta h_{x=6}} \text { and }\left(90 \% \mathrm{Cl} \text { of } \Delta h_{x=6}\right) \\
\text { for } \mathbf{Q}_{\text {Lobith }}=18,000 \mathrm{~m}^{3} / \mathrm{s}\end{array}$} \\
\hline Waal & Pan. Kanaal & $x=$ Waal km 30 & $x=I J s s e l \mid k m 30$ \\
\hline $\begin{array}{l}\text { Dike set-back } \\
\text { Dike set-back } \\
\text { Dike set-back } \\
\text { Fp. excavation }\end{array}$ & $\begin{array}{l}\text { - } \\
\text { Dike set-back } \\
\text { Fp. excavation } \\
\text { Dike set-back }\end{array}$ & $\begin{array}{l}+10.2 \mathrm{~cm}(2.3 \mathrm{~cm}) \\
-0.2 \mathrm{~cm}(2.7 \mathrm{~cm}) \\
+0.9 \mathrm{~cm}(2.7 \mathrm{~cm}) \\
-1.1 \mathrm{~cm}(2.9 \mathrm{~cm})\end{array}$ & $\begin{array}{l}-10.0 \mathrm{~cm}(2.5 \mathrm{~cm}) \\
+0.3 \mathrm{~cm}(2.6 \mathrm{~cm}) \\
-0.8 \mathrm{~cm}(2.6 \mathrm{~cm}) \\
+1.2 \mathrm{~cm}(2.7 \mathrm{~cm})\end{array}$ \\
\hline
\end{tabular}

and $\overline{\Delta h_{x=I J s s e l 30}} \sim 0$ ), as observed in section 3.3.3. Still, an uncertainty in downstream water levels is present that increases with increasing discharge.

The compensation configurations which have different types of interventions still do not lead to mean effects at either location for $Q_{\text {Lobith }}=16,000 \mathrm{~m}^{3} / \mathrm{s}$, as the interventions were designed to compensate for this discharge. Whether water levels increase or decrease at a location, depends on both the discharge and the intervention type attributed to a branch. A floodplain excavation is more effective at reducing water levels for discharges between the bankfull discharge and the design discharge of $16,000 \mathrm{~m}^{3} / \mathrm{s}$. Additionally, around bankfull discharge the effect is very uncertain (high RU90) as the floodplain excavation changes the bankfull height. Oppositely, a dike set-back is more effective at reducing water levels for discharges over $16,000 \mathrm{~m}^{3} / \mathrm{s}$. If one of the interventions is more effective, it will draw discharge towards the branch with that intervention, resulting in water level increases along that branch. In principle, the impact thus mirrors between the two compensating configurations which have different types of interventions (yellow vs. purple in Figure 3.7).

\subsection{Discussion}



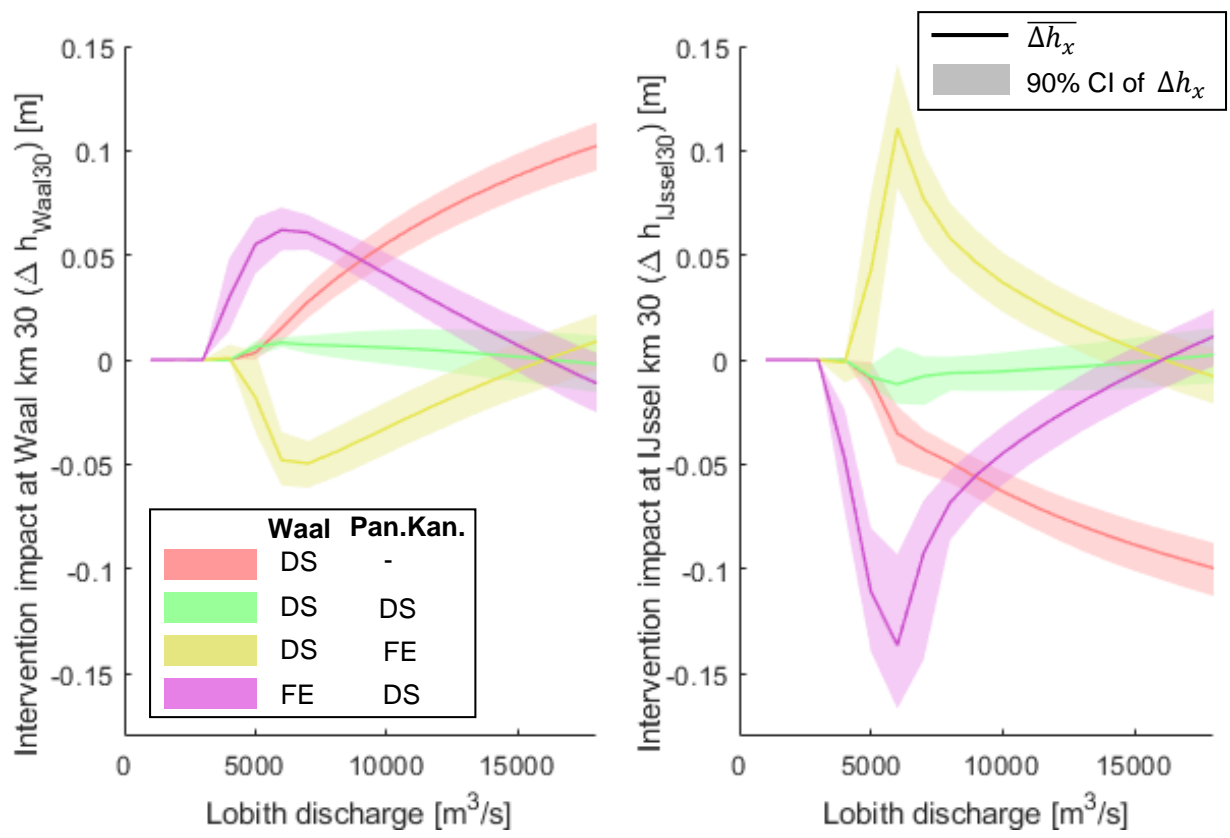

Figure 3.7: Impact of a set of compensating interventions of different types on the water levels 30 $\mathrm{km}$ into the Waal (left) and IJssel (right) branches, compared to a single intervention (red lines). The continuous lines are the mean effects on water levels $\left(\overline{\Delta h_{x=\text { Waal } 30}}\right)$ and $\left.\overline{\Delta h_{x=I J s s e l 30}}\right)$ and the shaded areas mark the $90 \%$ confidence interval of water level differences. The intervention types are a dike set-back (DS) or a floodplain excavation (FE).

\subsubsection{Water-level-uncertainty and flood water levels in a bifurcating river}

This study has shown that water levels can be reduced locally by the implementation of a 'Room for the River' type intervention. However, if implemented near a river bifurcation, this is generally accompanied by an unwanted water-level-increase elsewhere in the river system. Alternatively, interventions could be aimed at reducing water-level-uncertainty. This results in lower flooding probabilities as the highest water levels in the water-leveldistribution (e.g. $95^{\text {th }}$ percentile water levels) contribute most to this probability (Kok et al, 2017). A 'Room for the River' type intervention is able to reduce water-level-uncertainty upstream of its location, thus also reducing water-leveluncertainty at the bifurcation (Table 3.3). On top of the mean effect of the intervention, this further reduces the flooding probabilities at these locations. In the enlarged cross-section, water levels are less sensitive to discharge and to roughness parameters, because of the flattening the depth-discharge relationship. 
In a bifurcating river system, the uncertainty in discharge distribution is an important driver of water-level-uncertainty in the downstream reaches of the river system (Van Vuren et al, 2005). In the upper reaches, water-level-uncertainty and discharge distribution interact through the feedback mechanism. For downstream reaches, the discharge distribution affects water-level-uncertainty, but waterlevel-uncertainty does not influence the discharge distribution. Consequently, reducing the uncertainty in discharge distribution lowers the downstream waterlevel-uncertainty and thus flooding probabilities. However, it appears that an intervention in cross-sectional geometry in an upstream reach does not necessarily reduce, and may even increase, the uncertainty in discharge distribution, even though water-level-uncertainty is reduced at the bifurcation (Table 3.3). This is explained by the shape of the depth-discharge relationship in the intervened situation, which is flatter in comparison to the original situation. This means that a smaller perturbation in water levels is needed to trigger a certain change in discharge distribution compared to the original situation.

Table 3.3: Effects of the interventions in the system configuration for a discharge of $16,000 \mathrm{~m}^{3} / \mathrm{s}$ : on water-level-uncertainty, which is expressed as the $90 \%$ confidence intervals $(90 \% \mathrm{Cl})$ of water levels (WL) at the bifurcation and downstream in the Waal and IJssel, on discharge distribution uncertainty (DD) at the first bifurcation, and on $95^{\text {th }}$ percentile water depths $\left(h_{95 \%}\right)$ in the Waal and IJssel.

\begin{tabular}{|c|c|c|c|c|c|}
\hline \multicolumn{2}{|c|}{ Intervention type } & \multicolumn{4}{|c|}{ At bifurcation; Waal km 0} \\
\hline Waal & Pan. Kan. & \multicolumn{2}{|c|}{$90 \% \mathrm{Cl} W L$} & \multicolumn{2}{|c|}{$90 \% C I D D$} \\
\hline- & - & \multicolumn{2}{|l|}{$0.57 \mathrm{~m}$} & \multicolumn{2}{|c|}{$948 \mathrm{~m}^{3} / \mathrm{s}$} \\
\hline Dike set-back & - & \multicolumn{2}{|l|}{$0.57 \mathrm{~m}$} & \multicolumn{2}{|c|}{$939 \mathrm{~m}^{3} / \mathrm{s}$} \\
\hline Dike set-back & Dike set-back & \multicolumn{2}{|l|}{$0.55 \mathrm{~m}$} & \multicolumn{2}{|c|}{$949 \mathrm{~m}^{3} / \mathrm{s}$} \\
\hline Dike set-back & Fp. excavation & \multicolumn{2}{|l|}{$0.56 \mathrm{~m}$} & \multicolumn{2}{|c|}{$937 \mathrm{~m}^{3} / \mathrm{s}$} \\
\hline Fp. excavation & Dike set-back & $0.56 \mathrm{~m}$ & & $957 \mathrm{~m}^{3} /$ & \\
\hline \multicolumn{2}{|c|}{ Intervention type } & \multicolumn{2}{|c|}{ Waal km 30} & \multicolumn{2}{|c|}{ IJssel km 30} \\
\hline Waal & Pan. Kan. & $\begin{array}{l}90 \% \mathrm{Cl} \\
W L\end{array}$ & $\boldsymbol{h}_{95 \%}$ & $\begin{array}{l}90 \% \mathrm{Cl} \\
W L\end{array}$ & $\boldsymbol{h}_{95 \%}$ \\
\hline- & - & $0.52 m$ & $13.41 \mathrm{~m}$ & $0.67 \mathrm{~m}$ & $11.91 \mathrm{~m}$ \\
\hline Dike set-back & - & $0.53 \mathrm{~m}$ & $13.51 \mathrm{~m}$ & $0.67 \mathrm{~m}$ & $11.82 \mathrm{~m}$ \\
\hline Dike set-back & Dike set-back & $0.52 \mathrm{~m}$ & $13.41 \mathrm{~m}$ & $0.67 \mathrm{~m}$ & $11.91 \mathrm{~m}$ \\
\hline Dike set-back & Fp. excavation & $0.53 \mathrm{~m}$ & $13.41 \mathrm{~m}$ & $0.66 \mathrm{~m}$ & $11.90 \mathrm{~m}$ \\
\hline Fp. Excavation & Dike set-back & $0.51 \mathrm{~m}$ & $13.40 \mathrm{~m}$ & $0.68 m$ & $11.91 \mathrm{~m}$ \\
\hline
\end{tabular}

Potentially, water-level-uncertainty and thus flooding probabilities throughout the entire system could be lowered by reducing the uncertainty in underlying parameter uncertainty in the vicinity of the bifurcation points. In this study, uncertainty in roughness parameters was assessed. Several strategies can be pursued at reducing these uncertainties. For main channel roughness, potential flattening of bedforms for very high discharges is poorly understood (Naqshband et al, 2017), but it may trigger a large change in discharge distribution (Gensen et al, 2020). Preventing such flattening from occurring, e.g. through changing 
the sediment composition, therefore reduces flooding probabilities in downstream reaches. For floodplain roughness, a reduction in uncertainty can be achieved by eliminating errors in the classification of vegetation (Straatsma et al, 2013). Alternatively, stricter vegetation maintenance strategies can be implemented near the bifurcations (Makaske et al, 2011).

\subsubsection{Sensitivity to roughness distributions}

A simplified roughness-modelling approach was applied to study the effect of model parameter uncertainty on intervention impact. It was shown that this idealised approach could represent more realistic modelling studies, as the ones performed by Warmink et al (2013a) and Berends et al (2019). More realistic roughness distributions could improve the accuracy of the results, but the feedback mechanism between water levels and discharge would still have a similar qualitative effect on the uncertainty of intervention impact. If the roughness of the branches would be more uncertain than what was considered in this study, water-leveluncertainty and uncertainty of the impact would increase as well.

In this study, it is assumed that the roughness is constant along a branch. Some variability can be expected based on the local characteristics of the main channels and the floodplains. Such variability can affect the water-level-uncertainty along the branches (Warmink et al, 2013b). However, as the roughness conditions are the same in both the pre-intervention and the post-intervention models, the impact of incorporating variability of the roughness along a branch are expected to be rather small (equivalant to Berends et al, 2019).

Furthermore, the roughness between the branches was assumed independent. In reality, a certain degree of dependence can be expected (e.g. Straatsma and Huthoff, 2011). Figure 3.8 shows that even if the roughness would be fully correlated between the branches, uncertainty intervals would only be marginally different. The two extremes of full correlation and fully independent roughness show the maximum bandwidth of possible results. For the single intervention in the system configuration (red), the water-level-reduction achieved by the intervention is slightly more certain, while the downstream uncertainty is unaffected. In this configuration, the uncertainty is governed by the partitioning of flow over the main channel and floodplains, which in turn is determined by the local roughness conditions. The uncertainty related to the impact of the intervention is more affected by the assumption of independence for the compensating interventions configuration. If the roughness between the branches is fully correlated, the uncertainties of the two interventions do not cancel each other out anymore through the feedback mechanism at the bifurcation. Therefore, almost no downstream effect is expected in case of fully correlated roughness. 


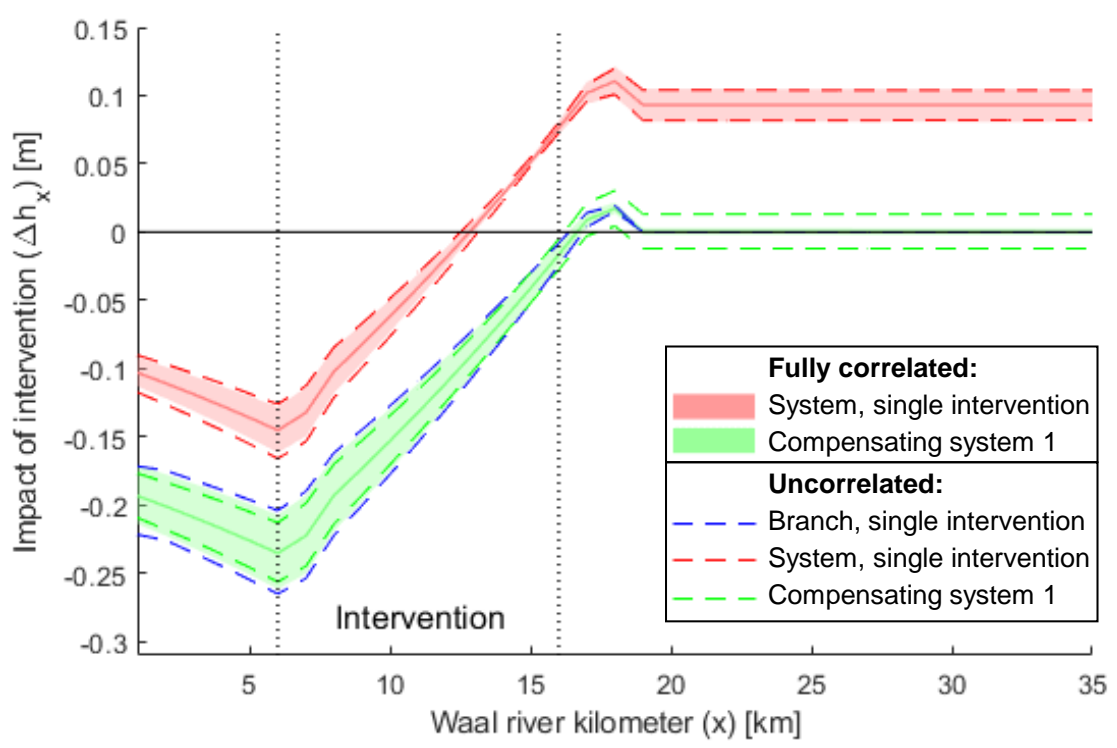

Figure 3.8: Impact of a single intervention (red) and of a set of compensating dike set-backs (compensating system 1; green), if the roughness parameters between the branches are fully correlated or uncorrelated.

\subsubsection{Uncertainty analysis of intervention impact}

In this study, an idealised 1D network model was applied that allowed the analysis of intervention impact for a large number of roughness conditions and discharges. In practice, more realistic and $2 \mathrm{D}$ model simulations are used for the design and assessment of river interventions, which have a much higher computational demand. In the early design phases, it is practically unfeasible to go through multiple iterations of combined intervention using such advanced models and at the same time to consider a range of discharge conditions as well as model parameter uncertainty.

Another constraint to a more practical assessment of discharge and model parameter uncertainty is that the full bifurcating system should be considered. This study has shown that the feedback mechanism between water levels and discharge distribution affects the impact of interventions and their uncertainties. Using the branch configuration with a stochastic discharge distribution to perform an uncertainty analysis could also provide similar results, while significantly reducing the computational demand. However, because the impacts on discharge distribution and impacts on water levels are linked together, it is essential to consider the feedback mechanism. This is illustrated by the results in section 3.3.4, where the downstream water level differences are entirely determined by 
the changes in discharge distribution. Therefore, to obtain accurate results in an uncertainty analysis of intervention impact in a bifurcation river system, a model that considers all branches is always recommended.

This study has isolated and quantified the order of magnitudes of interactions that occur between water levels, impacts of interventions, and discharge distribution. To perform the same analysis in a realistic river system, a reduction of computational demand is needed. Berends et al (2018) showed that this can be achieved by using the correlation in model results from pre-intervention and postintervention models in a single-branch model to estimate the uncertainties. This strategy can also be applied for a bifurcating river system, once a sufficiently accurate estimate of the water-level-uncertainties in the reference situation is obtained. However, this would also require quantification of correlations between the roughness of the branches, which is not readily available.

This study has shown that the changes in water levels and discharge distributions that are caused by an intervention depend on upstream discharge. For instance, water level increases can occur for discharges that compensating interventions were not designed for. As water level increases should be avoided as much as possible to prevent increases in flooding probabilities, it is recommended to consider a few discharge conditions in the design of interventions. Some of these conditions could be the bankfull discharge, a medium-high discharge (e.g. 12,000 $\mathrm{m}^{3} / \mathrm{s}$, the highest recorded discharge), and the maximum attainable discharge of the Rhine system.

\subsection{Conclusions}

In this study, the influence of river interventions on system-wide water levels in a bifurcating river system was assessed. It was shown that it is essential to consider the entire river system for accurate estimations of mean effects of interventions and their uncertainties.

For a single water-level-lowering intervention in a bifurcating river system, a high water level increase downstream of the intervention is observed due to an increase in discharge towards the branch. A compensating intervention in the opposing branch can offset the increase in discharge towards the branch, such that only for specific discharge and roughness conditions no water level increases are observed. For all other discharge and roughness conditions, water level increases may occur either downstream of the intervention or in the other branches of the system of which the magnitude depends on the types of interventions.

Flooding probabilities along downstream reaches can be lowered by reducing water-level-uncertainty at those locations, for which uncertainty in discharge distribution is an important source. However, discharge distribution uncertainty 
cannot be reduced by interventions in river geometry without triggering a mean shift in the discharge distribution. This means that water-level-uncertainty throughout the system and therefore the extremes of the water-level-distribution remain unaffected. Potentially, reducing underlying model parameter uncertainty can result in lower flooding probabilities. This may for instance be achieved by more accurate predictions of the main channel and floodplain roughness. For future research, we recommend to assess the sensitivity of the results to the locations and the size of the interventions. It is expected that the effect of the feedback mechanism and the resulting amount of downstream water level increase will become larger with increasing size of the intervention and if the intervention will be implemented closer to the bifurcation.

\section{Acknowledgements}

This work is part of the Perspectief research programme All-Risk with project number P15-21, which is (partly) financed by NWO Domain Applied and Engineering Sciences, in collaboration with the following private and public partners: the Dutch Ministry of Infrastructure and Water Management (Rijkswaterstaat), Deltares, STOWA, HKV, Natuurmonumenten and the regional water authorities Noorderzijlvest, Vechtstromen, it Fryske Gea, HHNK. 



\section{Chapter 4}

\section{Improving rating curve accuracy by incorporating water balance closure at river bifurcations}

\section{Abstract}

Accurate discharge records are essential for flood frequency analyses, hydraulic model calibration and flood forecasting. Discharge records are often obtained via a transformation of water levels to discharges using a rating curve. For accurate rating curves, a physical basis is important, particularly in the extrapolation domain towards extreme discharges. In this study, physical processes and constraints are incorporated in a rating curve model: water balance closure at a bifurcation and bed level degradation. The aim is to assess the effect of incorporating these physical processes and constraints for rating curves at two bifurcations of the Rhine river in the Netherlands. Intermittent gaugings are available for a 31 year period at these bifurcations. Bayesian inference and Markov Chain Monte Carlo sampling is used to estimate the posterior distributions of the rating curves. If rating curves are constructed independently, they show a large water balance error at bifurcations of up to $10 \%$. Incorporating bed level degradation is required for accurate rating curves as it reduces the residual errors by up to $50 \%$. If explicitly accounting for water balance closure, the water balance error can be reduced to $1 \%$, while residual errors remain equally small. As water balance closure is a physical constraint at a river bifurcation, the rating curves that account for water balance closure are expected to be more physically realistic. Therefore, it is recommended to specifically gauge at river bifurcations and confluences, such that the constraint of water balance closure can be used to improve the accuracy of rating curves and discharge records.

This chapter is submitted as M.R.A. Gensen, J.J. Warmink, K.D. Berends, F. Huthoff and S.J.M.H. Hulscher. Improving rating curve accuracy by incorporating water balance closure at river bifurcations. 


\subsection{Introduction}

Discharge records in streams and rivers are essential for water resources management of both low flow and flood conditions. At a river bifurcation, knowledge on the distribution of discharges over the branches is crucial (Dong et al, 2020; Gensen et al, 2020). However, continuously measuring the discharge is not easily done. Therefore, discharges are often derived by converting continuously measured water levels at gauging stations to discharges using a rating curve (e.g. ISO 1100-2, 2010; Rantz, 1982). A rating curve is a relationship between water levels and discharges at a specific cross-section of the stream or the river, which is established using earlier gaugings of discharges and water levels. These gauged discharges are often based on measured flow velocities and cross-sectional geometry.

Rating curve errors can lead to significant errors in the analyses in which the discharge records are used, such as flood frequency analysis (Lang et al, 2010; Steinbakk et al, 2016), hydraulic or hydrological model calibration (Domeneghetti et al, 2012; Peña Arancibia et al, 2014; Sikorska and Renard, 2017) and flood forecasting (Ocio et al, 2017). The largest errors in derived discharges arise when the rating curve is used during extremely high flow conditions (Domeneghetti et al, 2012; Pappenberger et al, 2006). In this domain, discharge gaugings are scarce or even unavailable and the discharge is thus derived by mere extrapolation of the rating curve. Rating curve uncertainty in the lower domain is amplified in the extrapolation domain, possibly leading to very large errors (Di Baldassarre et al, 2009). Still, the extrapolation of rating curves is often required to obtain knowledge on the flood conditions in a river (Pappenberger et al, 2006).

Physical constraints can be imposed to increase the accuracy of rating curves, especially in the extrapolation domain. In literature, several methods have shown to enable using additional physical basis to construct more accurate rating curves, through e.g. using knowledge on hydraulic controls at structures (e.g. weirs and dams, Le Coz et al, 2014), using physically realistic parameters in rating curve formulations (e.g. Le Coz et al, 2014) and using hydraulic modelling (Di Baldassarre and Claps, 2011; Lang et al, 2010). Furthermore, knowledge on the physical explanations for rating curve changes can be used to improve rating curve accuracy. Especially, if a long record of discharge gaugings is available, rating curve changes due to non-stationarities, are a significant source of errors (Pappenberger et al, 2006) and should therefore be incorporated if possible. Often, rating curve changes are the result of morphological development of the river bed (i.e. bed level degradation or aggradation; e.g. Mansanarez et al, 2019a), but may also be the result of hydraulic roughness changes (e.g. Gensen et al, 2020; Perret et al, 2021) and human intervention (Berends et al, 2019).

Water balance considerations is sometimes used in hydrological studies for more 
accurate rainfall-runoff estimates (Sebok et al, 2016; Beven, 2019) and can practically be used to physically constrain rating curves in the high discharge domain (Hollaway et al, 2018). At a river bifurcation, where a river splits into two or more branches, a water balance could be imposed as physical constraint. The water balance is closed if at a bifurcation the incoming discharge equals the sum of all outgoing discharges. A non-closed water balance is a direct indication of uncertainty in the respective rating curves. To our current knowledge, water balance considerations at a river bifurcation have not yet been addressed for the assessment of rating curves.

There is broad scientific consent that the uncertainty in discharges derived with rating curves must be better assessed (Di Baldassarre et al, 2009; McMillan et al, 2017; Pappenberger et al, 2006). In literature, many methods have been used to estimate this uncertainty, such as quantification from residual errors (Herschy, 1999; ISO 1100-2, 2010), Generalized Likelihood Uncertainty Estimation (Guerrero et al, 2012) and error assessment using hydraulic models (Di Baldassarre and Montanari, 2009; Domeneghetti et al, 2012; Lang et al, 2010). In recent years, combining Bayesian inference with Markov Chain Monte-Carlo has shown to be an effective method for rating curve establishment with which uncertainty assessment is easily performed (Le Coz et al, 2014; Perret et al, 2021; Mansanarez et al, 2019a; Moyeed and Clarke, 2005). Bayesian inference allows the inclusion of prior knowledge of the hydraulics in a river, while updating that prior knowledge based on water level and discharge gaugings.

In this study, gaugings at two bifurcations of the Dutch Rhine river are used to study the effect of incorporating two physical constraints in the rating curve construction. Those two constraints are the gradual bed level degradation that occurs close to the first bifurcation and the water balance closure at the two bifurcations. The following research question is addressed:

To what extent does the incorporation of bed level degradation and water balance closure affect the rating curves at two major bifurcations of the Dutch Rhine river?

This chapter is structured as follows. Section 4.2 describes relevant features of the Dutch Rhine river and its two major bifurcations, and the available discharge and water level gaugings. Section 4.3 describes the standard rating curve model, how the rating curve parameters are estimated using Bayesian inference and Markov Chain Monte Carlo sampling, and how bed level degradation and water balance closure are incorporated into the standard rating curve model. Section 4.4 describes the results for the two bifurcation and shows the potential added value of incorporating these physical constraints for the two analysed bifurcations. Sections 4.5 discusses the results. Finally, conclusions are drawn in section 4.6. 


\subsection{Study area and available gaugings}

\subsubsection{Study area}

The Rhine river enters the Netherlands near Lobith after which it splits at the Pannerdensche Kop (Figure 4.1). Here, the discharge of the Rhine is distributed in a ratio of approximately $2 / 3^{\text {rd }}$ and $1 / 3^{\text {rd }}$ over the Waal and Pannerdensch Kanaal respectively. After $11 \mathrm{~km}$, the Pannerdensch Kanaal splits at the IJsselkop into the Nederrijn and IJssel in again ratio of $2 / 3^{\text {rd }}$ and $1 / 3^{\text {rd }}$, respectively. The current planform of the two bifurcation exists since the $18^{\text {th }}$ century (Kleinhans et al, 2011). Since then, the bifurcations have been morphologically relatively stable and the discharge distribution has been fairly constant. The Rhine distributaries all have compound cross-sections with a main channel and floodplains on both sides. Groynes narrow the flow widths under low and moderate discharges. Embankments demarcate the main channels from the floodplains, and prevent flooding of the floodplains until a Rhine discharge of approximately $5,000 \mathrm{~m}^{3} / \mathrm{s}$. For lower discharges, movable weirs in the Nederrijn increase the water levels for better navigability.

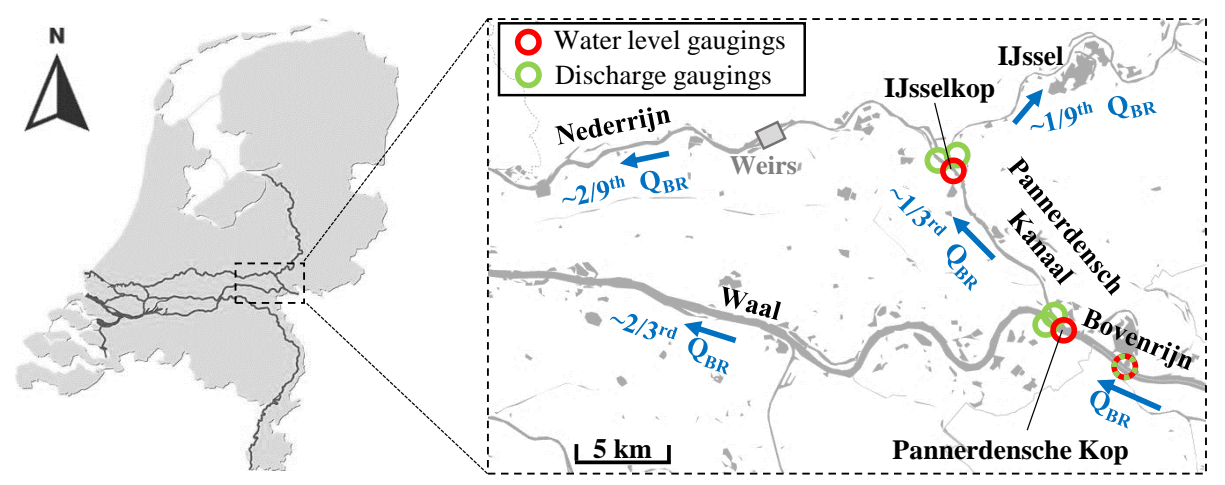

Figure 4.1: Map of the bifurcation area, including the discharge distribution over the distributaries, the location of the weirs in the Nederrijn and the gauging locations. In the Bovenrijn, water levels and discharge are gauged at the same locaiton. Figure adapted from Gensen et al (2020).

All of the Rhine branches are protected by dikes which are designed to withstand upstream Rhine discharges of $16,000 \mathrm{~m}^{3} / \mathrm{s}$. In 2017 , the Netherlands have adopted a new flood risk policy under which the river system is designed based on local flood risks along the branches instead of a single design discharge (Kok et al, 2017). Multiple failure mechanisms are accounted for in the calculation of the probability of flooding. Therefore, design conditions of dikes are determined by the entire range of possible discharges along the downstream branches, for which the discharge distribution at the bifurcations is important. The maximum attainable 
discharge in the Bovenrijn is estimated to be $18,000 \mathrm{~m}^{3} / \mathrm{s}$ (Bomers et al, 2019c) and is thus the highest discharge that is accounted for in flood safety assessment.

In 1995, the highest gauged discharge event of approximately $12,000 \mathrm{~m}^{3} / \mathrm{s}$ occurred. No major flooding occurred, but it was still the reason to set up the 'Room for the River' program. Under this program, 34 major projects were implemented along the Rhine distributaries. Besides dike reinforcements, many projects aimed at lowering water levels under flood discharges, through e.g. sidechannels, floodplain excavations and dike relocations. Most of these projects were completed between 2010 and 2015 .

\subsubsection{Available discharge and water level gaugings}

Discharges have been intermittently estimated by Rijkswaterstaat (Executive agency of the Dutch Ministry of Infrastructure and Water Management) from 1988 onwards at five locations close to the bifurcations (Figure 4.1). These discharge estimates are derived from cross-sectional flow velocity profiles, measured with mechanical hydrometric current meters up to 2002 and after that with an Acoustic doppler current profiler (ADCP). Generally, high discharge events are covered in the observational records, e.g. the events in $1993\left(\mathrm{Q}_{\text {Bovenrijn }} \approx 11,000 \mathrm{~m}^{3} / \mathrm{s}\right.$ ) and 1995 (Q Bovenrijn $\approx 12,000 \mathrm{~m}^{3} / \mathrm{s}$ ). The most gaugings are available for the Bovenrijn and the two distributaries from the Pannerdensche Kop bifurcation (Table 4.1). For the Nederrijn and IJssel distributaries much less gaugings are available, especially in the past decade.

Water levels are continuously measured at Lobith and at both bifurcation points using accurate automatic boat-driven shaft encoders. These measurements are available for the entire period of discharge gaugings.

\subsection{Methodology}

Rating curves are constructed by Bayesian inference for the three branches at each of the two bifurcations. First, the available data is processed (section 4.3.1). Then, a standard rating curve model is introduced in section 4.3.2, of which the parameters are estimated by Bayesian inference using Markov Chain Monte Carlo sampling (section 4.3.3). Subsequently, bed level degradation is incorporated into the standard rating curve model aiming to improve rating curve accuracy (section 4.3.4). Finally, the model is adapted to improve the water balance closure at the bifurcation (section 4.3.5). 


\subsubsection{Data processing}

The available data is processed in two steps: 1) relocate the gaugings such that they coincide at the bifurcation and 2) remove gaugings that are influenced by the weirs.

For step 1: At both bifurcations, the inflowing discharge is measured less than 10 kilometers upstream from the bifurcation (Figure 4.1). To make use of the physical constraint of water balance closure for a given water level at the bifurcation, the upstream gaugings must be relocated to the bifurcation: Lobith to Pannerdensche Kop and Pannerdensche Kop to IJsselkop. The available discharge gaugings are paired with coinciding day-averaged water levels at the bifurcation. It is assumed that by day-averaging, the error in water level gaugings caused by the time delay between the two locations is negligibly small. The Pannerdensch Kanaal discharge gaugings are thus paired with water levels at both the Pannerdensche Kop (where it is the outgoing discharge) and IJsselkop (where it is the incoming discharge).
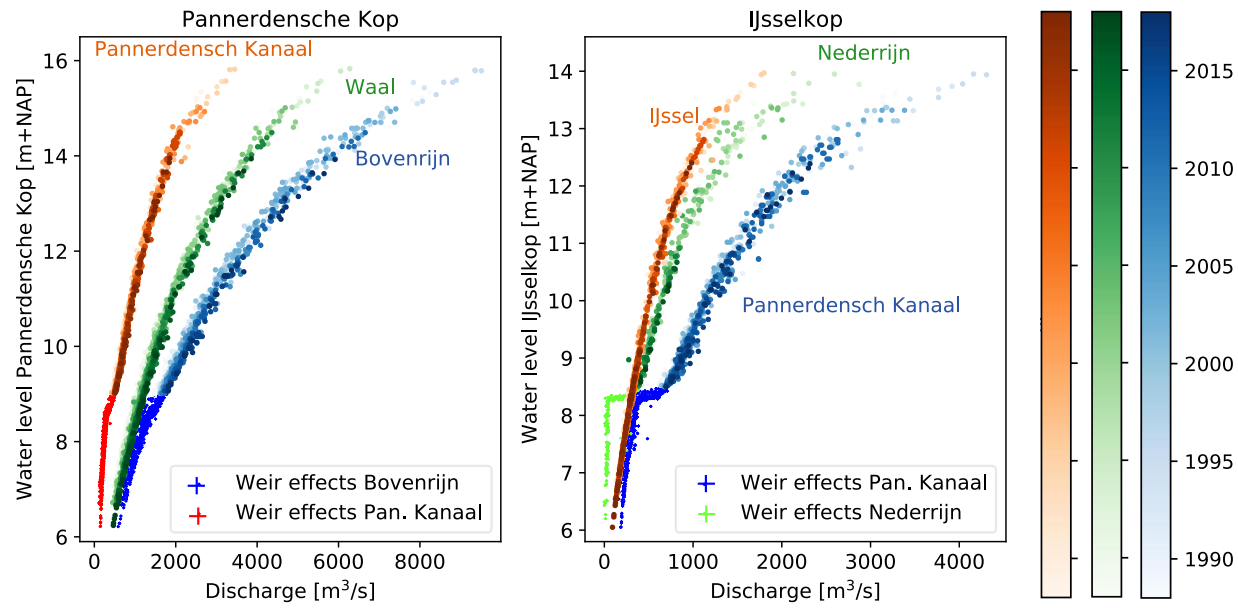

Figure 4.2: Discharge-water level gaugings at the 6 locations. The colorbars indicate the year of the gauging, making it insightful that the water level for given discharge at the Pannerdensche Kop decreases over time.

For step 2: In the lower discharge domain, the weirs in the Nederrijn influence the water levels at the gauging locations upstream. Furthermore, the weirs affect the discharge distribution in this domain, with relatively more discharge diverted towards the Waal at the Pannerdensche Kop and towards the IJssel at the IJsselkop. Even though it is possible to include the effects of the weirs in the rating curve model (e.g. Le Coz et al, 2014), it is chosen to exclude the gaugings in this domain from the rating curve construction as the main interest is in higher discharges. Therefore, after visual inspection, gaugings are excluded that have a 
water level below $9.00 \mathrm{~m}+\mathrm{NAP}$ and $8.50 \mathrm{~m}+\mathrm{NAP}$ at the Pannerdensche Kop and IJsselkop, respectively (Figure 4.2 and Table 4.1).

Table 4.1: Total and used number of gaugings at the Pannerdensche Kop and IJsselkop between 1988 and 2018. Gaugings were discarded that were under the influence of the weir.

\begin{tabular}{llll}
\hline Location & Branch & Total gaugings & Used gaugings \\
\hline \multirow{3}{*}{ Pannerdensche Kop } & Bovenrijn & 1303 & 727 \\
& Waal & 1202 & 1202 \\
& Pannerdensch Kanaal & 1535 & 747 \\
\cline { 2 - 4 } IJsselkop & Pannerdensch Kanaal & 1535 & 675 \\
& Nederrijn & 561 & 364 \\
& IJssel & 868 & 868 \\
\hline
\end{tabular}

\subsubsection{Standard rating curve model}

The standard form of the rating curve model is given in Eq. 4.1 and is based on the Manning-Strickler formula for steady and uniform flow in a wide, rectangular cross-section. For complex cross-sections, such as those of the Rhine branches, a rating curve often exists of successive or additive segments (Le Coz et al, 2014). In this study, the rating curve of the Rhine branches is described by two segments, as presented in Eq 4.1, roughly representing the main channel (mc) and the floodplains (fp). Prior analysis showed that a single segment could not represent the data well, while three segments may result in overfitting of the rating curve (see section 4.5.1).

$$
Q(h)= \begin{cases}0, & \text { if } h \leq b_{\mathrm{mc}} \\ a_{\mathrm{mc}}\left(h-b_{\mathrm{mc}}\right)^{p_{\mathrm{mc}}}, & \text { if } h>b_{\mathrm{mc}} \\ a_{\mathrm{mc}}\left(h-b_{\mathrm{mc}}\right)^{p_{\mathrm{mc}}}+a_{\mathrm{fp}}\left(h-b_{\mathrm{fp}}\right)^{p_{\mathrm{fp}}} & \text { if } h>b_{\mathrm{fp}}\end{cases}
$$

In this equation, $Q$ is the branch discharge $\left[\mathrm{m}^{3} / \mathrm{s}\right], h$ is the water level $[\mathrm{m}+\mathrm{NAP}]$, $a_{m c}$ and $a_{f p}$ are terms that mainly depend on the width, bed slope and hydraulic roughness of the sub-sections $\left[\mathrm{m}^{4 / 3} / \mathrm{s}\right], b_{m c}$ and $b_{f p}$ roughly represent the bed level (i.e. when there is no flow) and the floodplain level respectively $[\mathrm{m}+\mathrm{NAP}], p_{m c}$ and $p_{f p}$ are the hydraulic exponents [-] which should be close to $5 / 3$ according to the Manning-Strickler equation for a wide, rectangular cross-section. 


\subsubsection{Bayesian inference and Markov Chain Monte Carlo sampling}

Using the rating curve model from Eq. 4.1, the discharge at location $i$ can be modelled, $\left(\widehat{Q_{i}}\right)$, given the model parameters $\theta_{i}\left(a_{m c}, a_{f p}, b_{m c}, b_{f p}, p_{m c}, p_{f p}\right)$ :

$$
\widehat{Q_{i}}=f\left(h_{i} \mid \theta_{i}\right)
$$

To account for gauging and model errors, a structural error term is added:

$$
\begin{gathered}
Q_{i}=\widehat{Q_{i}}+\epsilon_{r c, i} \\
\epsilon_{r c, i}=\epsilon_{\text {gauging }, i}+\epsilon_{\text {model }, i} \sim \mathcal{N}\left(0, \varsigma_{r c, i}\right)
\end{gathered}
$$

where for the structural error $\epsilon_{r c, i}$ a normal distribution is assumed without bias and a variance that linearly depends on the modelled discharge and the structural error parameter $\varsigma_{r c, i}$.

The available gaugings $\mathcal{O}_{i}$ each consisting of discharge, water level and relative time, for every location are used for Bayesian inference to estimate the model parameters $\theta_{i}$ and unknown structural error $\varsigma_{r c, i}$. Measurement errors are included in the structural error term, such that the gaugings represent the true value. The likelihood equation is as follows:

$$
\mathcal{L}_{i}=p\left(\mathcal{O}_{i} \mid \theta_{i}, \varsigma_{r c, i}\right)=\mathcal{N}\left(\widehat{Q_{i}}, \epsilon_{r c, i}\right)
$$

For each parameter $\left(\theta_{i}, \varsigma_{r c, i}\right)$, a prior distribution is set based on a deterministic optimization process with a least-squares error approach (Table 4.2). For both hydraulic exponents $\left(p_{m c}\right.$ and $\left.p_{f p}\right)$, the prior distribution is centred around $5 / 3$ to ensure a physically realistic prior distribution. The prior distributions of $a_{m c, f p}$, $p_{m c, f p}$ and $\sigma$ are weakly informative, while $b_{m c}$ and $b_{f p}$ have non-overlapping uniform prior distributions. The weakly informative priors are necessary for convergence of the posterior distributions with physically realistic results. For the structural error parameter $\varsigma_{r c, i}$, a weakly informative half-Cauchy prior distribution is used (Gelman, 2006).

A Markov Chain Monte Carlo (MCMC) algorithm is used to sample from the posterior distribution as solving the posterior is non-trivial. MCMC is done using the No U-Turn Sampler (NUTS; Hoffman and Gelman, 2014). The MCMC contains 14,000 samples divided over 2 chains. The first 2000 samples of each trace are discarded. Correct MCMC convergence is checked visually for chain similarity, autocorrelation and prior expectations for the posterior distributions. 
Table 4.2: Prior distributions of the unknown variables in the rating curve model for each of the 6 locations. The parameter $\beta_{i}$ is used to incorporate bed level degradation (section 4.3.4). The parameter $\varsigma_{W B E}$ is used to incorporate water balance closure (section 4.3.5). $\mathcal{N}(m, s)$ corresponds to a normal distribution with mean $m$ and standard deviation $s . \mathcal{U}(\min , \max )$ corresponds to a uniform distribution with boundaries at $\min$ and $\max . H C(\mu, \sigma)$ corresponds to a half-Cauchy distribution with location $\mu$ and scale $\sigma$.

\begin{tabular}{|c|c|c|c|}
\hline \multicolumn{4}{|c|}{ Pannerdensche Kop } \\
\hline Parameter & Bovenrijn & Waal & Pan. Kanaal \\
\hline$a_{m c}\left[\mathrm{~m}^{4 / 3} / \mathrm{s}\right]$ & $\mathcal{N}(140,25)$ & $\mathcal{N}(78,25)$ & $\mathcal{N}(53,25)$ \\
\hline$b_{m c}[\mathrm{~m}+\mathrm{NAP}]$ & $\mathcal{U}(2.0,6.0)$ & $\mathcal{U}(1.2,5.2)$ & $\mathcal{U}(2.6,6.6)$ \\
\hline$p_{m c}[-]$ & $\mathcal{N}(1.67,0.1)$ & $\mathcal{N}(1.67,0.1)$ & $\mathcal{N}(1.67,0.1)$ \\
\hline$a_{f p}\left[\mathrm{~m}^{4 / 3} / \mathrm{s}\right]$ & $\mathcal{N}(417,25)$ & $\mathcal{N}(190,25)$ & $\mathcal{N}(326,25)$ \\
\hline$b_{f p}[\mathrm{~m}+\mathrm{NAP}]$ & $\mathcal{U}(9.7,15.7)$ & $\mathcal{U}(8.9,14.9)$ & $\mathcal{U}(10.6,16.6)$ \\
\hline$p_{f p}[-]$ & $\mathcal{N}(1.67,0.1)$ & $\mathcal{N}(1.67,0.1)$ & $\mathcal{N}(1.67,0.1)$ \\
\hline$\varsigma_{r c}[-]$ & $\mathrm{HC}(0,2)$ & $\mathrm{HC}(0,2)$ & $\mathrm{HC}(0,2)$ \\
\hline$\beta$ [m/year] & $\mathcal{U}(-0.03,0)$ & $\mathcal{U}(-0.03,0)$ & $\mathcal{U}(-0.03,0)$ \\
\hline SWBE $[-]$ & $\mathrm{HC}(0,2)$ & $\mathrm{HC}(0,2)$ & $\mathrm{HC}(0,2)$ \\
\hline \multicolumn{4}{|c|}{ IJsselkop } \\
\hline Parameter & Pan. Kanaal & Nederrijn & IJssel \\
\hline$a_{m c}\left[\mathrm{~m}^{4 / 3} / \mathrm{s}\right]$ & $\mathcal{N}(56,25)$ & $\mathcal{N}(42,25)$ & $\mathcal{N}(24,25)$ \\
\hline$b_{m c}[\mathrm{~m}+\mathrm{NAP}]$ & $\mathcal{U}(1.8,5.8)$ & $\mathcal{U}(2.8,6.8)$ & $\mathcal{U}(1.8,5.8)$ \\
\hline$p_{m c}[-]$ & $\mathcal{N}(1.67,0.1)$ & $\mathcal{N}(1.67,0.1)$ & $\mathcal{N}(1.67,0.1)$ \\
\hline$a_{f p}\left[\mathrm{~m}^{4 / 3} / \mathrm{s}\right]$ & $\mathcal{N}(326,25)$ & $\mathcal{N}(331,25)$ & $\mathcal{N}(123,25)$ \\
\hline$b_{f p}[\mathrm{~m}+\mathrm{NAP}]$ & $\mathcal{U}(8.6,14.6)$ & $\mathcal{U}(9.2,15.2)$ & $\mathcal{U}(8.6,14.6)$ \\
\hline$p_{f p}[-]$ & $\mathcal{N}(1.67,0.1)$ & $\mathcal{N}(1.67,0.1)$ & $\mathcal{N}(1.67,0.1)$ \\
\hline$\varsigma_{r c}[-]$ & $\mathrm{HC}(0,2)$ & $\mathrm{HC}(0,2)$ & $\mathrm{HC}(0,2)$ \\
\hline$\beta$ [m/year] & $\mathcal{U}(-0.03,0)$ & $\mathcal{U}(-0.03,0)$ & $\mathcal{U}(-0.03,0)$ \\
\hline SWBE [-] & $\mathrm{HC}(0,2)$ & $\mathrm{HC}(0,2)$ & $\mathrm{HC}(0,2)$ \\
\hline
\end{tabular}

\subsubsection{DegRC model: incorporating bed level degradation}

The upper reaches of the Dutch Rhine branches, most prominently the Waal branch, are experiencing gradual bed degradation at a rate of approximately 2 cm/year (Ylla Arbós et al, 2020a). This bed level degradation has been observed to cause a linear decrease of water levels over time (Berends et al, 2021). As this non-stationarity potentially gives a large rating curve uncertainty, the bed level degradation is incorporated in the standard rating model. The new rating curve model ("DegRC") is time-dependent.

The rate of bed level degradation $\beta$ is incorporated into the standard rating curve model (Eq. 4.1) as an additional stochastic parameter and where the date relative to 1-jan-1988, expressed as $t$ [year], determines the total amount of bed level change. The DegRC model is as follows: 


$$
Q(h, t)= \begin{cases}0, & \text { if } h \leq b_{\mathrm{mc}} \\ a_{\mathrm{mc}}\left(h-\left(b_{\mathrm{mc}}+\beta t\right)\right)^{p_{\mathrm{mc}}}, & \text { if } h>b_{\mathrm{mc}} \\ a_{\mathrm{mc}}\left(h-\left(b_{\mathrm{mc}}+\beta t\right)\right)^{p_{\mathrm{mc}}}+a_{\mathrm{fp}}\left(h-b_{\mathrm{fp}}\right)^{p_{\mathrm{fp}}} & \text { if } h>b_{\mathrm{fp}}\end{cases}
$$

A constant rate of bed level degradation $\beta$ is assumed for the entire observation period, in line with the linear decrease of water levels observed by Berends et al (2021). In section 4.5.1, it is discussed that splitting up the observational record into two periods and deriving independent rating curves for these periods, does not improve rating curve accuracy.

Bayesian inference and estimation of the posterior distribution of the model parameters $\theta$ and structural error parameter $\varsigma_{r c}$ is similar as before, but now the unknown bed level degradation $\beta$ is inferred as well. It is expected that the posterior distributions of model parameter $b_{m c}$ and $\beta$ are correlated. Therefore, a uniform prior distribution for $\beta$ is chosen that matches the uniform prior distribution of $b_{m c}$. The uniform prior distribution for $\beta$ is bounded between -0.03 and $0.0 \mathrm{~m} /$ year.

\subsubsection{BifRC model: improving water balance closure}

In a next step, water balance closure is incorporated in the derivation of the rating curves. The bifurcation rating curves ("BifRC") model is constructed in which the rating curves at a bifurcation are derived all at once and in which the water level error is calculated. In this set-up, the rating curves of the branches are dependent on each other. The BifRC model aims at reducing the water balance error at a bifurcation from rating curves at the individual locations, while maintaining accurate rating curves for each branch.

The BifRC model consists of the rating curve models at each location, similar to those in the DegRC model (Eq. 4.5), and a water balance error calculation (Eq. $4.6)$ :

$$
\left.W B E(h, t)=\frac{Q_{0}\left(\theta_{0} \mid h_{b i f}, t_{b i f}\right)-Q_{1}\left(\theta_{1} \mid h_{b i f}, t_{b i f}\right)-Q_{2}\left(\theta_{2} \mid h_{b i f}, t_{b i f}\right)}{Q_{0}\left(\theta_{0} \mid h_{b i f}, t_{b i f}\right.}\right)
$$

where $W B E$ is the water balance error for water level $h_{b i f}$ and relative time $t_{b i f}$, and $Q_{0}$ is the upstream discharge at the bifurcation and $Q_{1}$ and $Q_{2}$ are the discharges in the distributaries, and $\theta_{0}, \theta_{1}, \theta_{2}$ are the rating curve parameters including $\beta_{0}$, $\beta_{1}$ and $\beta_{2}$.

Using this BifRC model, the water balance error can be calculated for given water 
levels $h_{b i f}$ and relative times $t_{b i f}$ :

$$
\widehat{W B E}=f\left(h_{b i f}, t_{b i f} \mid \widehat{Q_{0,1,2}}\right)
$$

To account for the combined errors of the three rating curves, an error term is added, bringing the WBE close to 0:

$$
W B E=\widehat{W B E}+\epsilon_{W B E} \approx 0
$$

$\epsilon_{W B E}$ partly describes the same residual error between the rating curves and the gaugings as the rating curve error parameters $\epsilon_{r c, i}$. However, the errors do not add up, as WBE is determined by the modelled discharges $\widehat{Q_{i}}$.

In the BifRC model, the likelihood equation accounts for the accuracy of each of the rating curves as well as the closure of the water balance. The likelihood equation is a summation of the log-likelihoods (see Eq. 4.4) for each location at the bifurcation and a log-likelihood term based on water balance closure:

$$
\ell_{\text {bif }}=\log \mathcal{L}_{0}+\log \mathcal{L}_{1}+\log \mathcal{L}_{2}+\log p\left(\widetilde{\mathcal{O}_{W B E}} \mid \theta_{0,1,2}\right)
$$

The gaugings $\left(\mathcal{O}_{0,1,2}\right)$ that are used in the individual likelihood terms $\left(\mathcal{L}_{0,1,2}\right)$ do not cover the entire discharge domain for which the water balance error is aimed to be reduced. Therefore, a hypothetical record $\widetilde{\mathcal{O}_{W B E}}$ is used, consisting of water balance errors $\widetilde{W B} E$, water levels $\widetilde{h_{b i f}}$ and relative times $\widetilde{t_{b i f}} \cdot \widetilde{W B E}$ are random samples from a normal distribution with mean 0 and variance calculated from the available same-day gaugings: $\mathcal{N}(0,0.0186)$ at the Pannerdensche Kop and $\mathcal{N}(0,0.0434)$ at the IJsselkop. $\widetilde{h_{b i f}}$ are linearly spaced values between the water levels for which the weirs do not influence the water levels and the water level that roughly corresponds to the maximum discharge of the Bovenrijn of 18,000 $\mathrm{m}^{3} / \mathrm{s}$ : 9.0-18.0 $\mathrm{m}+\mathrm{NAP}$ at the Pannerdensche Kop and 8.5-17.0 $\mathrm{m}+\mathrm{NAP}$ at the IJsselkop. $\widetilde{t_{b i f}}$ are random values between 0 and 1, related to the start and end dates 01-jan.-1988, and 31-dec.-2018. The length of the hypothetical record $\widetilde{\mathcal{O}_{W B E}}$ determines the relative weight of the water balance term in the likelihood equation (Eq. 4.9). To ensure that the individual rating curves remain accurate, the length of the hypothetical record is chosen to be equal to the shortest record from the three branches at a bifurcation: 727 at the Pannerdensche Kop and 364 at the IJsselkop. The length of this hypothetical record has only a small influence on the rating curves (see section 4.3.5).

The prior distributions of the rating curve parameters for each location are the same as for the individual rating curves, see Table 4.2. For the water balance error parameter $\epsilon_{W B E}$, a weakly informative half-Cauchy prior distribution is used (Gelman, 2006). In total, the BifRC model consists of 25 parameters, 8 parameters for the rating curve of each branch $\left(a_{m c, f p}, b_{m c, f p}, p_{m c, f p}, \beta\right.$ and $\left.\varsigma_{r c}\right)$ and $\varsigma_{W B E}$ for the water balance. 


\subsection{Results}

The results are shown for the branches connected to the Pannerdensche Kop (section 4.4.1) and to the IJsselkop (section 4.4.2) separately.

\subsubsection{Pannerdensche Kop}

Standard rating curves are constructed for the three branches connected to the Pannerdensche Kop. Then, bed level degradation and water balance closure are incorporated and the resulting differences between the rating curves or rating curve parameters is shown.

\section{Rating curves without physical constraints at the Pannerdensche Kop}

The modelled rating curves for the branches connected to the Pannerdensche Kop matches the trends of the available gaugings (Figure 4.3). For low water levels $(<11.0 \mathrm{~m}+\mathrm{NAP})$, the modelled credibility intervals do not entail all data. The posterior distribution of the structural error parameter $\varsigma_{r c}$ (Figure 4.4) is dominated by the large spread in data at this lower domain, which then also results in wide credibility intervals for higher water levels, as the structural error $\epsilon_{r c, i}$ scales linearly with the modelled discharge (see Eq. 4.3).

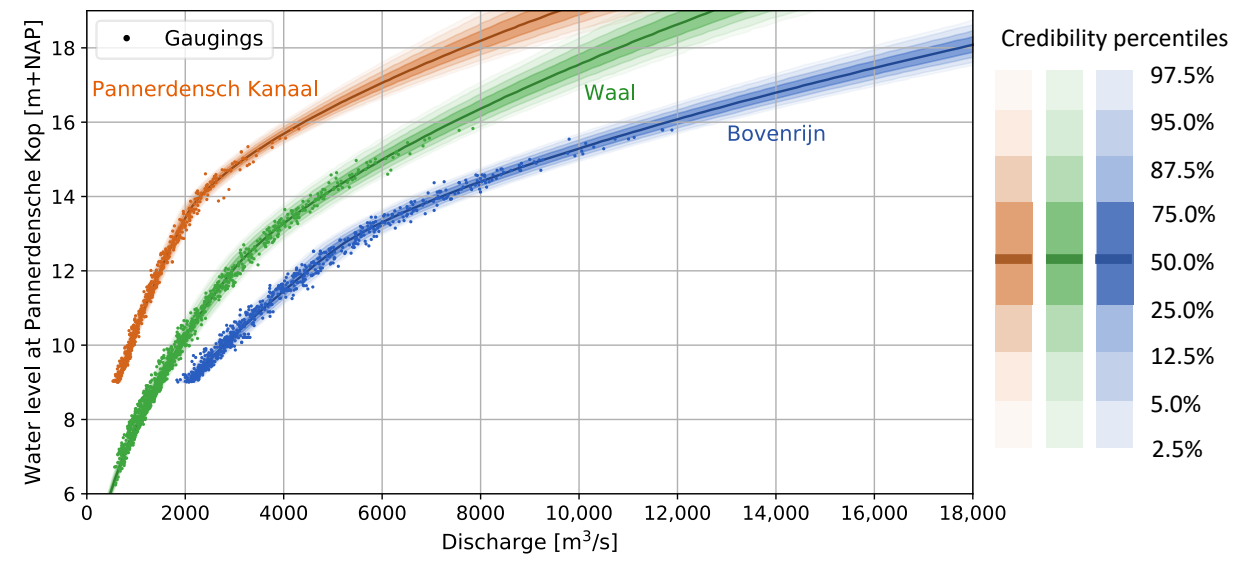

Figure 4.3: The mean and credibility intervals modelled with the Standard rating curve model for the Bovenrijn (Blue), Waal (Green) and the Pannerdensch Kanaal (Orange) at the Pannerdensche Kop bifurcation.

The effect of the second segment in the rating curve model, roughly describing the 
discharge contribution of the floodplains, is observed in all branches as the slope of the rating curve changes relatively abruptly. The water level at which this occurs differs in each branch, indicated by the median values of $\mathrm{b}_{\mathrm{fp}}$ : $12.60 \mathrm{~m}+\mathrm{NAP}$ in the Bovenrijn, $12.10 \mathrm{~m}+\mathrm{NAP}$ in the Waal and $13.58 \mathrm{~m}+\mathrm{NAP}$ in the Pannerdensch Kanaal (Figure 4.4). The differences between these values are consistent with the elevations of the embankments that demarcate the main channel from the floodplains, which are lower in the Waal river than in the Pannerdensch Kanaal.
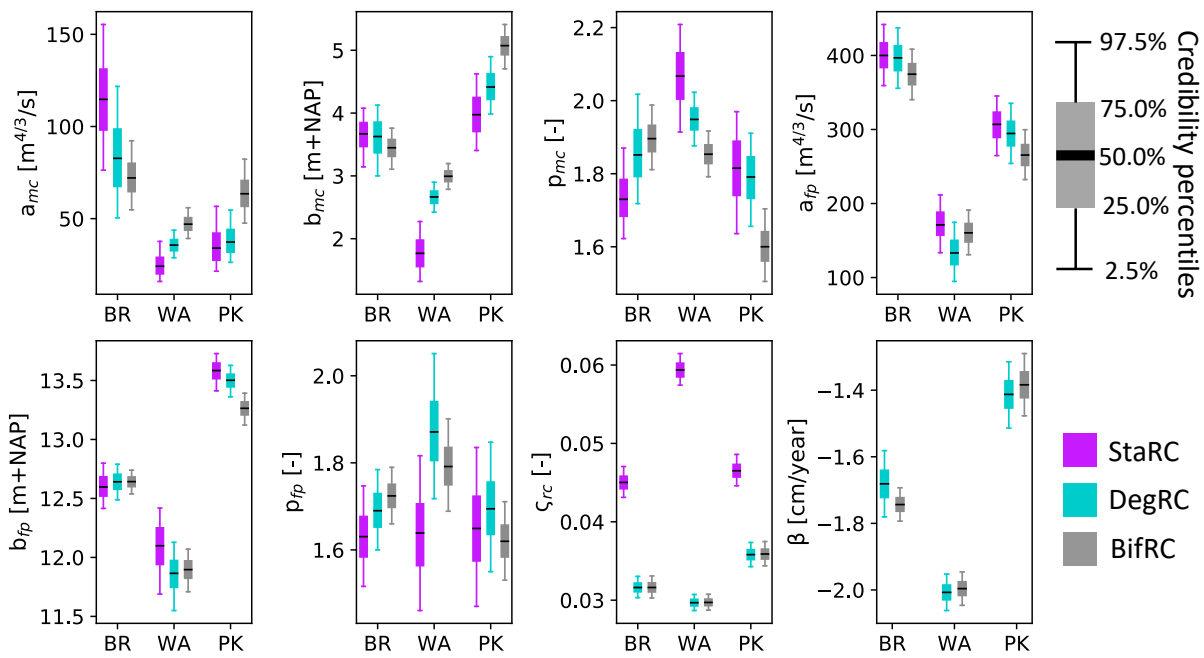

Figure 4.4: Posterior distributions of the rating curve parameters for the rating curves at the Pannerdensche Kop in the standard rating curve model (StaRC), the rating curve model with bed level degradation (DegRC) and the bifurcation rating curve model (BifRC).

\section{Rating curves with bed level degradation at the Pannerdensche Kop}

Figure 4.5 shows that the credibility intervals of the rating curves are narrower for a given year when bed level degradation is accounted for. This shows that a large amount of spread in the gaugings can be explained by a mean trend in water levels, which can be attributed to bed level degradation. Figure 4.4 shows that the narrowing of the credibility intervals can be attributed to a narrowing of the posterior distributions of some of the rating curve parameters in the first segment $\left(a_{m c}, b_{m c}, p_{m c}\right)$ as well as to large reductions of the structural error parameters $\varsigma_{r c}$ with respect to the StaRC model: $30 \%$ reduction in the Bovenrijn, $50 \%$ reduction in the Waal and $20 \%$ reduction in the Pannerdensch Kanaal.

The modelled bed level degradation rates $\beta$ (Figure 4.4) are in the same order as observed values (Ylla Arbós et al, 2020a), with median values of -1.7, -2.0 and $-1.4 \mathrm{~cm} /$ year in the Bovenrijn, Waal and Pannerdensch Kanaal, respectively. 


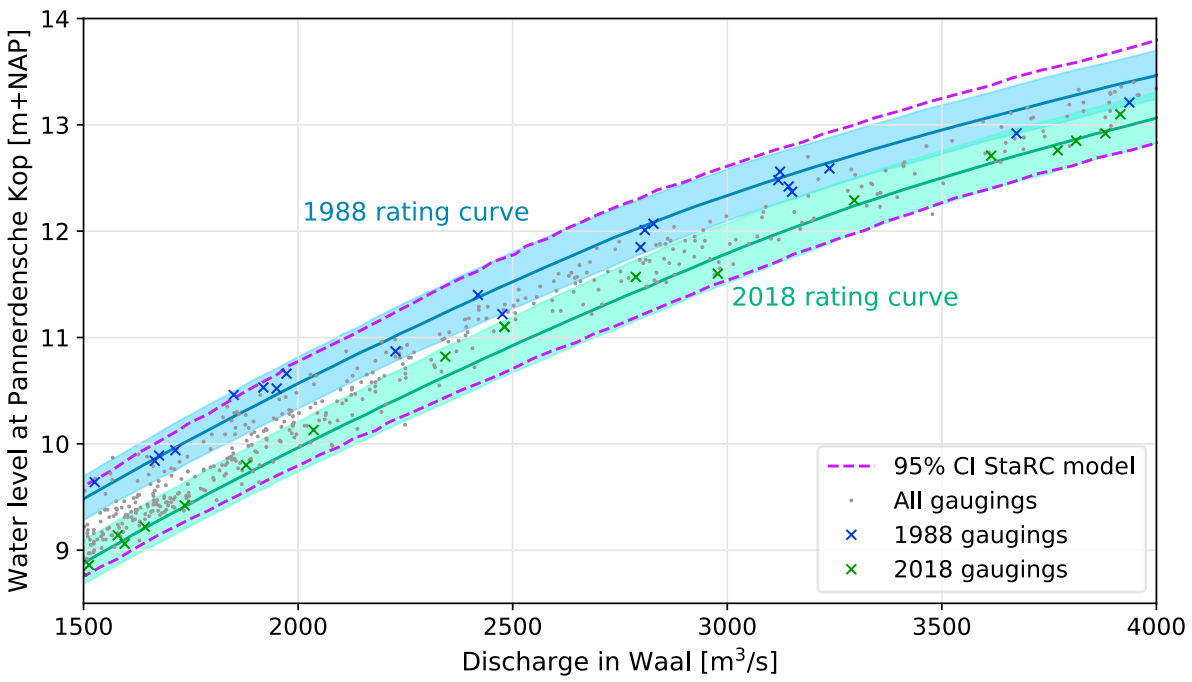

Figure 4.5: Rating curves in the Waal for the years 1988 and 2018 modelled with the DegRC model in comparison with the StaRC model (StaRC). The shaded areas mark the 95\% credibility intervals (Cl) and the continuous lines mark the median rating curves.

Also consistent with observed values of bed degradation rates by Ylla Arbós et al (2020a), the modelled bed degradation rate in the Waal is higher than in the Pannerdensch Kanaal. This also affects the discharge distribution, with in time increasingly more discharge diverted towards the Waal over time.

\section{Bifurcation rating curves with improved water balance closure at the Pannerdensche Kop}

If water balance closure is accounted for, the calculated water balance error $(\widehat{W B E})$ at the Pannerdensche Kop bifurcation is strongly reduced in the extrapolation domain (Figure 4.6A). In the StaRC and DegRC models, the Bovenrijn discharge is smaller than the sum of the Waal and Pannerdensch Kanaal discharges in the extrapolation domain, resulting in a negative water balance error. The rating curves constructed with the BifRC model result in a better closed water balance, with a slight bias towards a positive water balance error (Bovenrijn > Waal + Pannerdensch Kanaal). This bias may exist, as besides closing the water balance, the likelihood function in the BifRC model still includes the accuracy of the individual rating curves. While not shown, water balance closure is also maintained for different years.

In the BifRC model, a low water balance error is also achieved in the tails of the 

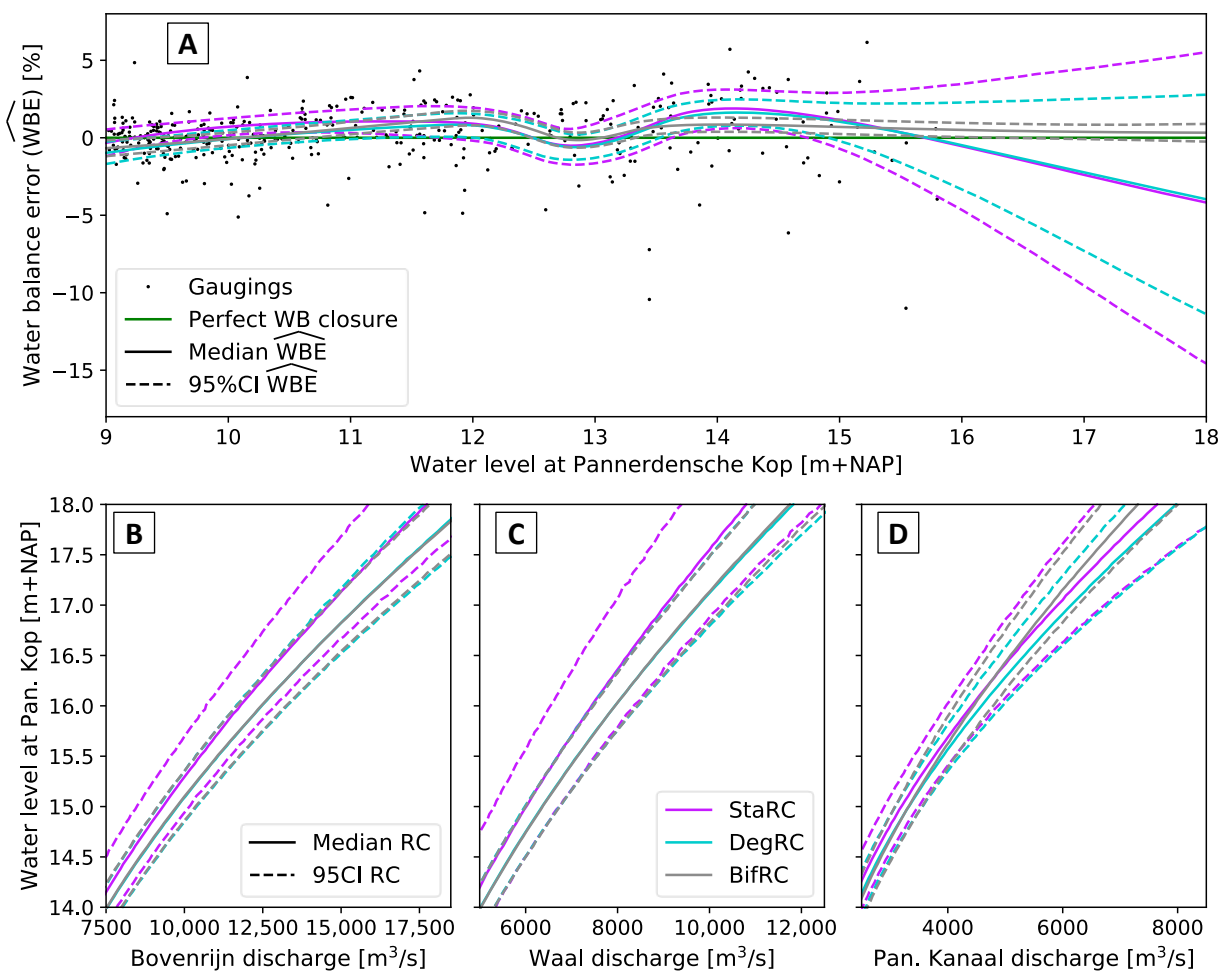

Figure 4.6: Comparison of the StaRC, DegRC and BifRC models at the Pannerdensche Kop. A) Water balance error $(\widehat{W B} E)$, as defined in Eq. 4.6, based on the modelled discharges $\left(\widehat{Q_{i}}\right)$ in 2018. The markers indicate the WBE calculated with same-day gaugings in each branch (400 gaugings). $B, C, D)$ : Extrapolation domain of the median rating curves and their $95 \%$ credibility intervals of the Pannerdensch Kanaal of the Bovenrijn (B), Waal (C) and Pannerdensche Kanaal (D).

posterior distributions of the modelled discharges, indicated by the narrow $95 \%$ credibility interval of $\widehat{W B} E$ (Figure 4.6A). In the StaRC and DegRC models, the modelled discharges are independent between the branches, which may result in large water balance errors. Instead, modelled discharges are dependent in the BifRC model, where the discharges compensate each other to result in a low water balance error.

Incorporating the water balance does not negatively impact the accuracy of the individual rating curves at the Pannerdensche Kop, as the structural error parameters $\varsigma_{r c}$ only slightly increase compared to the DegRC model. This indicates that the residual discharge errors are almost equal. The improved water balance closure in the BifRC model can mainly be attributed to a decrease in modelled Pannerdensch Kanaal discharges (Figure 4.6D). In the Pannerdensch Kanaal, fewer gaugings are available for higher water levels in comparison to the other 
two branches, such that a changed Pannerdensch Kanaal rating curve in the extrapolation domain does not go at the expense of its accuracy.

\subsubsection{IJsselkop}

The rating curves modelled with the StaRC model for the branches connected to the IJsselkop are shown first. Subsequently, bed level degradation and water balance closure are incorporated and the resulting differences in rating curves and their parameters are shown.

\section{Rating curves without physical constraints at the IJsselkop}

The modelled rating curves without physical constraints of the branches connected to the IJsselkop match the available gaugings well (Figure 4.7). The gaugings that lie outside the shown credibility intervals are not specifically related to a certain discharge domain, indicating a valid assumption of the linear increase of the structural discharge errors with the modelled discharge itself. Still, the credibility intervals of the rating curves are wide, especially in the Nederrijn branch. Figure 4.8 shows that this can be attributed to both high structural error parameters $\varsigma_{r c}$ (mainly in the Nederrijn) and wide posterior model parameter distributions in the first rating curve segment (mainly in the Pannerdensch Kanaal and Nederrijn) or second rating curve segment (mainly in the IJssel). Gaugings in the high discharge domain are scarce, especially recent gaugings (after 2002; Figure 4.2). Recent gaugings are expected to have less measurement uncertainty due to the use of ADCP measurement equipment and would thus likely show less spread compared to older gaugings. Future gaugings during high discharges could narrow the credibility intervals in the second segment of the rating curves.

\section{Rating curves with bed level degradation at the IJsselkop}

Incorporating bed level degradation for the rating curves at the IJsselkop only marginally increases their accuracy. The median bed degradation rates $\left(\beta_{50} \%\right)$ are $-0.9,-0.2$ and $-0.4 \mathrm{~cm} /$ year for the three branches, respectively (Figure 4.8 ). The structural error parameters $\varsigma_{r c}$ only slightly reduce under the DegRC model, as only a small amount of spread in the gaugings can be explained by the bed level degradation. As a result, credibility intervals of the modelled discharges only marginally narrow (Figure 4.9B-D). 


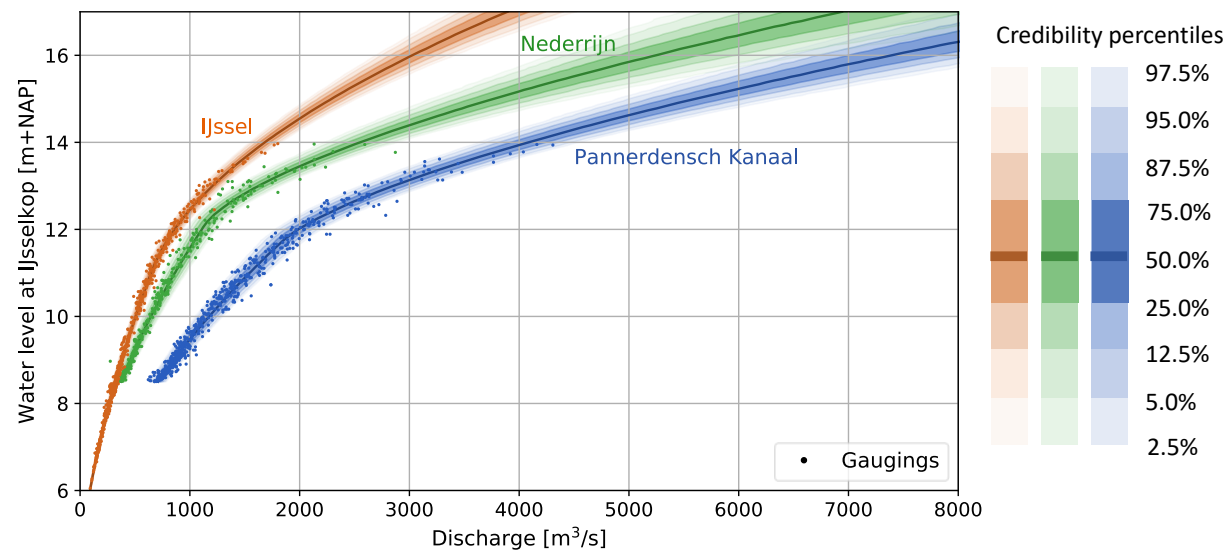

Figure 4.7: Rating curves for the Pannerdensch Kanaal (blue), Nederrijn (green) and IJssel (orange) at the IJsselkop bifurcation constructed with the standard rating curve model. The markers show all available gaugings for the branches.
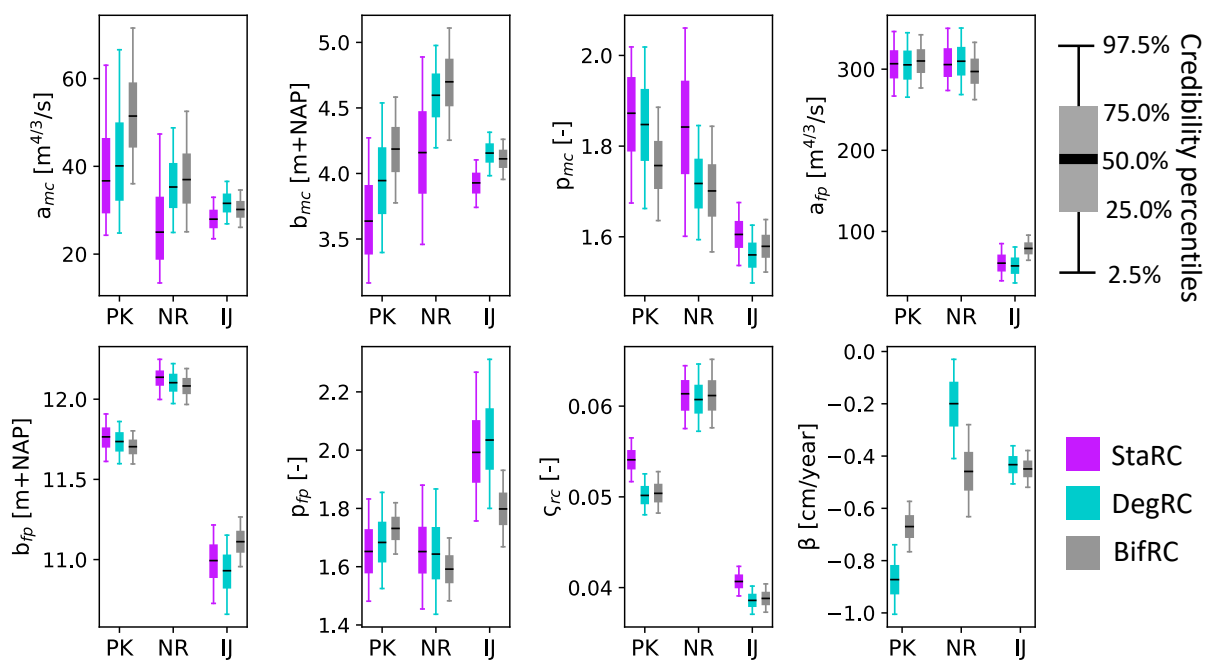

Figure 4.8: Posterior distributions of rating curve parameters for the rating curves at the IJsselkop in the standard rating curve model (StaRC), the rating curve model with bed level degradation (DegRC) and the bifurcation rating curve model (BifRC).

\section{Bifurcation rating curves with improved water balance closure at the IJsselkop}

Even though the water balance error under the StaRC and DegRC model at the IJsselkop is larger than at the Pannerdensche Kop, the BifRC model still minimizes 
the water balance error (Figure $4.9 \mathrm{~A})$. A slight bias $(\sim 1 \%)$ is observed, which may indicate a more structural and biased error in the discharge gaugings. The likelihood term balances the accuracy of the underlying rating curves and the water balance term. The positive bias in the WBE suggests that possibly the Pannerdensch Kanaal discharge is generally overestimated or that the Nederrijn or IJssel discharge is underestimated.
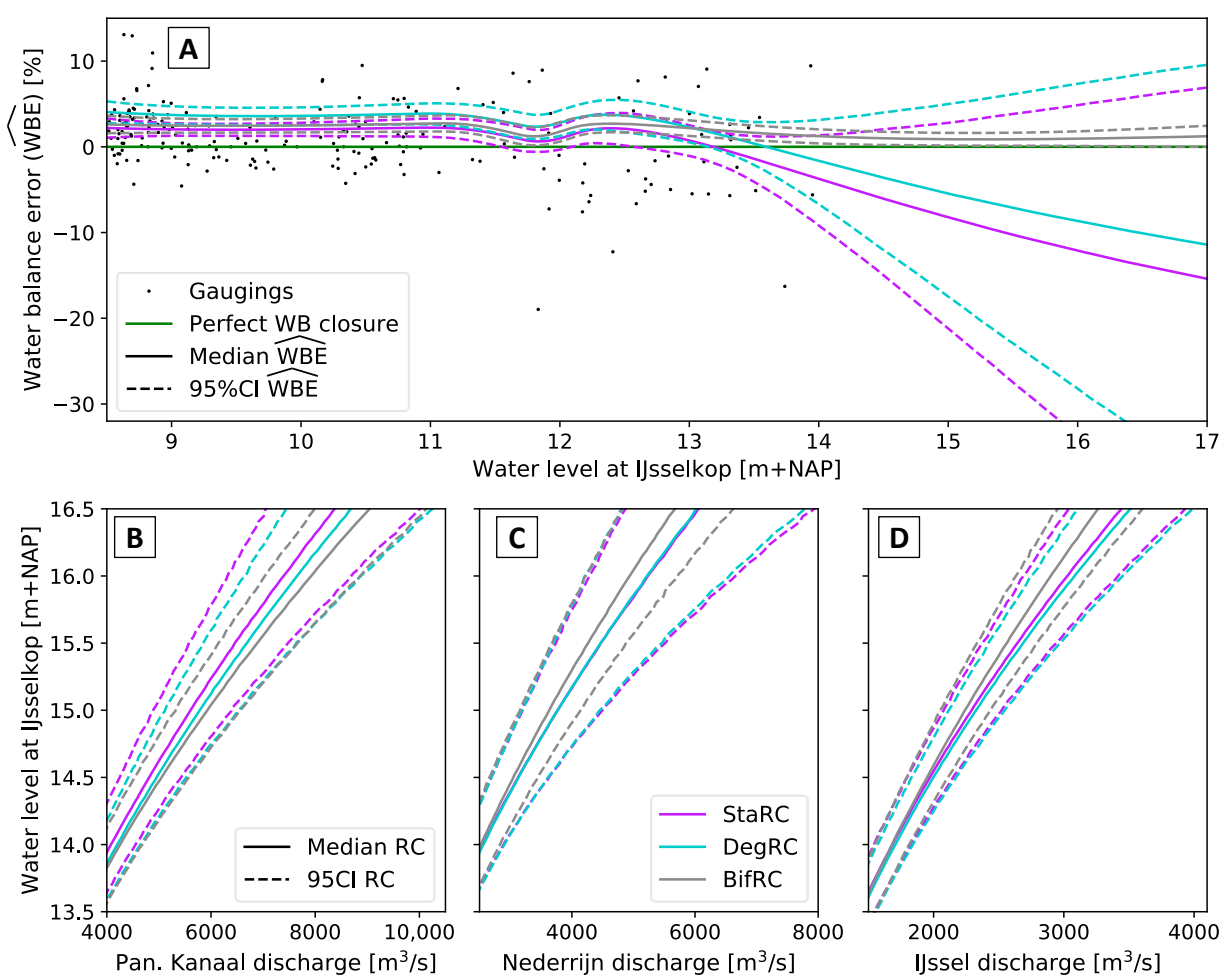

Figure 4.9: Comparison of the StaRC, DegRC and BifRC models at the IJsselkop. A) Water balance error $(\widehat{W B E})$, as defined in Eq. 4.6, based on the modelled discharges $\left.\left(\widehat{Q_{i}}\right)\right)$ in 2018. The markers indicate the WBE calculated with same-day gaugings in each branch (215 gaugings). $B, C, D)$ : Extrapolation domain of the median rating curves and their $95 \%$ credibility intervals of the Pannerdensch Kanaal (B), Nederrijn (C) and IJssel (D).

The reduction of the water balance error is attributed to all of the branches (Figure 4.9B-D). The Nederrijn and IJssel discharges are lower and the Pannerdensch Kanaal discharge is higher with the BifRC model. All IJsselkop branches have little gaugings for high water levels, such that the changes in rating curves are proportionally divided over all branches. Rating curve accuracy is maintained, indicated by the minor change of the structural error parameter $\varsigma_{r c}$ (Figure 4.8). 


\subsection{Discussion}

\subsubsection{Varying the physical constraints}

Generally, the rating curves are little sensitive to the modelling scenarios in physical constraints, with modelled discharges in the extrapolation domain showing little variation between the various modelling choices (Table 4.3).

In this study, a rating curve model with two segments was chosen, with the segments roughly representing the main channel and floodplains. However, a third segment can be considered, which would represent the contribution of flow over the groyne fields for water levels exceeding the groyne heights. If a third segment is added to the DegRC and BifRC models, the values of the structural error parameter $\varsigma_{r c}$ slightly reduce (Table 4.3 ), which indicates that the third segment explains a slight amount of residual errors from the model with two segments. The addition of the third segment increases the discharges for high water levels, which would match the observed underprediction of the modelled discharge for the flood events of 1993 and 1995 (see section 4.5.2). However, the prior distributions of the model parameters dominate the posterior distributions, resulting in much wider credibility intervals (Table 4.3), as very little gaugings are available for very high water levels $(>14 \mathrm{~m}+\mathrm{NAP})$. Overfitting of the rating curve model can occur when adding more segments to the model (Sörengård and Di Baldassarre, 2017). Therefore, it may be concluded that currently the gaugings do not warrant the inclusion of a third segment in the rating curve model.

Splitting the observational record into two sub-periods and fitting the DegRC and BifRC models to the observations in those periods separately, also explains a small portion of the residual errors (Table 4.3). Table 4.3 also shows that modelled Waal discharges in the extrapolation domain are much lower in the second subperiod (i.e. in 2018). This is equivalent to an increase in water levels for given discharges over time. However, this is not as expected, as water-level-lowering interventions have been implemented along the Waal river during this second subperiod (Berends et al, 2021). The lower than expected discharge is likely explained by the lack of recent gaugings of very high discharges in this period. So, while splitting up the observational record into multiple periods may match the available gaugings better, it does not necessarily increase rating curve accuracy.

The choice for a certain length of the hypothetical record of water balance errors (see section 4.3.5) finds the balance between the rating curve accuracy (i.e. low residual errors) and the reduction of the water balance errors (WBE). In the BifRC model, this length was set equal to the amount of gaugings in the least gauged branch. With a shorter record, the WBE increases, but is still smaller in comparison to the models in which the water balance is not considered (StaRC and DegRC models). Oppositely, with a longer record, the WBE can be reduced 
slightly more, but at the expense of a further increase of the residual errors between the modelled rating curve and the gaugings, reflected in a higher $\varsigma_{r c}$.

Table 4.3: Relevant rating curve extrapolation results (for a water level of $17 \mathrm{~m}+\mathrm{NAP}$ in 2018) for the Waal branch under various modelling scenarios. These results are 1) the median discharge $\left.\left(Q_{50 \%}\right), 2\right)$ the width of the $95 \%$ credibility interval of the model discharge $\left.\hat{Q}, 3\right)$ the median value of the structural error parameter $\varsigma_{r c}$ and 4) the median water balance error based on Eq. 4.6. The considered modelling scenarios are the addition of a third segment (i.e. a fourth equation with an additional term in Eq. 4.5) in the DegRC and BifRC models, two time periods in the DegRC and BifRC model with only a constant $\varsigma_{r c}$ between the two periods, and a different length of the hypothetical record of observed water balance errors (see section 4.3.5).

\begin{tabular}{lllll}
\hline Scenarios (Waal) & $\mathbf{Q}_{50 \%}\left[\mathrm{~m}^{3} / \mathrm{s}\right]$ & W95\%Cl $\left[\mathrm{m}^{3} / \mathrm{s}\right]$ & $\varsigma_{\mathrm{rc}, 50 \%}$ & WBE \\
\hline StaRC model & 9,040 & 1,047 & 0.0594 & $-2.5 \%$ \\
DegRC model & 9,767 & 634 & 0.0297 & $-2.3 \%$ \\
BifRC model & 9,742 & 442 & 0.0297 & $+0.4 \%$ \\
3 segments in DegRC & 10,179 & 1,579 & 0.0284 & $-5.3 \%$ \\
3 segments in BifRC & 9,646 & 644 & 0.0284 & $+0.4 \%$ \\
2 periods in DegRC & 8,054 & 578 & 0.0290 & $+5.8 \%$ \\
2 periods in BifRC & 8,697 & 1,320 & 0.0294 & $+0.5 \%$ \\
1/4x WBE samples & 9,596 & 486 & 0.0296 & $+1.1 \%$ \\
4x WBE samples & 9,903 & 477 & 0.0299 & $+0.3 \%$ \\
\hline
\end{tabular}

\subsubsection{Sensitivity of rating curves to single flood events}

The flood events of 1993 and 1995 were important for flood risk management in the Netherlands in multiple aspects. During the 1995 event, the highest observed discharge was gauged in the Bovenrijn branch (i.e. $11,885 \mathrm{~m}^{3} / \mathrm{s}$ ). Daily gaugings are available for each of the branches. The event is therefore generally used for the calibration of the hydraulic models used in flood risk analyses in the Netherlands. These calibrated hydraulic models are widely used to estimate the water levels for design conditions (former design discharge of the Rhine river system: Q Bovenrijn $=16.000 \mathrm{~m}^{3} / \mathrm{s}$ ). Therefore, errors in the discharge gaugings of this $1995 \mathrm{high}$ discharge event may have a large effect on estimates of design water levels.

Also in this study, the gaugings of the 1995 flood event have a strong influence on the results. Figure 4.10 shows that by excluding the gaugings from the 1995 flood event, modelled rating curves would show lower discharges for given water levels. With the DegRC model, the rating curve change is larger than with the BifRC. This shows that adding the physical constraint of water balance closure reduces the dependency of rating curves on a single high discharge event. 


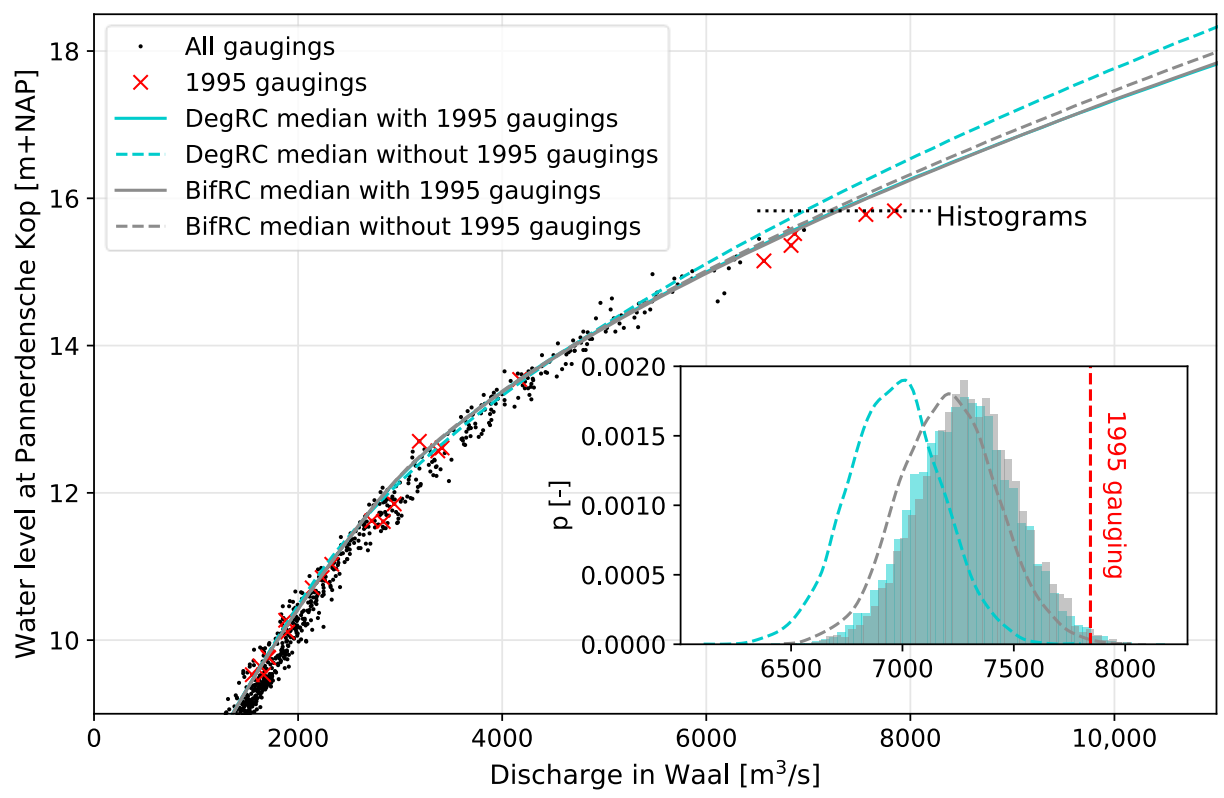

Figure 4.10: Median Waal rating curves in 1995 with the DegRC and BifRC models when including (continuous lines; are nearly equal) or excluding (dotted lines) the 1995 gaugings from the observational record. For the highest observed water level (15.83 m+NAP), the probability distributions of the discharges is shown.

\subsubsection{Discharge distribution at the bifurcations}

In a bifurcating river system, accurate predictions on the distribution of discharge over the downstream branches are crucial for flood risk management (Gensen et al, 2020). With the modelled rating curves using the BifRC model, the discharge distribution over the branches can be estimated while excluding or including the structural error $\epsilon_{r c}$ :

$$
\begin{array}{ll}
\widehat{D D}=\frac{\widehat{Q_{1}}}{\widehat{Q_{0}}} & \left(\text { excl. } \epsilon_{r c}\right) \\
D D=\frac{Q_{1}}{Q_{0}} & \text { (incl. } \left.\epsilon_{r c}\right)
\end{array}
$$

Where DD is the (modelled) discharge distribution, and $\mathrm{Q}_{0}$ and $\mathrm{Q}_{1}$ the (modelled) discharges in the incoming branch and one of the outgoing branches, respectively.

The estimated discharge distribution at the Pannerdensche Kop (Figure 4.11) is consistent with observations and hydraulic model results (Gensen et al, 2020), with less discharge diverted towards the Waal branch for higher water levels. The change in this trend, between water levels of $12 \mathrm{~m}+\mathrm{NAP}$ and $14 \mathrm{~m}+\mathrm{NAP}$, is 
caused by the difference in water levels for which the second segment of the rating curve model becomes active (reflected in the value of $b_{f p}$, see Figure 4.4). The embankments that form the division between the main channel and the floodplains are lower in the Waal than in the Pannerdensch Kanaal, which causes relatively more discharge diverted towards the Waal in this domain.

The estimated discharge distribution at the IJsselkop also matches observed values well (Figure 4.11). The increasing percentage of discharge diverted towards the Nederrijn for unobserved water levels is inconsistent with hydraulic model results (Gensen et al, 2020). Instead, they predict a decreasing fraction of discharge towards the Nederrijn for increasing water levels. This inconsistency is likely the result of the lack of (recent) gaugings in the high water level domain.

Figure 4.11 shows that the uncertainty in discharge distribution is dominated by the structural error $\epsilon_{r c}$. In the BifRC model, these structural errors are assumed independent between the branches. However, it can be expected that the structural errors are to some degree correlated between the branches. Such correlation may be caused by e.g. hysteresis or biased gaugings. Therefore, the uncertainty in discharge distribution is expected to be smaller than the yellow shaded area, but still larger than the blue shaded area.
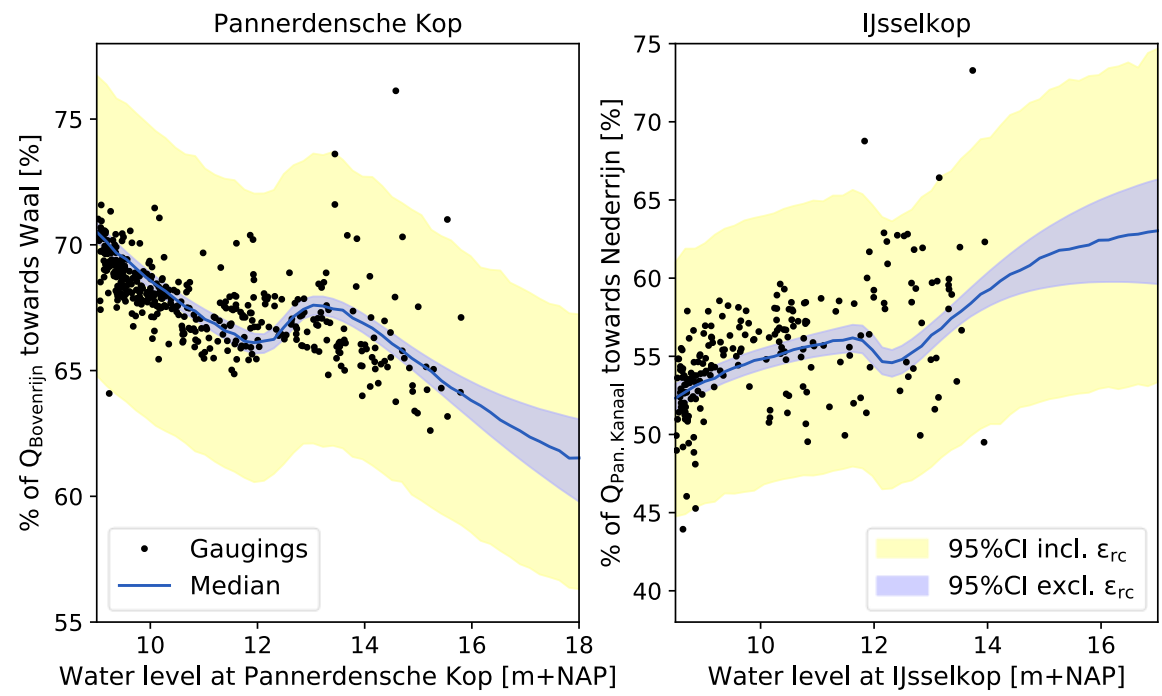

Figure 4.11: Estimated discharge distributions and their 95\% credibility intervals $(\mathrm{Cl})$ using the BifRC model at the Pannerdensche Kop (A) and IJsselkop (B). The figure shows that the structural error dominates the uncertainty in discharge distribution. 


\subsubsection{Using the physical constraint of water balance closure for accurate rating curves in river systems}

This study has showed that the physical constraint of water balance closure at a river bifurcation can be incorporated into rating curve construction and that it leads to physically more realistic rating curves. Particularly in the extrapolation domain, rating curves are constrained, resulting in better water balance closure and narrower credibility intervals. At a river confluence, the same constraint of water balance closure holds, which can be used to improve rating curve accuracy and thus discharge estimates. As rating curve accuracy can be improved, it can be beneficial to construct rating curves specifically at bifurcations and confluences instead of at another location along a single river branch. Additionally, the most accurate rating curves may be obtained by gauging in each branch at the bifurcation or confluence during one measurement campaign instead of multiple campaigns in a single branch. When limited resources are available, it is thus recommend to plan measurement campaigns at bifurcations or tributaries at the same time.

\subsection{Conclusions}

This study showed that the physical constraints water balance closure and bed level degradation can be incorporated in the construction of rating curves at two river bifurcations. Accounting for bed level degradation strongly improves the accuracy of the rating curves at the bifurcation which experiences bed level degradation, with a reduction of up to $50 \%$ of the residual errors from the modelled rating curves with respect to the standard rating curve model. To improve water balance closure, a bifurcation rating curves model was established in which the rating curves of the separate branches at the bifurcation become dependent by adding an explicit water balance term to the likelihood function of the Bayesian inference. The results showed that water balance closure is significantly improved at both of the analysed river bifurcations of the Rhine river, while rating curve accuracy is maintained with residual errors only marginally increasing. As water balance closure is a physical constraint at a bifurcation, the newly constructed rating curves are not only more accurate, they are also expected to be more physically realistic.

\section{Acknowledgements}

This work is part of the Perspectief research programme All-Risk with project number P15-21, which is (partly) financed by NWO Domain Applied and Engineering Sciences, in collaboration with the following private and public partners: the Dutch Ministry of Infrastructure and Water Management 
(Rijkswaterstaat), Deltares, STOWA, HKV, Natuurmonumenten and the regional water authorities Noorderzijlvest, Vechtstromen, it Fryske Gea, HHNK.

The authors would like to thank Jetze Twijnstra for his preliminary work into this topic. 


\section{Chapter 5}

Discussion 
The aim of this thesis was to quantify uncertainties in water levels in a bifurcating river system. Both hydraulic modelling and data analysis were performed with the bifurcating Rhine river in the Netherlands as an example. The outline of this chapter is as follows. In section 5.1, considerations on uncertainty analysis near bifurcation are discussed, including the potential and the limitations of the research performed in this thesis. In section 5.2, it is discussed how combining data analysis and hydraulic modelling approaches may potentially further improve the accuracy of discharge and water level estimates. In section 5.3, the effects of the Room for the River program on water levels and water level uncertainties are discussed, thereby considering the role of the bifurcation. Finally, in section 5.4, it is discussed what the implications of this research may be for flood risk management, and more specifically, the Flood Protection Program in the Netherlands.

\subsection{Considerations for uncertainty analysis of water levels in bifurcating rivers}

In this thesis, the role of bifurcations in water level and discharge uncertainty was assessed. In Chapters 2 and 3, it was shown that the feedback mechanism between the discharge distribution and water levels strongly affects these uncertainties. By not accounting for the feedback mechanism, estimates of water level uncertainties in a bifurcating river may be inaccurate. Also in other bifurcating rivers around the world, accounting for the feedback mechanism at bifurcations may increase the accuracy of uncertainty analyses of water levels and discharges. Likely, this improved accuracy is the largest for river bifurcations in lowland rivers, where the water surface slopes are mild. For steeper slopes, the local conditions are more important than the downstream water levels for determining the discharge distribution. Furthermore, in Chapter 4 it was shown that by considering water balance closure at the bifurcation, more physically realistic rating curves can be constructed. Thereby, water levels and discharges under flood conditions may be estimated more accurately.

In this section, the most relevant aspects in uncertainty analysis of water levels in bifurcating are discussed. Also, it is discussed how the accuracy of uncertainty estimates can be improved further.

\subsubsection{Uncertainty analysis through hydraulic modelling}

A 1D hydraulic modelling approach was adopted in this thesis. Alternatively, Quasi2D, 2D, and fully 3D models may be used for flow routing. Generally, absolute water level predictions are expected to be more accurate with higherdimensional models (Berends et al, 2018). Similarly, more accurate predictions 
of the absolute discharge distribution may be achieved with higher-dimensional models. However, the feedback mechanism at the bifurcation is driven by relative water level differences between the branches. The accuracy of the predictions of these relative differences and of their effect on discharge distribution may not be significantly improved by using higher-dimensional models. In Chapters 2 and 3, it was shown that the water level uncertainties for single-branch rivers quantified in this thesis are in the same order as modelling studies with higher-dimensional models, like the ones performed by Warmink et al (2013b) and Berends et al (2019).

More accurate predictions of absolute water levels and discharge distribution may be achieved by $2 \mathrm{D}$ hydraulic modelling, mainly in the case that local conditions are important. For example, structures near the bifurcation, such as the regulation structures are not well-represented in a 1D model. A higher-dimensional model is required to accurately evaluate their effect on the water levels and discharge distribution at the bifurcation. Furthermore, spatial variation in floodplain geometry and vegetation may not be well represented in a 1D model. If a lowerlying area or an area with very low vegetation-induced roughness is present near the bifurcation, the conveyance capacity of the floodplain may be underestimated in a $1 \mathrm{D}$ model, in which cross-sectionally averaged values are used. Vice-versa, the conveyance capacity may be overestimated if high grounds or densely vegetated areas are present.

Higher-dimensional modelling approaches may require significant computational demand, especially if uncertainty analysis is performed on many stochastic variables (Pianosi et al, 2016). A model domain of a bifurcating river is very large as the entire domain should be considered because of the feedback mechanism at the bifurcation. A sub-domain of the bifurcation and the upper reaches of the distribution should consider the uncertainty in the downstream boundary condition, which may not be independent of the conditions in the sub-domain if backwater effects from the (uncertain) downstream boundary may reach the bifurcation. Uncertainty analysis of water levels in a bifurcating river may thus be practically unfeasible by traditional approaches, in which a 2D model would need to be run many times in a Monte Carlo Analysis.

Berends et al (2018) have developed an approach for faster uncertainty analysis. They showed that any (substantial) correlation in model results can be used to estimate probability distributions of model outputs. This approach can potentially also be applied to a bifurcating river. For example, a correlation may exist between model results under varying discharges. Berends et al (2018) used a constant inflow boundary condition and thus considered a single river discharge. As the entire range of discharges is relevant for flood risk management purposes, water level uncertainties for other river discharges should also be quantified. It can be expected that the water level uncertainties are correlated between different discharges. Therefore, if a full uncertainty analysis has been performed for a 
single discharge, the uncertainty can be estimated for other discharges. Exploring such and other correlations may make a full uncertainty analysis of water level predictions for flood risk analyses in bifurcating rivers using $2 \mathrm{D}$ hydraulic models feasible.

Alternatively, Artificial Neural Networks (ANNs) may also be used for faster uncertainty analysis. An ANN is a data-driven model that can link inputs and outputs based on model results or observations, thereby strongly reducing computational demand. ANNs have been applied in hydrological studies (Dawson and Wilby, 2001; Dibike and Solomatine, 2001) and flow and flood forecasting studies (Snieder et al, 2020; Bomers, 2021). Given similarly large domains that ANNs have been applied to before (e.g. Bomers, 2021), an ANN may be successfully used to accurately estimate discharge and water level uncertainty in bifurcating rivers.

\subsubsection{The effect of correlated uncertainties on the feedback mechanism at bifurcations}

Correlations within or between sources of uncertainty may change the effect of the feedback mechanism at bifurcations on water level and discharge uncertainty. Riverine conditions may be correlated as a result of similar discharge regimes, similar sediment characteristics or the use of the same flow and roughness equations. Generally, the feedback mechanism has the most significant influence on water levels and discharges if the difference in riverine conditions (e.g. main channel roughness, floodplain roughness, and morphological development) between the branches is signicant. Then, as shown in Chapters 2 and 3 , the variation in discharge distribution is also significant. These variations in discharge distribution reduce the water level uncertainty near the bifurcation compared to the uncertainty in a single-branch river, but can increase the water level uncertainty further downstream.

If the riverine conditions between the branches are correlated, thus having a smaller difference between them, the feedback mechanism has a smaller influence on water level and discharge uncertainty. Therefore, lower uncertainty in discharge distribution, higher water level uncertainty near the bifurcation, and smaller water level uncertainty downstream can be expected compared to the uncorrelated case.

Correlated riverine conditions along a branch also affect water level uncertainty in a bifurcating river. With high correlations in riverine conditions along a branch, water level uncertainty in the downstream reaches is expected to be lower than in the uncorrelated case. For example, a low roughness in the upper reaches will result in an increase in discharge diverted towards this branch. With correlated roughness along the branch, the downstream reaches are expected to have low roughness as well. Simultaneous occurrence of a higher than expected discharge 
and a higher than expected roughness in a downstream reach is less likely, thus resulting in lower water level uncertainty in this downstream reach.

\subsubsection{Other sources of uncertainty}

Any source of uncertainty that affects water levels near bifurcations also affects the uncertainty in discharge distribution and thus the water levels throughout the entire river system. In the analysis in Chapter 2, upstream discharge uncertainty and main channel roughness uncertainty were included, which are generally considered to be the dominant sources of uncertainty (Warmink et al, 2011; Bozzi et al, 2015). In Chapter 3, also the uncertainty in floodplain roughness was included. Accounting for additional uncertainty sources possibly increases the uncertainty in water levels and discharge distribution. However, only the most important sources of uncertainty are expected to have a signifcant influence on water levels under design conditions (Warmink et al, 2011). Similarly, this would then hold for the uncertainty in discharge distribution. Therefore, as major sources of uncertainty have been assessed in this thesis, it is expected that the estimated uncertainties in water levels and discharge distribution are in the correct order of magnitude. Still, other sources of uncertainty may affect water level and discharge distribution uncertainty. Such sources of uncertainty may have been captured in the available discharge and water gaugings, while others may play a role under very high and yet unobserved discharge conditions.

In Chapter 4, the effect of any other source of uncertainty that is captured in the observations are included in the construction of the rating curves and thus included in the uncertainty estimates. In the next section (5.2.1), hydraulic modelling results and the rating curves are compared. This comparison shows that the uncertainties in water levels and discharge distribution quantified with the rating curves are larger than those quantified with hydraulic modelling. This difference may be partly attributed to the inclusion of other sources of uncertainty in the construction of the rating curves.

In both the observed and unobserved discharge domain, non-stationary discharges may increase the uncertainty in (peak) water levels and discharges. Non-stationary discharge may affect water level and discharge distribution uncertainty as flood wave attenuation reduces peak discharges and water levels, while hysteresis effects cause a non-linear relationship between water levels and discharges in which the peak water levels occur during the falling limb of a flood wave. Multiple physical mechanisms can cause hysteresis in river floods. Firstly, it can be caused by the phenomenon that flow velocities are relatively higher during the front of a flood wave than during the back of a flood wave (Mander, 1978). Secondly, it can be caused by the lag of river bedform growth relative to the discharge conditions, such that the highest bedforms, highest hydraulic roughness, and resulting peak water levels occur during the falling limb of the flood wave. Non-stationary discharges 
may also affect the discharge distribution, although their effects were only minor during a single observed discharge event at the Rhine bifurcations (Frings and Kleinhans, 2008). The effects of non-stationary discharges likely increase for narrow-peaked flood waves (Ten Brinke, 2013). In Chapter 2 and 3, water levels and discharge distributions were modelled under stationary discharges. Thereby, it can be expected that the peak water levels are overestimated as hysteresis effects and flood wave attenuation reduce the peak water levels. Contrarily, the gaugings used in Chapter 4 contain both the rising and falling limbs of flood waves, such that the wide uncertainty bands may be partly explained by the presence of hysteresis in the gaugings and peak water levels may generally be above the median rating curves.

Other sources of uncertainty may also affect water level and discharge distribution uncertainties for very high and yet unobserved discharge. Firstly, future Bovenrijn discharges may exceed the limit of $18,000 \mathrm{~m}^{3} / \mathrm{s}$ that was used in this study. This may occur if dikes along the Rhine in Germany are reinforced, such that more discharge is able to reach the Bovenrijn. For discharges higher than 18,000 $\mathrm{m}^{3} / \mathrm{s}$, other extreme scenarios may be triggered, e.g. upper stage plane bed (Hulscher et al, 2017), increasing uncertainty in discharge distribution and water level uncertainty. Secondly, breaching of flood defences close to the bifurcation, thereby lowering the water levels in the river, will also trigger a change in discharge distribution. An initiatory expert study, conducted by Steenblik et al (2020) has indicated that the effect on discharge distribution uncertainty may be small. Thirdly, fast morphological development, such as the erosion of the river bed in one of the branches (Ten Brinke, 2013) or the breaching of cross-flow embankments occurs (Steenblik et al, 2020), may decrease water levels and trigger a change in discharge distribution. It can be expected that such sources of uncertainty are highly negatively correlated, as breaching or erosion in one branch will trigger extra discharge being diverted towards that branch and thus reduce the discharge in the opposing branch. Thereby, breaching or erosion is less likely to occur in that branch. Due to the high relative differences between the branches, this source of uncertainty can significantly influence the uncertainty in discharge distribution, depending on the likeliness of the erosion or breaching event occurring.

\subsection{Combining rating curves and hydraulic modelling}

In this thesis, both hydraulic modelling (Chapter 2 and 3) and rating curves (Chapter 4) have been used to estimate water level and discharge distribution uncertainty. In this section, these two approaches are compared (section 5.2.1), and it is discussed how the two approaches may be combined to improve the accuracy of estimates of the water level and discharge distribution uncertainty 
(sections 5.2.2 and 5.2.3).

\subsubsection{Comparing rating curve and hydraulic modelling results}

In this section, the hydraulic model results from Chapter 2 and the rating curve results from Chapter 4 are compared. In Chapter 2, uncertainties in water levels and discharge distribution were quantified using the 1D hydraulic Sobek model considering a range of roughness scenarios. Here, the maximum and minimum modelled water levels using those scenarios are considered to be the $90 \%$ confidence interval for water levels. These are compared to the results obtained with the rating curve model that accounts for water balance closure (BifRC model). The rating curve uncertainty using the BifRC model can be represented by the model uncertainty and the total uncertainty. The model uncertainty is described by the ensemble of modelled rating curves in which the rating curves only vary due to the variations in the underlying rating curve parameters. The total uncertainty contains the model uncertainty and a structural error term $\left(\epsilon_{r c}\right)$. This $\epsilon_{r c}$ term increases linearly with the discharge and is further determined by random samples from a normal distribution of which the standard deviation is based on the residual errors between the modelled rating curves and the gaugings. These residual errors may be due to measurement errors in the gaugings and physics that the rating curve model does not explicitly describe, such as hysteresis and seasonal vegetation growth.

For moderate and moderately high discharges $\left(<5000 \mathrm{~m}^{3} / \mathrm{s}\right)$, the results for the Waal branch obtained with the two approaches are similar with the steepness of the stage-discharge relationship decreasing for increasing discharge (Figure 5.1). For these discharges under $<5000 \mathrm{~m}^{3} / \mathrm{s}$, the uncertainty band obtained with the rating curve model (total uncertainty, so including the structural error based on the residual errors) is much narrower than that obtained with the Sobek model. The narrow uncertainty intervals in this discharge domain are inherent to the BifRC model, for which it was chosen that the residual errors between the modelled rating curves and the gaugings increase linearly with the modelled discharges. In this discharge domain in the Sobek model, the uncertainty intervals are wide, reflecting the large variations in estimated and imposed roughness (section 2.3.1). The hydraulic model and the rating curve model results diverge for higher discharges $\left(>5000 \mathrm{~m}^{3} / \mathrm{s}\right)$. For a given Waal discharge, lower water levels are obtained with the Sobek model. For a Waal discharge of $10,165 \mathrm{~m}^{3} / \mathrm{s}$, which corresponds to the former design discharge of the Waal, the average difference between the two approaches is $\sim 0.7 \mathrm{~m}$, while the widths of the $90 \%$ uncertainty bands are very similar $(\sim 0.5 \mathrm{~m})$. Little gaugings are available for discharges over $>5000$ $\mathrm{m}^{3} / \mathrm{s}$, especially more recent ones. For unrecorded discharges, the rating curve results entirely depend on extrapolation, which generally results in large errors 
(Domeneghetti et al, 2012). As the hydraulic model includes more physics, such as the cross-sectional geometry, the hydraulic model results in the very high discharge domain are more credible than the rating curve results.
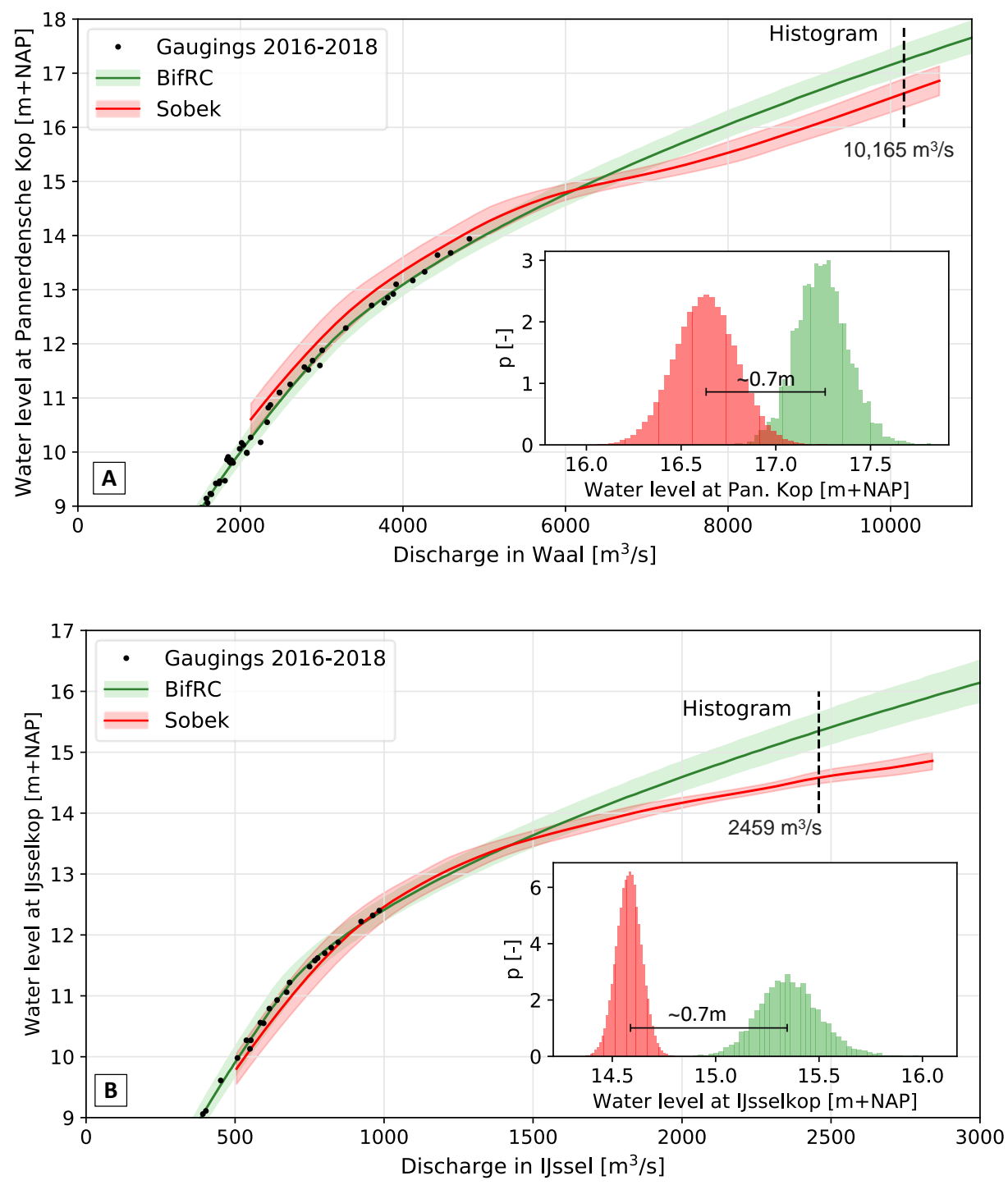

Figure 5.1: Stage-discharge relationships and their uncertainty intervals for the Waal $(A)$ and the IJssel (B) estimated using the 1D Sobek model of Chapter 2 (red) and using the rating curve model that accounts for water balance closure (BifRC) of Chapter 4 (green), of which the total uncertainty interval comprising of the model uncertainty and the structural error term is shown. Both approaches consider the river situation in 2016. The black dots mark all available gaugings for the period 19882018 
For the IJssel branch, the results match well for discharges lower than 1500 $\mathrm{m}^{3}$ (Figure 5.1). The stage-discharge relationships strongly diverge for higher discharges. The average difference between the two approaches is $0.7 \mathrm{~m}$ for the former design discharge of $2459 \mathrm{~m}^{3} / \mathrm{s}$. The Sobek model gives a very flat stage-discharge relationship, which can be attributed to the relatively very wide floodplains of the IJssel branch. These wide floodplains also limit the water level uncertainty, with a $90 \%$ uncertainty interval of $0.2 \mathrm{~m}$ for the former design discharge of $2459 \mathrm{~m}^{3} / \mathrm{s}$. The few gaugings available for discharges over $1500 \mathrm{~m}^{3} / \mathrm{s}$ happen to be insufficient to flatten the stage-discharge relationship obtained with the rating curve model. The few gaugings also result in the wider uncertainty intervals in the rating curve model, with a $90 \%$ uncertainty interval of $0.5 \mathrm{~m}$ for the former design discharge of $2459 \mathrm{~m}^{3} / \mathrm{s}$.

The discharge distributions at the Pannerdensche Kop and IJsselkop modelled with the Sobek model and the rating curve models (DegRC excl. $\epsilon_{r c}$ and BifRC incl. and excl. $\left.\epsilon_{r c}\right)$ are compared in 5.2. For the BifRC model, the model uncertainty (the ensemble of rating curves, so excl. $\epsilon_{r c}$ ) and the total uncertainty (which includes the $\epsilon_{r c}$ term based on the residual errors between the gaugings and the modelled rating curves) are shown. For the DegRC model, only the model uncertainty is shown.

At the Pannerdensche Kop bifurcation, the modelled discharge distributions match very well. All approaches show a decreasing percentage of discharge diverted towards the Waal for Bovenrijn discharges above $7000 \mathrm{~m}^{3} / \mathrm{s}$. They also show the increased percentage of discharge diverted towards the Waal for discharges between 5000 and $7000 \mathrm{~m}^{3} / \mathrm{s}$. This can be attributed to the minor embankments that are lower along the Waal's upper reaches than along the Pannerdensch Kanaal. They all show a slightly lower fraction of discharge diverted towards the Waal compared to the design discharge distribution for a discharge of $16,000 \mathrm{~m}^{3} / \mathrm{s}$. The hydraulic model results and the BifRC model (incl. $\epsilon_{r c}$ ) show a constant width of the uncertainty band, indicating that the uncertainty in discharge distribution scales linearly with Bovenrijn discharge. If only considering the model uncertainty of the rating curves (excl. $\epsilon_{r c}$ ), both the BifRC and the DegRC model show wide uncertainty bands in the extrapolation domain as the ensemble of rating curves show larger variations in this domain. The uncertainty band is much narrower in the BifRC model than in the DegRC model, showing that the incorporation of water balance physically constrains the rating curves and thereby reduces the model uncertainty in discharge distribution in this domain.

The uncertainty band of the hydraulic model results fall between the rating curve results if excluding and including the structural error $\epsilon_{r c}$. In section 4.5.3, it was discussed that the residual errors between rating curves and the gaugings (captured by the structural error) are expected to be to some extent correlated between the branches as physical processes such as hysteresis and seasonal vegetation growth are not explicitly incorporated in the rating curve model. Such processes are 
likely to have a similar influence on the rating curves and thereby cause similar residual errors between the gaugings and the modelled rating curves in all branches. With correlated residual errors, the width of the uncertainty band of the discharge distribution is likely between the two extremes (incl. and excl. $\epsilon_{r c}$ ). Considering that the uncertainty bands of the hydraulic model are between those two, and that the gaugings showing similar variability, it indicates that the hydraulic model results are more realistic for the case of the Pannerdensche Kop bifurcation.
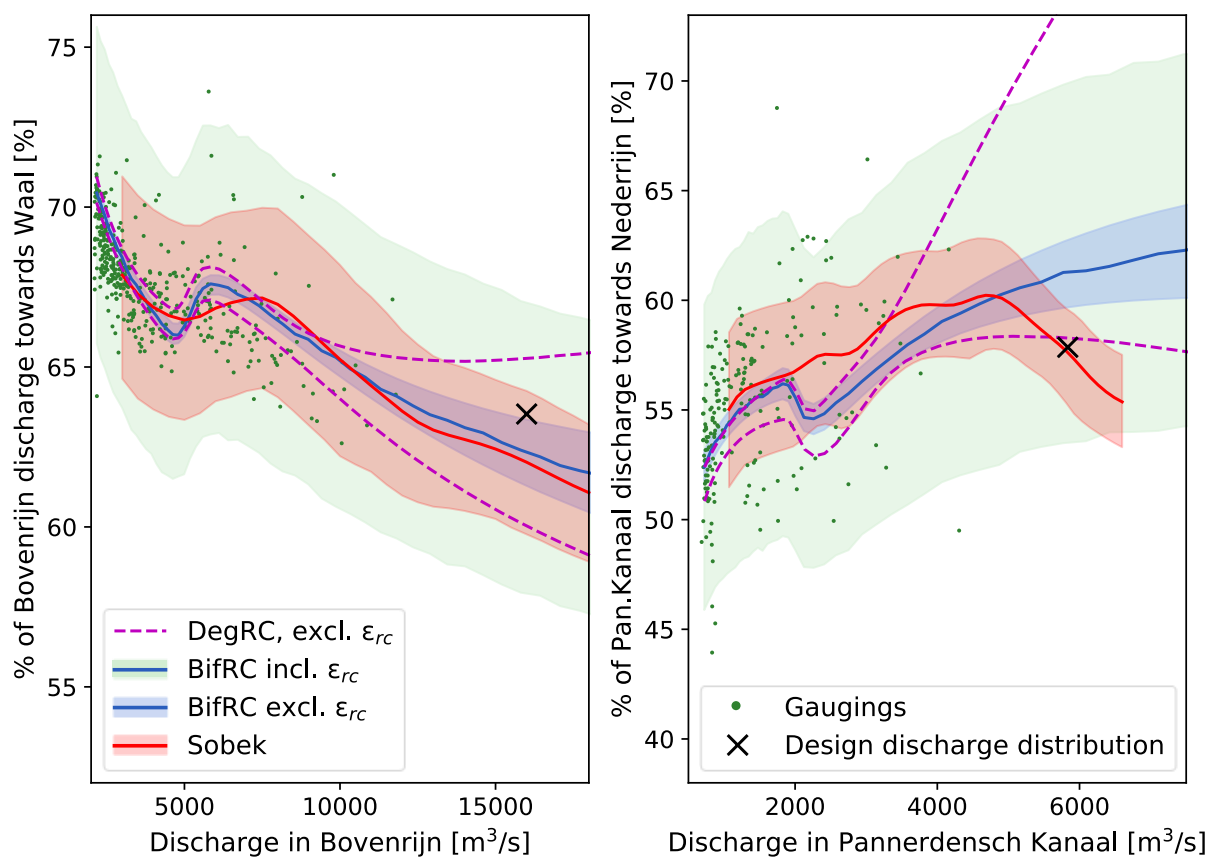

Figure 5.2: Mean and $90 \%$ confidence intervals of the modelled discharge distributions at the Pannerdensche Kop as a function of Bovenrijn discharge (left) and at the IJsselkop as a function of Pannerdensch Kanaal discharge (right). These were estimated using the hydraulic Sobek model of Chapter 2 (red), using the DegRC model that does not account for water balance closure (magenta), and using the BifRC model if including (green) and excluding the structural error (blue).

At the IJsselkop bifurcation, all modelled discharge distributions are in the same order of magnitude, but show larger differences than at the Pannerdensche Kop. For discharges under $4000 \mathrm{~m}^{3} / \mathrm{s}$, the percentage of discharge diverted towards the Nederrijn increases with Pannerdensch Kanaal discharge in both the hydraulic model and rating curves approaches. This percentage is expected to decrease for higher discharges, considering that the effects on water levels of the very wide floodplains further downstream the IJssel then reach the bifurcation. While this decreasing percentage is observed in the hydraulic model, matching the design discharge distribution, it is not observed in the rating curve models. This is likely due to the lack of (recent) gaugings available of above bankfull discharges, as the 
currently available gaugings do not support a decreasing percentage of discharge towards the Nederrijn. More gaugings of above bankfull discharges in the Nederrijn and IJssel are needed for improved accuracy of the rating curves and modelled discharge distribution and to validate the hydraulic model results. Similar to the Pannerdensche Kop case, the uncertainty band of the hydraulic model is between those of the BifRC rating curves if including or excluding the structural error $\epsilon_{r c}$, indicating that the hydraulic model uncertainty band is more realistic. The DegRC model shows very wide uncertainty bands in the high discharge domain, showing that the BifRC model reduces the extrapolation uncertainty. However, the discrepancy with the hydraulic model results shows that the accuracy of the predictions is not necessarily improved.

It is important to note that the results of both the hydraulic model and the rating curve model are based on the same discharge gaugings. The hydraulic model is calibrated on the high discharge event of 1995, while the rating curve model is very dependent on the gaugings of the same event (see section 4.5.2). In Chapter 4, it was observed that the gaugings of the 1995 discharge event lie at the lower end of the credibility interval of the modelled rating curves. Considering that discharge gaugings are prone to significant measurement uncertainty (Di Baldassarre and Montanari, 2009), raises the question to what extent the accuracy of the results is dependent on this single discharge event. In the following sections, it is discussed how this dependency could be decreased by combining hydraulic modelling and rating curve modelling.

\subsubsection{Adding hydraulic model results into rating curve modelling}

Rating curves are often used in their extrapolation domain for flood risk management purposes. If design flood conditions have never occurred or if it was not possible to conduct a measurement campaign during such conditions (Pedersen and Rüther, 2019), extrapolation of the rating curve is often required (Pappenberger et al, 2006). Errors in the discharge estimations are known to be large in this domain (Domeneghetti et al, 2012). The hydraulic model results for rivers with wide floodplains often show lower water levels than the extrapolated rating curve as the significant floodplain flow that occurs in this discharge domain is underestimated by the rating curve. This was also observed for the Rhine branches (section 5.2.1). Rating curves, particularly in their extrapolation domain, can be constrained by adding hydraulic model results (Di Baldassarre and Claps, 2011; Domeneghetti et al, 2012).

Here, the sensitivity of the rating curves constructed in Chapter 4 to the addition of a hydraulic model result in the extrapolation domain is tested. In the observational record of each branch, one Sobek model is added (red cross in Figure 5.3). The 
hydraulic model result for a steady discharge of $16,000 \mathrm{~m}^{3} / \mathrm{s}$ is obtained with a $1 \mathrm{D}$ Sobek model that is calibrated on the 1995 flood event. Using a steady discharge in the hydraulic model likely overestimates the expected water level that would occur during a discharge wave with a peak discharge of $16,000 \mathrm{~m}^{3} / \mathrm{s}$. Nevertheless, it will indicate how a single model result can affect the rating curves in the extrapolation domain.

As observed in section 5.2.1, the Sobek model result falls well below the extrapolated rating curve and its 90\% credibility interval (Figure 5.3). By including the single model result, the rating curves are shifted downwards in the high discharge domain. For the design discharges of the branches, the median water levels are reduced by $15 \mathrm{~cm}$ in each rating curve. These reductions are almost equal in all branches as the water balance closure should be maintained.

Besides reducing the water levels in the high discharge domain, including the Sobek model result slightly narrows the credibility interval. This can be attributed to a reduction of the model uncertainty of the rating curve (the spread in the ensemble of modelled rating curves) as now an observation is available in this domain. However, as the Sobek model result has a large error relative to the modelled rating curves, the structural error term $\epsilon_{r c}$ that is added to the rating curves to account for residual errors increases. This counteracts the decrease in model uncertainty, together resulting in only a slight narrowing of the total uncertainty interval.

While these newly constructed rating curves match the Sobek model result more closely, a significant difference is still observed. Rating curves could be constrained further by including additional model results. However, the rating curves then become more and more dependent on the accuracy of the hydraulic model results. As the hydraulic model is calibrated on available gaugings, uncertainty is added because measurements errors have not been accounted for during model calibration, and because the model is used outside of the calibrated conditions. In the next section, it is discussed how instead, the rating curves may be used for hydraulic model calibration.

\subsubsection{Hydraulic modelling calibration in a bifurcating river}

All discharge gaugings contain errors, and therefore hydraulic model calibration on single discharge events can result in calibrated models that may diverge from expected values. For example, Domeneghetti et al (2012) showed that for a reach of the Po river in Italy, calibrated hydraulic roughness values may strongly diverge from physically realistic values reported in the literature. Pianosi et al (2016) state that measurement uncertainty affects model calibration and that a sensitivity analysis of the model results to multiple observations could help to show how well a model is calibrated. Thus, rating curves, being based on multiple discharge 


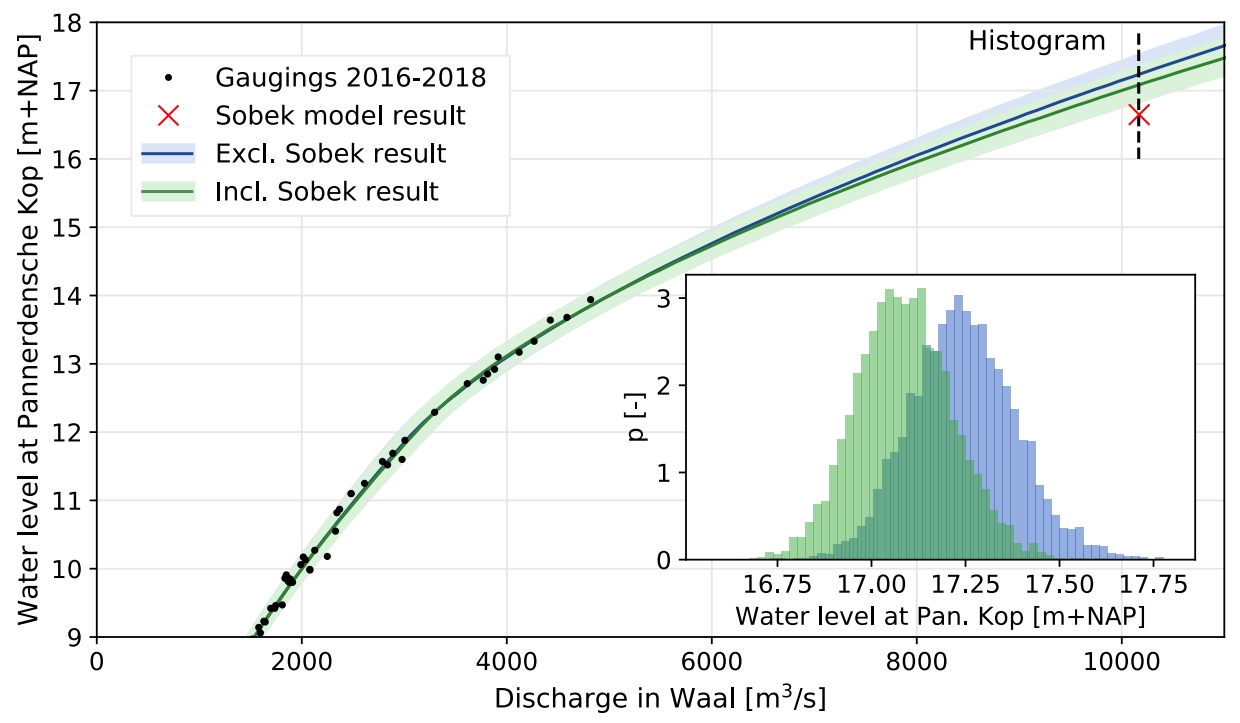

Figure 5.3: Median and $90 \% \mathrm{Cl}$ of the Waal rating curve for the Waal using the BifRC model, if excluding or including a Sobek model result corresponding to $Q_{\text {Bovenrijn }}=16,000 \mathrm{~m}^{3} / \mathrm{s}$

events may be used as calibration conditions (e.g. Domeneghetti et al, 2012; Peña Arancibia et al, 2014).

Currently, the calibration strategy for the 1D and 2D hydraulic models of the bifurcating Rhine branches is as follows. Firstly, the main channel roughness of each distributary (Waal, Nederrijn, and IJssel) is calibrated independently to match the local stage-discharge observations. The main channel roughness is calibrated for several reaches and for a few discharge levels which correspond to observed high discharge events (Domhof et al, 2018). As a result, variations as a function of streamwise location and discharge occur in the calibrated hydraulic roughness. Secondly, the distributaries are coupled at the bifurcations to obtain a model for the entire river system. The modelled discharge distribution and water level at the bifurcation are calibrated by changing the main channel in short reaches downstream from the bifurcations. The resulting hydraulic roughness in the short reaches may diverge strongly from the hydraulic roughness in other reaches, either being very low or very high, or showing large jumps in roughness as a function of discharge. Especially in the unrecorded discharge domain, these physically unrealistic hydraulic roughness values may cause inaccurate model results.

The current strategy heavily relies on the accuracy of the discharge distribution estimates on which the hydraulic model is calibrated. Alternative calibration strategies may provide more realistic roughness values, although hydraulic model 
results then do not exactly match observed events anymore. Two alternative strategies may be considered (Figure 5.4).

\section{Calibration strategy 1}

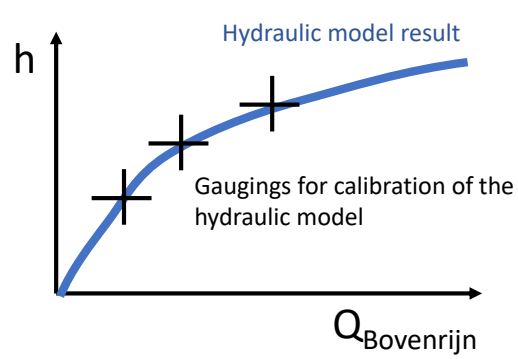

Calibration strategy 2

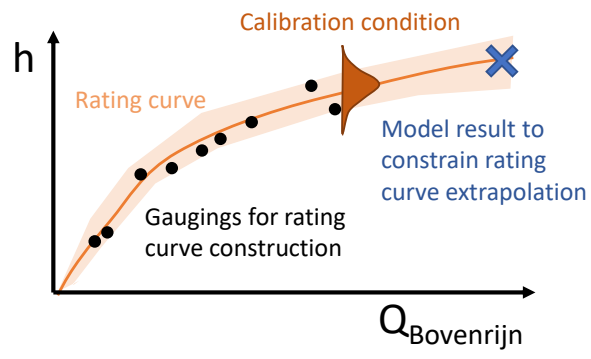

Figure 5.4: Two alternative calibration strategies. Left: calibration variables are the downstream water levels as function of Bovenrijn discharge. Right: simultaneous calibration of rating curves and hydraulic model results

In the first strategy, calibration may be performed simultaneously on (downstream) water levels along all distributaries and Bovenrijn discharge observations. In that case, the discharge distribution is merely a function of the model results and not a calibrated variable in itself. In this approach, equifinality may occur, meaning that multiple combinations of roughness parameters give equally accurate results. Illustratively, relatively high water levels in branch one may be reached by a high roughness in that branch itself, but also by a high roughness in branch two to increase the discharge towards branch one. To solve the issue of equifinality, an additional constraint can be introduced in which it is considered how physically realistic the calibrated roughness values are (Pappenberger et al, 2005; Kim et al, 2013). For instance, limits to the calibrated roughness values could be imposed, although they may still need to be wide to account for other model errors (e.g. discretisation errors). Also, similarity in roughness values along branches and between the branches may be considered, as it is unlikely that roughness values show much variation besides the variation that can be explained from the differences in river bed sediment and vegetation types.

In the second strategy, rating curve construction and hydraulic calibration are performed simultaneously. Such simultaneous modelling has been proposed in the literature for small streams (Pappenberger et al, 2006; Mansanarez et al, $2019 \mathrm{~b}$ ) and for downstream boundary conditions (Karamuz et al, 2016). In this strategy, rating curves are constructed for each branch at the bifurcation, and simultaneously a hydraulic model is run to obtain water level estimates in the extrapolation domain. The hydraulic roughness in the model is calibrated using a probability distribution of water levels at the highest observed discharge, which is common practice in literature (e.g. Pappenberger et al, 2006; Di Baldassarre et al, 2010). This probability distribution is based on the probabilistic rating 
curve, which is constructed using all available gaugings. Additionally, the hydraulic model is used to constrain the rating curve in the extrapolation domain. With this strategy, hydraulic model calibration is not dependent on specific discharge events, which may be prone to measurement uncertainties, while at the same time rating curves are more accurate around the highest observed discharge. Also, this strategy may be prone to equifinality, in this case meaning that multiple combinations of rating curves and hydraulic model parameters can give equally accurate results. Again, this may be solved by considering the degree of divergence from the prior estimation of the rating curve and roughness parameters. Furthermore, hysteresis may need to be included to improve the accuracy of this strategy. This can be achieved by incorporating the Jones formula for non-steady flow in the rating curve model ((e.g. Petersen-Øverleir, 2006) and running a non-stationary boundary condition in the hydraulic model. Although the effect of hysteresis has not been assessed in this thesis, it is expected that its inclusion will narrow the uncertainty bands of the rating curve as hysteresis may explain some of the residual errors. Subsequently, the hydraulic model results will be more accurate as well.

If these approaches are applied to the Rhine branches, expected water levels for extremely high discharges (including the design water levels) may be higher than they are currently. The rating curves constructed in Chapter 4 indicate that higher water levels may be expected for discharge events such as the 1993 and 1995 flood events. Calibrated roughness values would increase, and as a result, the water levels would be higher as well. It is recommended to verify this hypothesis.

\subsection{Effects of the Room for the River program at the Rhine bifurcations}

\subsubsection{Water balance considerations for rating curve changes throughout time}

Changes in the stage-discharge relationship over time may have several causes, e.g. seasonal vegetation growth (Perret et al, 2021), morphological development in the main channel (Mansanarez et al, 2019a) or human interventions that increase the conveyance-capacity of a river cross-section (Berends et al, 2021). Such changes need to be accounted for in the construction of rating curves to attain sufficiently accurate rating curves.

Under the Room for the River program, the conveyance capacities of the Dutch Rhine branches were increased. Some of the Room for the River projects are expected to reduce the water levels near the Pannerdensche Kop bifurcation. In Chapter 3, it was shown that such interventions can result in large water level 
reductions at the bifurcation point and may also alter the discharge distribution. The largest water level reduction at the bifurcation under the Room for the River program can likely be attributed to the dike relocations and the side channel near Nijmegen in the Waal executed between 2012 and 2015. Based on hydraulic model results of Berends et al (2021), this project is expected to reduce the water level under design conditions at the Pannerdensche Kop by approximately $30 \mathrm{~cm}$. However, the rating curve analysis conducted by Berends et al (2021) did not show such changes in water levels which could be attributed to the Room for the River project near Nijmegen. Instead, their results showed a linear decrease in water levels for a given discharge over the period 1988-2018, which gave the base for implementation of a constant bed level degradation in Chapter 4.

Under the assumption of constant bed level degradation that was made for the rating curve model in Chapter 4, the rating curves only gradually change over time. In this model, sudden rating curve changes are thus not possible, also not with the rating curve model that considered water balance closure (BifRC). The advantage of the BifRC model is that the gaugings in all three branches at a bifurcation are included when constructing the rating curves. Therefore, an accurate rating curve may be constructed in one branch even if in the considered period little to no gaugings are available in that branch. Therefore, it is tested whether the BifRC model can be successfully applied at the Pannerdensche Kop to construct accurate rating curves for individual years for which the gaugings of only that specific year are used to construct the rating curves. Bed level degradation is disregarded, as it is assumed that its influence on water levels is negligible within a single year.

In Figure 5.5, the modelled water levels over time for a given Waal discharge of $5000 \mathrm{~m}^{3} / \mathrm{s}$ are shown that are estimated using the original BifRC model (using all gaugings and including bed level degradation), the BifRC model for individual years, and the standard rating curve model for individual years (StaRC; without water balance incorporated, which gives results similar to Berends et al (2021)). The results of the BifRC applied to individual years do not show a clear deviation from a linearly decreasing water level in recent years, which may have been attributed to the Room for the River projects. Therefore, the assumption of a constant bed level degradation over time to be able to use all gaugings in the construction of the rating curves, is likely valid.

The water balance considerations of the BifRC model still improve rating curve accuracy if the model is applied to individual years, as the BifRC results show narrower uncertainty intervals than the StaRC results. This is explained by the higher number of gaugings used in the BifRC model, namely those of the other two branches. The results for some years show strongly deviating mean water levels and much wider uncertainty intervals, which are mostly the years in which no high discharge occurred or was not recorded. Still, the BifRC is able to narrow the uncertainty intervals in those years, thus confirming that water balance considerations can increase rating curve accuracy. As an illustration, in 2017, the 
highest recorded Waal discharge is only $2249 \mathrm{~m}^{3} / \mathrm{s}$, resulting in a large deviation of the water levels from the linear trend and a wide uncertainty interval. The BifRC model shows a smaller deviation from the trend and narrower uncertainty intervals, as the gaugings during the same discharge event in the other branches constrain the Waal rating curve.

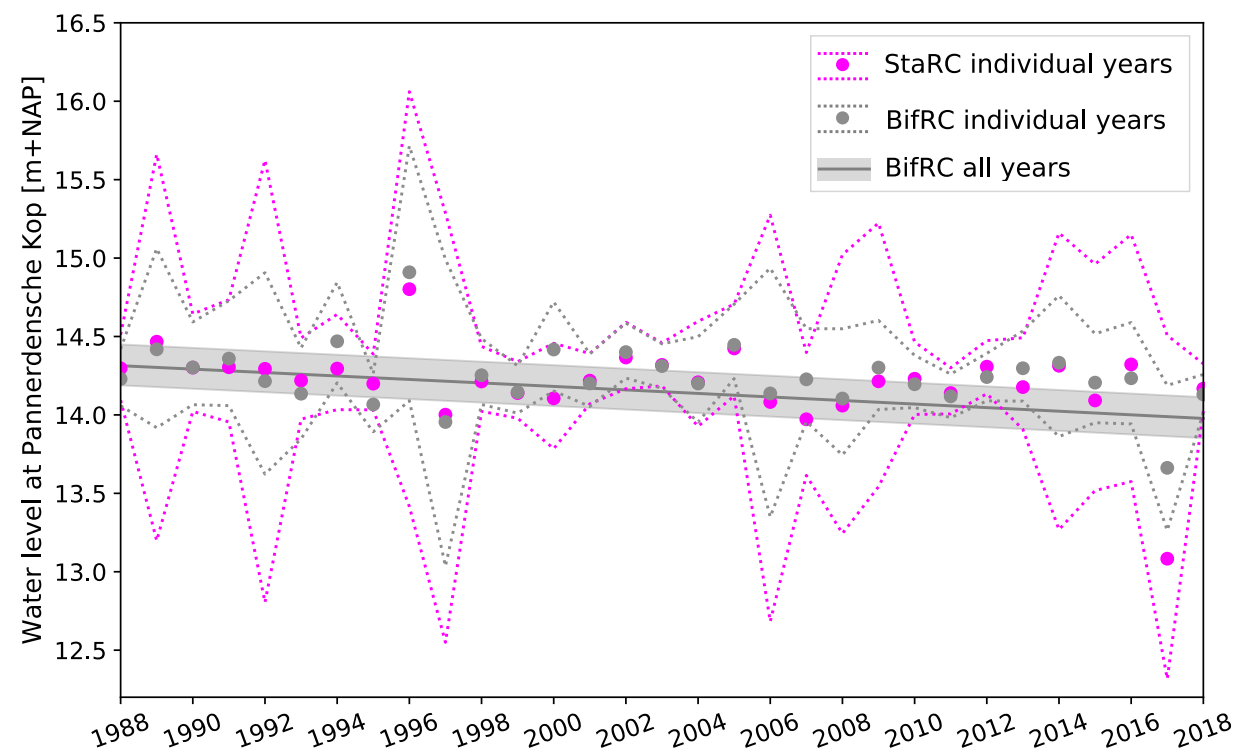

Figure 5.5: Mean and $90 \%$ credibility intervals $(\mathrm{Cl})$ of the water levels at the Pannerdensche Kop for a Waal discharge of $5000 \mathrm{~m}^{3}$ over the period 1988-2018. These are obtained by using the rating curve model without water balance incorporated for each year individually (StaRC individual years), using the rating curve model with water balance and bed level degradation incorporated for all years simultaneously (BifRC all years), and using the BifRC model for each year individually (BifRC individual years).

Additional water balance considerations give another hypothesis of why no sudden rating curve changes are observed. Figure 5.6 shows that observed water balance errors at the Pannerdensche Kop for discharges over $3000 \mathrm{~m}^{3} / \mathrm{s}$ show a positive bias in recent years. However, in the BifRC model of Chapter 4, and to obtain the results in Figure 5.5 the bias in water balance errors was assumed negligible. With a positive bias in water balance errors, the Bovenrijn discharge is often higher than the sum of discharges of the Waal and Pannerdensch Kanaal. Especially in 2018, marked in yellow, large and positive water balance errors are observed. The positive bias in the water balance error indicates that the Bovenrijn discharge may consistently be overestimated or that the discharge in the Waal or Pannerdensch Kanaal is consistently underestimated.

To analyse the potential effect of the biased water balance error on water levels 


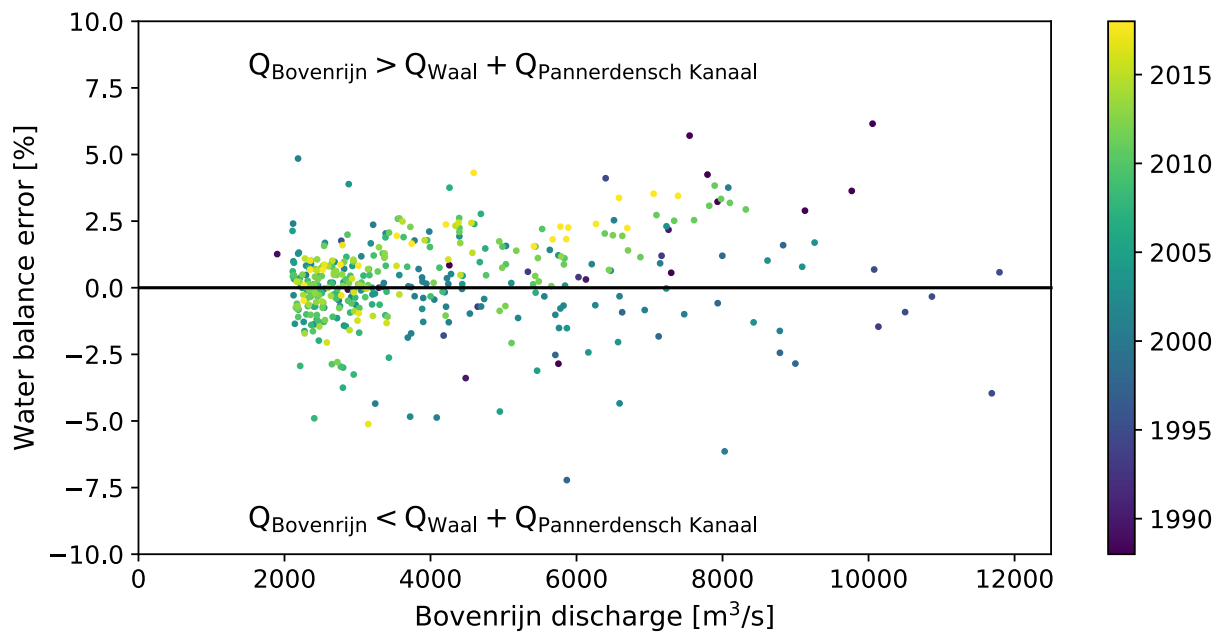

Figure 5.6: Water balance errors of the available same-day gaugings at the Pannerdensche Kop as function of Bovenrijn discharge (x-axis) and of time (color scale)

obtained with the BifRC model, the water balance error is explicitly corrected. This correction is done by adapting the Waal discharges to close the water balance. This can only be done for the gaugings obtained on a day on which gaugings are available in all branches. The water balance error is attributed to the Waal as it is hypothesised that the Waal discharge gaugings contain the largest errors (Twijnstra et al, 2020), possibly partly due to the implementation of Room for the River projects in the Waal close to the bifurcation.

Under the assumption that the water balance errors can be attributed to the Waal gaugings, Figure 5.7 shows the water levels over time for a given Waal discharge of $5000 \mathrm{~m}^{3} / \mathrm{s}$ modelled with the BifRC model for individual years if and if not correcting for the water balance errors. Until 2006, correcting for water balance errors often does not significantly change the mean water levels. The exceptions are years in which no gaugings of high discharges are available (e.g. 1989 and 2005, but later also 2014 and 2017). In such years, the correction of water balance errors may lead to a large difference. Remarkably, from 2007 onwards, correcting for the water balance errors generally reduces the mean water levels. These years often have gaugings with a positive bias in water balance errors (Figure 5.6, which is corrected for by increasing the Waal discharge, which results in a less steep rating curve. Illustratively, the difference in mean water levels is $31 \mathrm{~cm}$ in 2018 , which is a year in which gaugings of Waal discharges over $4500 \mathrm{~m}^{3} / \mathrm{s}$ are available. Similar water level reductions were found in 2015 and 2016, both being years that have gaugings of discharges over $3000 \mathrm{~m}^{3} / \mathrm{s}$. These water level reductions are in the same order as the expected effect of the Room for the River projects at the Pannerdensche Kop (Berends et al, 2021). 


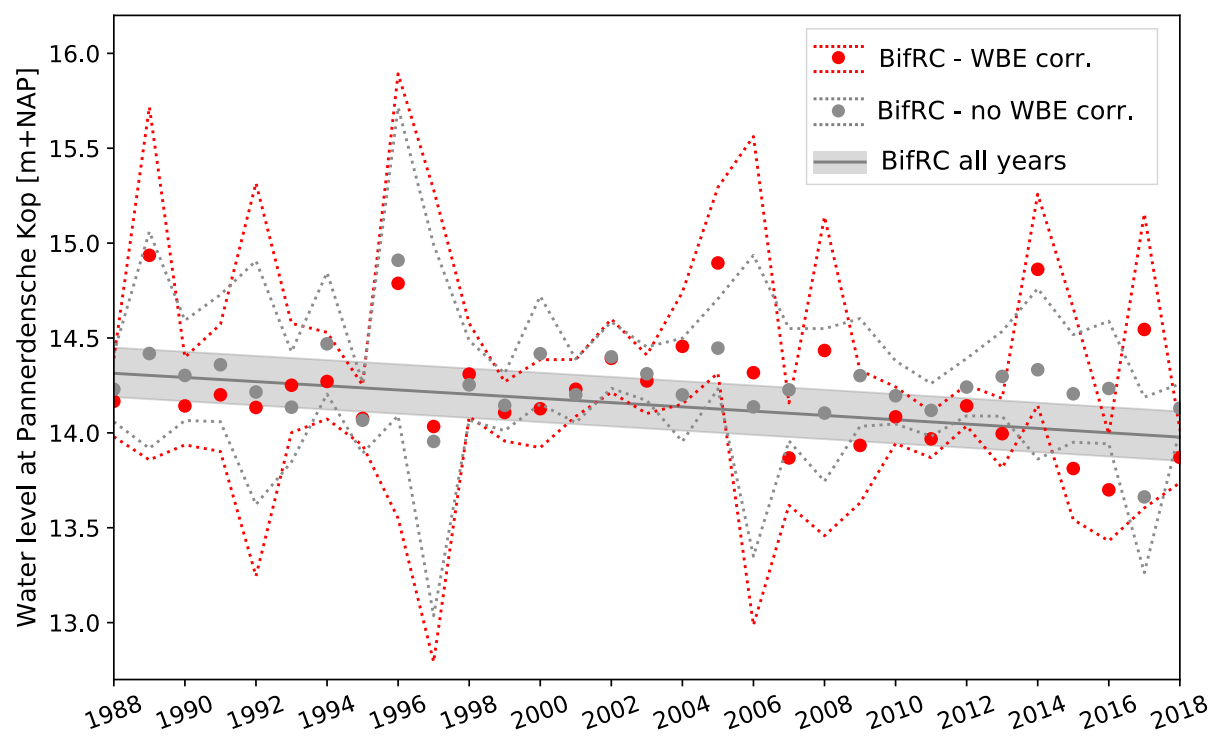

Figure 5.7: Mean and $90 \%$ credibility intervals $(\mathrm{Cl})$ of the water levels at the Pannerdensche Kop for a Waal discharge of $5000 \mathrm{~m}^{3}$ over the period 1988-2018. These are obtained by using the BifRC model for: all years, individual years with and without explicit water balance error (WBE) corrections.

This analysis shows that a bias in water balance errors affects rating curves and that sudden rating curve changes may be observed if these errors are corrected. Therefore, this analysis provides further evidence that water balance closure is essential for accurate water level predictions. In hydraulic models of bifurcating rivers, water balance closure is always guaranteed. This is not necessarily the case in rating curves, and water balance errors may propagate towards discharge and water level predictions. In Chapter 4, water balance closure was improved for both of the Rhine bifurcations. Explicitly correcting for (biased) water balance errors may further improve rating curve accuracy. However, it may be challenging to identify to which branch or branches the water balance error should be attributed.

\subsubsection{The effect of the regulation structures on water level uncertainty}

The regulation structures (Figure 1.4) that were built downstream of the bifurcations within the Room for the River program were not studied in this thesis. Using the regulation structures, the discharge distribution at the bifurcations can be altered by adding or removing slabs from the weir structure, such that the design discharge distribution can be met. Active steering during the flood season 
is currently not possible though. In this section, the effect of these regulation structures on water levels and discharges and their uncertainties are discussed.

It is not exactly known how large the effect of the regulation structures on the discharge distribution is for design conditions (Ogink, 2006; Ten Brinke, 2013). First, as the conditions for which the regulation structures were designed have never occurred, the detailed flow conditions around and over the regulation structure are uncertain. Second, the uncertain division of discharge between the main channel and floodplains likely affects the impact of the regulation structures on the discharge distribution. This division is mainly driven by the uncertain roughness differences between the main channel and the floodplains. These differences are possibly affected by the hydraulic model calibration, which has been done for a lower discharge than the design discharge. Regulation structures are effectively a local reduction of the conveyance capacity of the floodplains. The effects on discharge distribution are thus likely equivalent to those caused by the increase in floodplain conveyance capacity under the floodplain widening or deepening that were analysed in Chapter 3. That analysis showed that the water-level-lowering impact of interventions and thus their impact on the discharge distribution increases with an increasing portion of discharge conveyed by the floodplains. Similarly, the regulation structures can be expected to have a large effect on the discharge distribution if the floodplains convey a large portion of the discharge.

While the mean effects of the regulation structures on the discharge distributions are thus uncertain, it can be argued that the regulation structures only marginally affect the uncertainty of the discharge distribution itself. Again, the equivalence with the impact analysis of a floodplain widening of Chapter 3 is drawn. There, it was shown that floodplain widening flattens the stage-discharge relationship (i.e. water levels rise less with increasing discharge compared to the original situation). Thereby, water level uncertainty is reduced locally at the location of the widening, because water levels in the widened reach become less sensitive to the discharge of that branch. However, this reduced sensitivity to discharge also implies that a smaller change in water levels can trigger a large change in discharge distribution. Therefore, while water level uncertainty does reduce locally due to the floodplain widening, discharge distribution uncertainty and consequently water level uncertainty downstream of the intervention remain approximately equally large. Intuitively, the same holds if a regulation structure narrows the floodplain. The local stage-discharge relationship becomes steeper, and water level uncertainty increases. With the increased sensitivity of the water levels to discharge, larger water level changes are required to trigger a large change in discharge distribution. Therefore, equivalent to the floodplain widening, the net result on discharge distribution uncertainty of the regulation structures is expected to be marginal.

To summarise, it is thus expected that the regulation structures affect the mean 
discharge distribution by an uncertain amount, but they only marginally affect its uncertainty. Detailed hydraulic modelling studies are required to analyse the uncertain effects of the regulation structures on the mean discharge distribution and possibly reduce their uncertainties.

\subsection{Implications for the Flood Protection Program}

In this section, possible implications of this thesis for the Dutch Flood Protection Program (Dutch: Hoogwaterbeschermingsprogramma) are discussed. Within this program, hundreds of kilometers of dikes along the Rhine branches will be reinforced to meet the safety requirements that are set in the new flood risk policy (Kok et al, 2017); see section 1.7.3). Under this new flood risk policy, flood risk should be determined probabilistically, thereby considering a range of discharge conditions.

Chapter 3 showed that the Waal branch is the dominant driver of water level uncertainties along all distributaries. Relatively small discharge variations driven by the Waal branch can result in large water level uncertainty in the smaller Nederrijn and IJssel branches. As changes in the Waal branch can cause large system-wide water level changes, interventions in the upstream reaches of the Waal should be designed with extra care. Contrarily, interventions in the upper reaches of the Nederrijn and IJssel branches are expected to have a smaller effect on system-wide water levels. Therefore, the strict rules concerning the discharge distribution changes due to an intervention (Rijkswaterstaat, 2019) may be slightly loosened for interventions in the Nederrijn and IJssel branches.

Generally, discharge distribution uncertainty is not explicitly considered in the design and assessment of flood defences in the Netherlands (Deltares, 2016). Along with other sources of (model) uncertainty, it used to be accounted for by a safety margin of $0.3 \mathrm{~m}$, which was added to the calculated hydraulic loads that are subsequently used in the flood risk analysis. A recent analysis by Deltares (2017) showed that when explicitly accounting for the uncertainties under the new flood risk framework (Kok et al, 2017), the former safety margin of 0.3 $\mathrm{m}$ was overly conservative, and a value of $0.2 \mathrm{~m}$ would be realistic, but that discharge distribution uncertainty likely is an important source of uncertainty for very high discharges. How these values compare to the water level uncertainty quantifications done in this thesis requires further analysis.

Figure 5.8 shows a qualitative indication of how the uncertainty in discharge distribution may affect the failure probabilities of the flood defences along the Waal and IJssel branches. The scheme shows fragility curves as conditional failure probabilities (CFP) conditioned on the fraction of Bovenrijn discharge that the Waal branch receives for a given Bovenrijn discharge. Here it is assumed that the 
probability distribution of the discharge distribution is centred around the design discharge distribution. For that specific discharge distribution, the conditional failure probabilities along the branches are equal, as the flood defences along both branches are designed for these discharge conditions. Contrarily, in both tails of the probability distribution of the discharge distribution, flood defence failure at some location in the river system, either along the Waal or IJssel, is (very) likely to occur. For an increasing percentage of discharge diverted towards the Waal, the conditional failure probabilities along the Waal strongly increase. Vice-versa, for a decreasing percentage and thus an increasing IJssel discharge, the conditional failure probabilities along the IJssel increase. This increase is more rapid than it is along the Waal branch, because of the higher sensitivity to discharge of IJssel water levels compared to Waal water levels. Thus, the Waal flood defences are relatively more robust than the IJssel flood defences with respect to discharge distribution uncertainty.

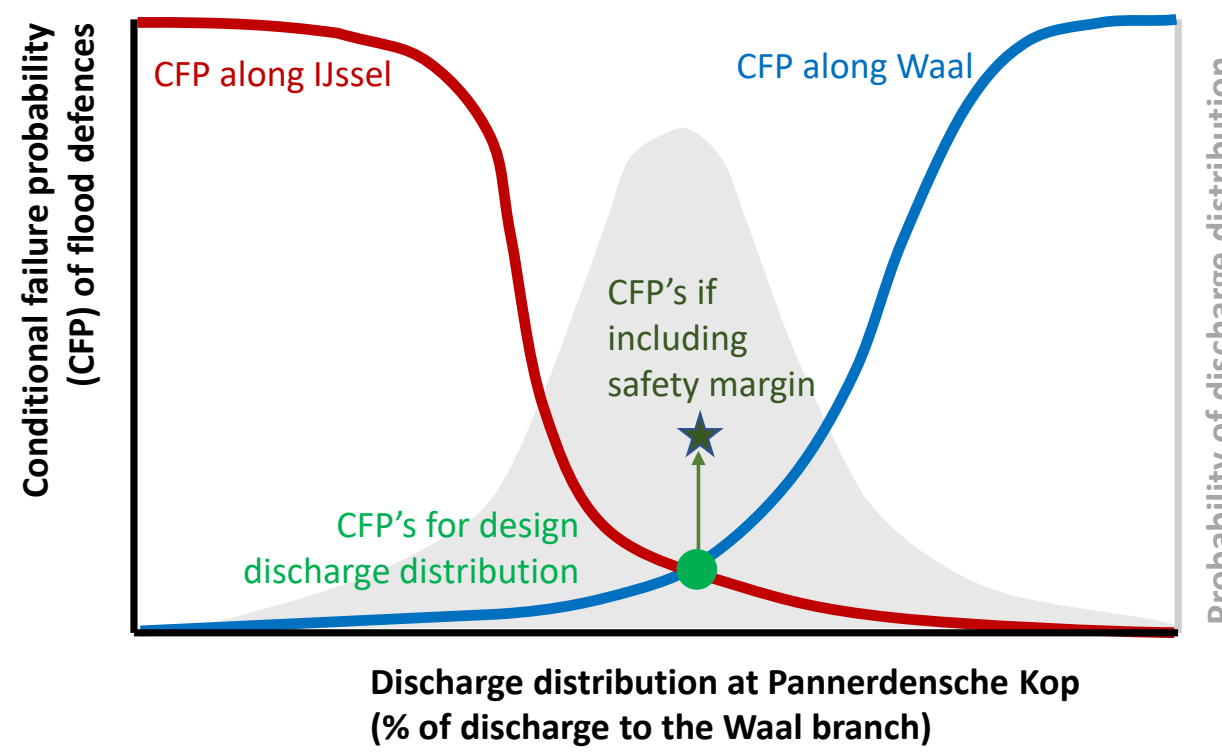

Figure 5.8: Schematisation of the conditional failure probabilities along the Waal and the IJssel branches, conditioned on the percentage of Bovenrijn discharge diverted towards the Waal.

To what extent the discharge distribution uncertainty affects the failure probabilities of flood defences depends on the type of failure mechanism that is dominant for a specific flood defence section. Wave overtopping and consequent erosion of the flood defence on the landward side has a very steep fragility curve (Van Bergeijk et al, 2021). With a steep fragility curve, failure probabilities are very sensitive to changes in the water levels and thus to changes in the discharge distribution. Contrarily, failure mechanisms such as piping and macro-stability have milder fragility curves (Marijnissen et al, 2019). Therefore, the uncertainty 
in discharge distribution has a smaller influence on the probability of failure due to these failure mechanisms than it has on the probability of failure due to wave overtopping.

Finally, it is pointed out that the discharge distribution uncertainty may become (even) more important in the future. In the next decades, dikes will be reinforced to meet the new safety requirements. Specifically, the resistance of dikes to geotechnical failure mechanisms will be improved. In the future, flooding probabilities will thus be more dependent on other failure mechanisms, such as overflow and wave overtopping. 



\section{Chapter 6}

Conclusions and recommendations 


\subsection{Conclusions}

The aim of this thesis was to quantify uncertainties in water levels in a bifurcating river system. The main focus was to assess the effect of the feedback mechanism between water levels and discharge distribution on the water level uncertainty along distributaries. Both a hydraulic modelling approach and a data analysis approach were taken to reach the aim. Both approaches explicitly considered the entire range of possible discharges to account for the uncertainty in discharge upstream of the bifurcations. The bifurcating Rhine river in the Netherlands was used as a case study. This section answers the research questions that were formulated in section 1.5 and subsequently reflects on the main aim of this thesis.

RQ1: What is the sensitivity of water levels in a bifurcating river system to an uncertain main channel roughness?

The sensitivity of water levels to main channel roughness is quantified for the bifurcating Dutch river Rhine system. This sensitivity is compared to the sensitivity if considering single-branch rivers. It was found that the feedback mechanism between downstream water levels and discharge distribution at a river bifurcation reduces the sensitivity of local water levels to the roughness variations in that branch. While in single-branch rivers a roughness change only has an effect upstream, in bifurcating rivers there is also an effect downstream. This is due to the shift in discharge distribution that counteracts the water level changes driven by the roughness changes. The roughness of the largest branch dominates the water levels in all branches. A roughness change in a large branch can induce system-wide water level changes of a few decimeters, while a roughness change in a small branch can only induce local and system-wide water level changes of a few centimeters up to a decimeter. Compared to the single-branch river, in a bifurcating river total water level variability increases in the smaller branches and decreases in the larger branches. Generally, it can thus be concluded that uncertainties in riverine conditions in the larger branch dominate the water level uncertainties throughout the entire river system.

RQ2: What is the water-level-lowering impact of interventions in a bifurcating river system under discharge and roughness uncertainty?

The impact of river interventions on water levels in a bifurcating river system was assessed. The feedback mechanism at the bifurcation reduces the impact and the uncertainty of a water-level-lowering intervention in a single branch. Downstream of the intervention, a water level increase is observed as a result 
of the increased discharge. It was also shown that increasing the conveyance capacity in a distributary close to the bifurcation slightly reduces the water level uncertainty at the location of the intervention, but does not reduce the uncertainty in the discharge distribution. Thus, a local intervention does not reduce systemwide uncertainties in water levels. To account for the unwanted downstream water level increase as a result of an intervention, a compensating intervention in the opposing branch can offset the increase in discharge towards the branch. For specific discharge and roughness conditions, the water level increase can be avoided by a specific design of the compensating intervention. Outside of these specific conditions, water level increases occur in one of the branches of which the magnitudes depend on the type of interventions. These water level increases are small if compensating interventions are of the same type, but larger water level increases can be expected if the compensating interventions are of different types.

RQ3: To what extent does incorporating water balance closure at river bifurcations affect the rating curves and subsequent discharge and water level uncertainty

Water balance closure (discharge continuity) was incorporated in the construction of rating curves at the bifurcations of the Dutch Rhine river. Furthermore, bed level degradation was incorporated as it was shown to be essential for rating curve accuracy. If water balance closure is not incorporated, large water balance errors between the rating curves are observed, mainly in the high discharge domain. These errors are strongly reduced when incorporating water balance closure. Incorporating water balance closure only marginally increases the residual errors between the rating curves and the gaugings, indicating that rating curve accuracy is maintained. Because water balance closure is a physical characteristic of a bifurcation, the constructed rating curves that account for water balance closure are expected to be more physically realistic.

\section{Reflection on aim}

This thesis has quantified water level and discharge uncertainty in a bifurcating river system and has shown what the role of the bifurcation is in that. In the recorded domain, the hydraulic model and the rating curve analysis produce similar results, thereby giving credibility to both approaches. In the high and unrecorded discharge, the results between the two approaches diverge and the results of the hydraulic model are expected to be more credible as more physics are included. Explicitly considering the bifurcation in both approaches significantly improved the accuracy of the water level and discharge uncertainty estimates. Firstly, this is done by acknowledging that the bifurcating river system should be analysed as one interconnected system. Secondly, water balance closure at the 
bifurcation should be considered. Whereas in a hydraulic model the water balance closes by definition, improved water balance closure between rating curves can be attained by incorporating water balance closure in the construction of rating curves.

\subsection{Recommendations}

In this section, recommendations for future research and for flood risk managers are given.

\subsubsection{Future research}

\section{Analyse the constraints of a bifurcation in other river systems}

This thesis used the Rhine bifurcation in the Netherlands as a case study. It is recommended to analyse other bifurcating river systems around the world to generalise the conclusions further. It is expected that the feedback mechanism at the bifurcation has a similar influence on water level and discharge distribution uncertainty. However, the magnitude of this effect may depend on the characteristics of the river system, such as the cross-sectional geometry, the bed slopes and possible backwater effects. Furthermore, it is recommended to analyse whether water balance considerations can also be used to constrain rating curves at other bifurcations and at river confluences (see section 4.5.4), especially at locations where fewer gaugings are available. If so, the accuracy of rating curves and of downstream design discharge conditions can be improved.

\section{Combine hydraulic modelling and rating curves}

A hydraulic model was applied, and rating curves were constructed to assess water level and discharge uncertainty. Although both approaches were applied separately, they rely on the same water level and discharge gaugings. Considering that discharge gaugings may show large measurement errors, the same error is introduced in both approaches. Potentially, the accuracy of the uncertainty estimations can be improved when combining hydraulic modelling and rating curves in a probabilistic approach (section 5.2). 


\section{Perform an efficient uncertainty analysis with a 2D model}

The applied methods in this thesis have shown to be able to accurately predict water level changes as a result of hydraulic roughness changes and geometrical changes. A hydraulic model with higher dimensionality may be necessary for accurate predictions of absolute water levels and discharge distribution. Using a $2 \mathrm{D}$ model, the effect of the regulation structures and the variability in geometry and vegetation on the floodplains on water levels and the discharge distribution can be assessed. However, as the computational demand is large, especially in a bifurcating river, where the entire river system should be considered, a fully probabilistic uncertainty analysis with a 2D modelling approach is infeasible. Efficient uncertainty analysis methods, such as an Artificial Neural Network (e.g. Bomers, 2021) or the method of Berends et al (2018), are thus required.

\subsubsection{Recommendations for flood risk managers}

\section{Explicitly consider for the feedback mechanism at the bifurcation}

In Chapter 2, it was shown that the feedback mechanism between discharge distribution at the bifurcation and downstream water levels balances out water level variations. At the same time, the feedback mechanism also affects the impact of river interventions on water levels. Together with upstream discharge uncertainty, the uncertainty in the discharge distribution determines the discharge uncertainty in a branch. The discharge uncertainty is a dominant aspect of flood risk management. Therefore, discharge distribution uncertainty should be accounted for in the design and assessment of flood defences and interventions. Single-branch studies are generally not representative of the actual physics in a bifurcating river. Therefore, instead of considering a bifurcating river as a combination of single-branch rivers, it is recommended that the bifurcating river system is explicitly considered as one interconnected system.

\section{Consider water balance closure in the construction of rating curves at bifurcations}

In Chapter 4, it was shown that water balance closure could be improved by accounting for it in the construction of rating curves. As water balance closure is a physical property of a bifurcation, rating curves that have improved water balance closure are physically more realistic. Furthermore, section 5.3.1 showed that biased errors in the water balance can strongly affect the rating curves. Therefore, considering water balance closure is essential for accurate rating curves, and it is recommended to consider water balance closure in the construction of 
rating curves at bifurcations.

\section{Measure discharges on the same day}

Discharge gaugings are essential for rating curve construction and hydraulic model calibration. Gaugings in the higher domain strongly affect modelled water levels and discharge distributions. Especially, same-day gaugings in all branches at a river bifurcation are necessary, because then water balance closure can be considered in the construction of rating curves. Furthermore, same-day gaugings can be used as an indicator for the accuracy of the gaugings, as they should show an approximately closed water balance. Therefore, it is recommended to focus on same-day gauging at the bifurcations of the Rhine. Furthermore, it is recommended to analyse a potential bias in discharge gaugings at the Pannerdensche Kop in recent years, which is indicated by a non-closing water balance (see section 5.3.1). Also, more discharge gaugings in the high discharge domain in the Nederrijn and IJssel are necessary to improve rating curve accuracy and the estimates of the discharge distribution at the IJsselkop.

\section{Assess the effect of discharge distribution uncertainty on flood risk}

Section 5.4 discussed the potential implications on flood risk management and more specifically the Flood Protection Program in the Netherlands. There, it was stated that if the discharge distribution would deviate from its design value, the failure probabilities of flood defences, and consequently of flood risk along one or more of the distributaries would increase. Expressing whether the current safety margins are overly conservative or whether they are insufficiently high requires further and more comprehensive analysis. Therefore, it is recommended to analyse the water level uncertainties and their feedback with the uncertainty in discharge distribution for the entire range of upstream discharges, and to quantify their effect on flood risk throughout the entire river system. Furthermore, it was argued that currently discharge distribution uncertainty already contributes to the flood risk along the distributaries, but that this influence will likely increase in the future as dikes are being strengthened. It is important to consider this increased uncertainty in the future design of flood defences. 


\section{List of references}

Apel H, Thieken AH, Merz B, Blöschl G (2006) A Probabilistic Modelling System for Assessing Flood Risks. Natural Hazards 38:79-100, DOI: 10.1007/s11069-005-8603-7

Apel H, Merz B, Thieken AH (2008) Quantification of uncertainties in flood risk assessments. International Journal of River Basin Management 6(2):149-162, DOI: 10.1080/15715124.2008.9635344

Ardıçlıoğlu M, Kuriqi A (2019) Calibration of channel roughness in intermittent rivers using HEC-RAS model: case of Sarimsakli creek, Turkey. SN Applied Sciences 1, DOI: $10.1007 / \mathrm{s} 42452-019-1141-9$

Asselman NEM, Klijn F (2016) Making room for rivers: quantification of benefits from a flood risk perspective. E3S Web Conferences; FLOODrisk 2016 - 3rd European Conference on Flood Risk Management 7:12001

Becker A, Scholten M, Kerkhoven D, Spruyt A (2014) Das behördliche Modellinstrumentarium der Niederlande. In: Stamm J (Ed.) Dresdner Wasserbaukolloquium 2014 Simulationsverfahren und Modelle für Wasserbau und Wasserwirtschaft, Dresden University of Technology, Dresden, Germany, pp 539-548

Berends KD, Warmink JJ, Hulscher SJMH (2018) Efficient uncertainty quantification for impact analysis of human interventions in rivers. Environmental Modelling and Software 107:50-58, DOI: https://doi.org/10.1016/j.envsoft.2018.05.021

Berends KD, Straatsma MW, Warmink JJ, Hulscher SJMH (2019) Uncertainty quantification of flood mitigation predictions and implications for interventions. Natural Hazards and Earth System Sciences 19:1737-1753, DOI: 10.5194/nhess-19-17372019
Berends KD, Ji U, Penning WE, Warmink JJ, Kang J, Hulscher SJMH (2020) Stream-scale flow experiment reveals large influence of understory growth on vegetation roughness. Advances in Water Resources 143:103675, DOI: 10.1016/J.ADVWATRES.2020.103675

Berends KD, Gensen MRA, Warmink JJ, Hulscher SJMH (2021) Multidecadal Analysis of an Engineered River System Reveals Challenges for Model-Based Design of Human Interventions. CivilEng 2(3):580598, DOI: 10.3390/civileng2030032

Best J (2005) The fluid dynamics of river dunes: A review and some future research directions. Journal of Geophysical Research 110(F04S02), DOI: 10.1029/2004JF000218

Beven KJ (2019) Towards a methodology for testing models as hypotheses in the inexact sciences. In: Proceedings of the Royal Society A: Mathematical, Physical and Engineering Sciences, Royal Society Publishing, vol 475:2224, DOI: 10.1098/rspa.2018.0862

Blöschl G, Hall J, Viglione A, Perdigão RAP, Parajka J, Merz B, Lun D, Arheimer B, Aronica G, Bilibashi A, Boháč M, Bonacci O, Borga M, Čanjevac I, Castellarin A, Chirico GB, Claps P, Frolova N, Ganora D, Gorbachova L, Gül A, Hannaford J, Harrigan S, Kireeva M, Kiss A, Kjeldsen TR, Kohnová S, Koskela JJ, Ledvinka O, Macdonald N, Mavrova-Guirguinova M, Mediero L, Merz R, Molnar P, Montanari A, Murphy C, Osuch M, Ovcharuk V, Radevski I, Salinas JL, Sauquet E, Šraj M, Szolgay J, Volpi E, Wilson D, Zaimi K, Živković N (2019) Changing climate both increases and decreases European river floods. Nature 573(7772):108-111, DOI: 10.1038/s41586019-1495-6

Bomers A (2021) Predicting outflow hydrographs of potential dike breaches in a bifurcating river system using narx 
neural networks. Hydrology 8(2):87, DOI: 10.3390/hydrology8020087

Bomers A, Schielen R, Hulscher S (2019a) Decreasing uncertainty in flood frequency analyses by including historic flood events in an efficient bootstrap approach. Natural Hazards and Earth System Sciences 19(8):1895-1908, DOI: 10.5194/nhess-191895-2019

Bomers A, Schielen RMJ, Hulscher SJMH (2019b) Application of a lower-fidelity surrogate hydraulic model for historic flood reconstruction. Environmental Modelling and Software 117:223-236, DOI: $10.1016 /$ j.envsoft.2019.03.019

Bomers A, Schielen RMJ, Hulscher SJMH (2019c) Consequences of dike breaches and dike overflow in a bifurcating river system. Natural Hazards 97(1):309-334, DOI: $10.1007 / \mathrm{s} 11069-019-03643-\mathrm{y}$

Bozzi S, Passoni G, Bernardara P, Goutal N, Arnaud A (2015) Roughness and Discharge Uncertainty in 1D Water Level Calculations. Environmental Modeling and Assessment 20(4):343-353, DOI: 10.1007/s10666-0149430-6

Brilhuis R (1988) Enkele Hydraulische en Morfologische Parameters van de Nederlandse Rijntakken. Technical report, Rijkswaterstaat, Arnhem, The Netherlands

Buschman FA, Hoitink AJF, Van der Vegt M, Hoekstra P (2010) Subtidal flow division at a shallow tidal junction. Water Resources Research 46(12):12515, DOI: 10.1029/2010WR009266

Chow VT (1959) Open-Channel Hydraulics. McGraw-Hill, New York, USA

Ciullo A, Bruijn KM, Kwakkel JH, Klijn F (2019) Accounting for the uncertain effects of hydraulic interactions in optimising embankments heights: Proof of principle for the IJssel River. Journal of Flood Risk Management 12(S2), DOI: $10.1111 /$ jfr3.12532

Dawson CW, Wilby RL (2001) Hydrological modelling using artificial neural networks: Progress in Physical Geography: Earth and Environment 25(1):80-108, DOI: $10.1177 / 030913330102500104$
De Ruijsscher TV, Naqshband S, Hoitink AJF (2020) Effect of non-migrating bars on dune dynamics in a lowland river. Earth Surface Processes and Landforms 45(6):1361-1375, DOI: $10.1002 /$ esp.4807

Deltaprogramma Rivieren (2014) Synthesedocument Rivieren. Technical report, Rijkswaterstaat, Arnhem

Deltares (2016) WBI - Onzekerheden; Overzicht van belasting- en sterkteonzekerheden in het wettelijk beoordelingsinstrumentarium. Technical report, Delft

Deltares (2017) Vergelijking WBI2017 met OI2014. Technical report, Delft

Deltares (2018a) Afvoerverdeling Rijntakken na 2050: Lijkt een wijziging kosteneffectief of niet? Technical report, Rijkswaterstaat, Delft

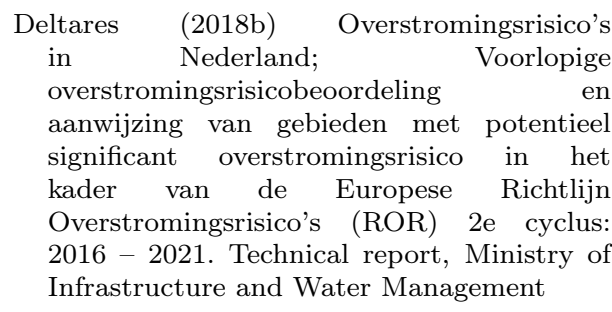

Deltares (2020) SOBEK3, D-Flow 1D User Manual Version 3.4.0. Technical report, Delft; Netherlands

Di Baldassarre G, Claps P (2011) A hydraulic study on the applicability of flood rating curves. Hydrology Research 42(1):10-19, DOI: $10.2166 /$ nh. 2010.098

Di Baldassarre G, Montanari A (2009) Uncertainty in river discharge observations: a quantitative analysis. Hydrology and Earth System Sciences 13:913-921, DOI: 10.5194/hess-13-913-2009

Di Baldassarre G, Laio F, Montanari A (2009) Design flood estimation using model selection criteria. Physics and Chemistry of the Earth, Parts A/B/C 34(10-12):606-611, DOI: $10.1016 /$ j.pce.2008.10.066

Di Baldassarre G, Schumann G, Bates PD, Freer JE, Beven KJ (2010) Floodplain mapping: a critical discussion of 
deterministic and probabilistic approaches. Hydrological Sciences Journal 55(3):364376, DOI: $10.1080 / 02626661003683389$

Di Baldassarre G, Laio F, Montanari A (2012) Effect of observation errors on the uncertainty of design floods. Physics and Chemistry of the Earth 42-44:85-90, DOI: $10.1016 /$ j.pce.2011.05.001

Di Baldassarre G, Kreibich H, Vorogushyn S, Aerts J, Arnbjerg-Nielsen K, Barendrecht M, Bates P, Borga M, Botzen W, Bubeck P, De Marchi B, Llasat C, Mazzoleni M, Molinari D, Mondino E, Mård J, Petrucci O, Scolobig A, Viglione A, Ward PJ (2018) Hess Opinions: An interdisciplinary research agenda to explore the unintended consequences of structural flood protection. Hydrology and Earth System Sciences 22(11):5629-5637, DOI: 10.5194/hess-225629-2018

Dibike YB, Solomatine DP (2001) River flow forecasting using artificial neural networks. Physics and Chemistry of the Earth, Part B: Hydrology, Oceans and Atmosphere 26(1):17, DOI: 10.1016/S1464-1909(01)85005-X

Dierauer J, Pinter N, Remo JWF (2012) Evaluation of levee setbacks for flood-loss reduction, Middle Mississippi River, USA | Elsevier Enhanced Reader. Journal of Hydrology 450-451:1-8, DOI: https://doi.org/10.1016/j.jhydrol.2012.05.044

Diermanse FLM (2017) Overzichtsrapport Onzekerheden: Overzicht van Belastingen Sterkte-Onzekerheden in Het Wettelijk Beoordelingsinstrumentarium. Technical report, Deltares, Delft, Netherlands

Dierx JR, Bomers A, van der Meulen B, Cohen KM, Hulscher SJMH (2021) Modelling early medieval flood-induced breaching of a coversand ridge in the IJssel valley, Rhine delta, the Netherlands. Geomorphology p 107913, DOI: $10.1016 /$ j.geomorph.2021.107913

Dilley M, Chen RS, Deichmann U, Lerner-Lam A, Arnold M, Agwe J, Buys P, Kjekstad O, Lyon B, Yetman G (2005) Natural disaster hotspots: A global risk analysis. 5, The World Bank, Washington, D.C., USA

Domeneghetti A, Castellarin A, Brath A (2012) Assessing rating-curve uncertainty and its effects on hydraulic model calibration. Hydrology and Earth System Sciences 16:1191-1202, DOI: 10.5194/hess-16-11912012

Domhof BCA, Berends KD, Spruyt A, Warmink JJ, Hulscher SJMH (2018) Discharge and location dependency of calibrated main channel roughness: case study on the River Waal. In: River Flow 2018 - Ninth International Conference on Fluvial Hydraulics, E3S Web of Conferences 40, p 06038

Dong TY, Nittrouer JA, McElroy B, Il'icheva E, Pavlov M, Ma H, Moodie AJ, Moreido VM (2020) Predicting Water and Sediment Partitioning in a Delta Channel Network Under Varying Discharge Conditions. Water Resources Research 56(11):e2020WR027199, DOI: 10.1029/2020WR027199

Downton MW, Morss RE, Wilhelmi OV, Gruntfest E, Higgins ML (2005) Interactions between scientific uncertainty and flood management decisions: Two case studies in Colorado. Environmental Hazards 6(3):134146, DOI: 10.1016/j.hazards.2006.05.003

Edmonds DA (2012) Stability of backwaterinfluenced river bifurcations: A study of the Mississippi-Atchafalaya system. Geophysical Research Letters 39(8):1-5, DOI: 10.1029/2012GL051125

Edmonds DA, Caldwell RL, Brondizio ES, Siani SMO (2020) Coastal flooding will disproportionately impact people on river deltas. Nature Communications 11:4741, DOI: $10.1038 /$ s41467-020-18531-4

Feng H, Tang L, Wang Y, Guo C, Liu D, Zhao H, Zhao L, Wang WJ (2020) Effects of recent morphological change on the redistribution of flow discharge in the Yangtze River Delta. Continental Shelf Research 208:104218, DOI: $10.1016 /$ j.csr.2020.104218

Frings RM, Kleinhans MG (2008) Complex variations in sediment transport at three large river bifurcations during discharge waves in the river Rhine. Sedimentology 55(5):1145-1171, DOI: $10.1111 / \mathrm{j} .1365-$ 3091.2007.00940.x

Gelman A (2006) Prior distributions for variance parameters in hierarchical models. 
Bayesian Analysis 1(3):515-534, DOI: 10.1214/06-BA117A

Gensen MRA, Warmink JJ, Huthoff F, Hulscher SJMH (2020) Feedback Mechanism in Bifurcating River Systems: the Effect on Water-Level Sensitivity. Water 12(7):1915, DOI: $10.3390 /$ w12071915

Guerrero JL, Westerberg IK, Halldin S, $\mathrm{Xu}$ CY, Lundin LC (2012) Temporal variability in stage-discharge relationships. Journal of Hydrology 446-447:90-102, DOI: 10.1016/j.jhydrol.2012.04.031

Guida RJ, Swanson TL, Remo JWF, Kiss T (2015) Strategic floodplain reconnection for the Lower Tisza River, Hungary: Opportunities for flood-height reduction and floodplain-wetland reconnection. Journal of Hydrology 521:274-285, DOI: 10.1016/j.jhydrol.2014.11.080

Habert J, Ricci S, Le Pape E, Thual O, Piacentini A, Goutal N, Jonville G, Rochoux M (2016) Reduction of the uncertainties in the water level-discharge relation of a $1 \mathrm{D}$ hydraulic model in the context of operational flood forecasting. Journal of Hydrology 532:52-64, DOI: 10.1016/j.jhydrol.2015.11.023

Hall JW, Solomatine D (2008) A framework for uncertainty analysis in flood risk management decisions. International Journal of River Basin Management 6(2):85-98

Hegnauer M, Beersma JJ, den Boogaard HFP, Buishand TA, Passchier RH (2014) Generator of Rainfall and Discharge Extremes (GRADE) for the Rhine and Meuse basins

Herschy RW (1999) Hydrometry, Principles and Practices. Wiley

Hoffman MD, Gelman A (2014) The No-UTurn Sampler: Adaptively Setting Path Lengths in Hamiltonian Monte Carlo. Journal of Machine Learning Research 15:1593-1623

Hollaway MJ, Beven KJ, Benskin CMWH, Collins AL, Evans R, Falloon PD, Forber KJ, Hiscock KM, Kahana R, Macleod CJA, Ockenden MC, Villamizar ML, Wearing C, Withers PJA, Zhou JG,
Barber NJ, Haygarth PM (2018) A method for uncertainty constraint of catchment discharge and phosphorus load estimates. Hydrological Processes 32(17):2779-2787, DOI: $10.1002 /$ hyp. 13217

Horritt MS, Di Baldassarre G, Bates PD, Brath A (2007) Comparing the performance of a 2-D finite element and a 2-D finite volume model of floodplain inundation using airborne SAR imagery. Hydrological Process 21(20):2745-2759, DOI: $10.1002 /$ hyp. 6486

Hulscher SJMH, Daggenvoorde RJ, Warmink JJ, Vermeer K, Van Duin OJM (2017) River dune dynamics in regulated rivers. In: 4th International Symposium of Shallow Flows, Eindhoven, Netherlands, pp 1-4

ISO 1100-2 (2010) Hydrometry measurement of liquid flow in open channels-Part 2: Determination of the stage-discharge relationship. International Organization for Standardization, Geneva, Switzerland

Jansen PP, Van Bendegom L, Van den Berg J, De Vries M, Zanen A (1979) Principles of River Engineering: The NonTidal Alluvial River. Delftse Uitgevers Maatschappij, Delft, Netherlands

Julien PY, Klaassen GJ (1995) SandDune geometry of large rivers during floods. Journal of Hydraulic Engineering 121(9):657-663, DOI: 10.1061/(ASCE)07339429(1995)121:9(657)

Julien PY, Klaassen GJ, Ten Brinke WBM, Wilbers AWE (2002) Case Study: Bed Resistance of Rhine River during 1998 Flood. Journal of Hydraulic Engineering 128(12):10421050, DOI: $10.1061 /$ (ASCE)07339429(2002)128:12(1042)

Karamuz E, Osuch M, Romanowicz RJ (2016) The influence of rating curve uncertainty on flow conditions in the River Vistula in Warsaw. In: GeoPlanet: Earth and Planetary Sciences, Springer Verlag, vol none, pp 153-166

Kim Y, Tachikawa Y, Shiiba M, Kim S, Yorozu K, Noh SJ (2013) Simultaneous estimation of inflow and channel roughness using 2D hydraulic model and particle filters. Journal of Flood Risk Management 6(2):112-123, DOI: $10.1111 /$ j.1753-318X.2012.01164.x 
Kleinhans MG, Jagers HRA, Mosselman E, Sloff CJ (2008) Bifurcation dynamics and avulsion duration in meandering rivers by one-dimensional and three-dimensional models. Water Resources Research 44(8):131, DOI: 10.1029/2007WR005912

Kleinhans MG, Cohen KM, Hoekstra J, IJmker JM (2011) Evolution of a bifurcation in a meandering river with adjustable channel widths, Rhine delta apex, The Netherlands. Earth Surface Processes and Landforms 36(15):2011-2027, DOI: 10.1002/esp.2222

Kleinhans MG, Klijn F, Cohen KM, Middelkoop H (2013) Wat wil de rivier zelf eigenlijk?

Klijn F, de Bruin D, de Hoog MC, Jansen S, Sijmons DF (2013) Design quality of roomfor-the-river measures in the Netherlands: role and assessment of the quality team (Q-team). International Journal of River Basin Management 11(3):287-299, DOI: $10.1080 / 15715124.2013 .811418$

Klijn F, Asselman NEM, Mosselman E (2018a) Robust river systems: On assessing the sensitivity of embanked rivers to discharge uncertainties, exemplified for the Netherlands' main rivers. Journal of Flood Risk Management p e12511, DOI: $10.1111 /$ jfr3.12511

Klijn F, Asselman NEM, Wagenaar D (2018b) Room for Rivers: Risk Reduction by Enhancing the Flood Conveyance Capacity of The Netherlands' Large Rivers. Geosciences 8(6):224, DOI: $10.3390 /$ geosciences 8060224

Kok M, Jongejan R, Nieuwjaar M, Tánczos I (2017) Fundamentals of Flood Protection. Technical report, Expertise Network for Flood Protection and the Ministery of Infrastructure and the Environment, Breda, Netherlands

Kuczera G (1996) Correlated Rating Curve Error in Flood Frequency Inference. Water Resources Research 32(7):2119-2127, DOI: 10.1029/96WR00804

Lang M, Pobanz K, Renard B, Renouf E, Sauquet E (2010) Extrapolation of rating curves by hydraulic modelling, with application to flood frequency analysis. Hydrological Sciences Journal 55(6):883898, DOI: 10.1080/02626667.2010.504186
Le Coz J, Renard B, Bonnifait L, Branger F, Le Boursicaud R (2014) Combining hydraulic knowledge and uncertain gaugings in the estimation of hydrometric rating curves: A Bayesian approach. Journal of Hydrology 509:573-587, DOI: 10.1016/j.jhydrol.2013.11.016

Liu Z, Merwade V (2018) Accounting for model structure, parameter and input forcing uncertainty in flood inundation modeling using Bayesian model averaging. Journal of Hydrology 565:138-149, DOI: 10.1016/j.jhydrol.2018.08.009

Makaske B, Maas GJ, van den Brink C, Wolfert HP (2011) The Influence of Floodplain Vegetation Succession on Hydraulic Roughness: Is Ecosystem Rehabilitation in Dutch Embanked Floodplains Compatible with Flood Safety Standards? Ambio 40(4):370-376, DOI: $10.1007 / \mathrm{S} 13280-010-$ 0120-6

Mander RJ (1978) Aspects of unsteady flow and variable backwater. In: Herschy R (Ed.) Hydrometry: Principles and Practice, John Wiley \& Sons, Chichester, UK

Mansanarez V, Renard B, Le Coz J, Lang M, Darienzo M (2019a) Shift Happens! Adjusting Stage-Discharge Rating Curves to Morphological Changes at Known Times. Water Resources Research 55(4):2876-2899, DOI: $10.1029 / 2018$ WR023389

Mansanarez V, Westerberg IK, Lam N, Lyon SW (2019b) Rapid Stage-Discharge Rating Curve Assessment Using Hydraulic Modeling in an Uncertainty Framework. Water Resources Research 55(11):97659787, DOI: 10.1029/2018WR024176

Marijnissen R, Kok M, Kroeze C, Van LoonSteensma J (2019) Re-evaluating safety risks of multifunctional dikes with a probabilistic risk framework. Natural Hazards and Earth System Sciences 19(4):737-756, DOI: 10.5194/NHESS-19-737-2019

McMillan H, Seibert J, Petersen-Overleir A, Lang M, White P, Snelder T, Rutherford K, Krueger T, Mason R, Kiang J (2017) How uncertainty analysis of streamflow data can reduce costs and promote robust decisions in water management applications. Water Resources Research 53(7):5220-5228, DOI: 10.1002/2016WR020328 
Merz B, Thieken AH (2009) Flood risk curves and uncertainty bounds. Natural Hazards 51(3):437-458, DOI: 10.1007/s11069-0099452-6

Middelkoop H, Erkens G, Van der Perk M (2010) The Rhine delta - a record of sediment trapping over time scales from millennia to decades. Journal of Soils and Sediments 2010 10:4 10(4):628-639, DOI: 10.1007/S11368-010-0237-Z

Moyeed RA, Clarke RT (2005) The use of Bayesian methods for fitting rating curves, with case studies. Advances in Water Resources 28(8):807-818, DOI: 10.1016/j.advwatres.2005.02.005

Naqshband S, Ribberink JS, Hulscher SJMH (2014) Using Both Free Surface Effect and Sediment Transport Mode Parameters in Defining the Morphology of River Dunes and Their Evolution to Upper Stage Plane Beds. Journal of Hydraulic Engineering 140(6):06014010, DOI: $10.1061 /$ (asce)hy.1943-7900.0000873

Naqshband S, Hoitink AJF, McElroy B, Hurther D, Hulscher SJMH (2017) A Sharp View on River Dune Transition to Upper Stage Plane Bed. Geophysical Research Letters 44(22):437-11, DOI: 10.1002/2017GL075906

Nelson JM, Logan BL, Kinzel PJ, Shimizu Y, Giri S, Shreve RL, McLean SR (2011) Bedform response to flow variability. Earth Surface Processes and Landforms 36(14):1938-1947, DOI: 10.1002/esp.2212

Ocio D, Le Vine N, Westerberg IK, Pappenberger F, Buytaert W (2017) The role of rating curve uncertainty in real-time flood forecasting. Water Resources Research 53(5):4197-4213, DOI: 10.1002/2016WR020225

Ogink HJM (2006) Onzekerheid afvoerverdeling splitsingspunten Rijn. Technical report, WL|Delft Hydraulics

Okoli K, Breinl K, Mazzoleni M, Di Baldassarre G (2019) Design flood estimation: Exploring the potentials and limitations of two alternative approaches. Water (Switzerland) 11(4):729, DOI: $10.3390 / \mathrm{w} 11040729$
Paarlberg A, Barneveld H, Van Vuren BG, Van Balen W (2010) Onzekere afvoerverdeling en hoogwaterstanden rondom de Pannerdensche Kop; Invloed van onzekerheid in Bovenrijn-afvoer en bodemdynamiek. Technical report, HKV Lijn in Water; PR1682.10.

Pahl-Wostl C, Jeffrey P, Isendahl N, Brugnach M (2011) Maturing the New Water Management Paradigm: Progressing from Aspiration to Practice. Water Resources Management 25(3):837-856, DOI: $10.1007 /$ s11269-010-9729-2

Pappenberger F, Beven KJ, Horritt M, Blazkova S (2005) Uncertainty in the calibration of effective roughness parameters in HEC-RAS using inundation and downstream level observations. Journal of Hydrology 302(1-4):46-69, DOI: 10.1016/J.JHYDROL.2004.06.036

Pappenberger F, Matgen P, Beven KJ, Henry JP, Pfister L, De Fraipont P (2006) Influence of uncertain boundary conditions and model structure on flood inundation predictions. Advances in Water Resources 29(10):14301449, DOI: $10.1016 /$ j.advwatres.2005.11.012

Pappenberger F, Beven KJ, Ratto M, Matgen P (2008) Multi-method global sensitivity analysis of flood inundation models. Advances in Water Resources 31(1):1-14, DOI: $10.1016 /$ j.advwatres.2007.04.009

Parrish MA, Moradkhani H, Dechant CM (2012) Toward reduction of model uncertainty: Integration of Bayesian model averaging and data assimilation. Water Resources Research 48(3):W03519, DOI: 10.1029/2011WR011116

Pedersen $\varnothing$, Rüther N (2019) CFD modeling as part of a hybrid modeling case study for a gauging station with challenging hydraulics. Engineering Applications of Computational Fluid Mechanics 13(1):265278, DOI: $10.1080 / 19942060.2019 .1581661$

Peña Arancibia JL, Zhang Y, Pagendam DE, Viney NR, Lerat J, Van Dijk AIJM, Vaze J, Frost AJ (2014) Streamflow rating uncertainty: Characterisation and impacts on model calibration and performance. Environmental Modelling \& Software 63:3244, DOI: 10.1016/j.envsoft.2014.09.011 
Perret E, Renard B, Le Coz J (2021) A Rating Curve Model Accounting for Cyclic StageDischarge Shifts due to Seasonal Aquatic Vegetation. Water Resources Research 57(3), DOI: 10.1029/2020WR027745

Petersen-Øverleir A (2006) Modelling stagedischarge relationships affected by hysteresis using the Jones formula and nonlinear regression. Hydrological Sciences Journal 51(3):365-388, DOI: 10.1623/hysj.51.3.365

Pianosi F, Beven K, Freer J, Hall J, Rougier J, Stephenson D, Wagener T (2016) Sensitivity analysis of environmental models: A systematic review with practical workflow. Environmental Modelling \& Software 79:214-232, DOI: 10.1016/j.envsoft.2016.02.008

Pinter N, Van der Ploeg RR, Schweigert P, Hoefer G (2006) Flood magnification on the River Rhine. Hydrological Processes 20(1):147-164, DOI: 10.1002/hyp.5908

Prinsen G, Van den Boogaard H, Hegnauer M (2015) Onzekerheidsanalyse hydraulica in GRADE. Technical report, Deltares

Rantz SE (1982) Measurement and Computation of Streamflow: Volume 1. Measurement of Stage and Discharge. Technical report, United States Geological Survey, Washington, D.C., USA

Reeze B, van Winden A, Postma J, Pot R, Hop J, Liefveld W (2017) Watersysteemrapportage Rijntakken 19902015 : ontwikkelingen waterkwaliteit en ecologie. Technical report, Bart Reeze Water \& Ecologie; Bureau Stroming; Ecofide; Roelf Pot onderzoek- en adviesbureau; Bureau Waardenburg

Refsgaard JC, van der Sluijs JP, Højberg AJ, Vanrolleghem PA (2007) Uncertainty in the environmental modelling process A framework and guidance. Environmental Modelling \& Software 22(11):1543-1556, DOI: $10.1016 /$ j.envsoft.2007.02.004

Refsgaard JC, van der Sluijs JP, Højberg AL, Vanrolleghem PA (2010) Uncertainty analysis in model-based water management. In: Vanrolleghem PA (Ed.) Modelling Aspects of Water Framework Directive Implementation, IWA Publishing, London, UK
Rijkswaterstaat (2009) IJsselkop bifurcation; Beeldbank Rijkswaterstaat, Ruimte voor de Rivier/Joop van Houdt

Rijkswaterstaat (2012) Hondsbroeksche Pleij; Beeldbank Rijkswaterstaat, Ruimte voor de Rivier/Con Mönnich

Rijkswaterstaat (2019) Rivierkundig beoordelingskader voor ingrepen in de Grote Rivieren. Technical report, Rijkswaterstaat Water, Verkeer en Leefomgeving, Lelystad, The Netherlands

Robinson E, Ogunyoye F, Sayers P, Van den Brink T, Tarrant O (2017) Accounting for residual uncertainty: updating the freeboard guide. Technical report, Environment Agency, Bristol

Saltelli A, Annoni P, Azzini I, Campolongo F, Ratto M, Tarantola S (2010) Variance based sensitivity analysis of model output. Design and estimator for the total sensitivity index. Computer Physics Communications 181(2):259-270, DOI: 10.1016/j.cpc.2009.09.018

Sebok E, Refsgaard JC, Warmink JJ, Stisen S, Jensen KH (2016) Using expert elicitation to quantify catchment water balances and their uncertainties. Water Resources Research 52:5111-5131, DOI: 10.1002/2015WR018461

Sieben J (2008) Taal van de rivierbodem. Technical report, Rijkswaterstaat, Lelystad, The Netherlands

Sikorska AE, Renard B (2017) Calibrating a hydrological model in stage space to account for rating curve uncertainties: general framework and key challenges. Advances in Water Resources 105:51-66, DOI: $10.1016 /$ j.advwatres.2017.04.011

Silva W, Dijkman JPM, Loucks DP (2004) Flood management options for The Netherlands. International Journal of River Basin Management 2(2):101-112, DOI: $10.1080 / 15715124.2004 .9635225$

Snieder E, Shakir R, Khan U (2020) A comprehensive comparison of four input variable selection methods for artificial neural network flow forecasting models. Journal of Hydrology 583:124299, DOI: 10.1016/J.JHYDROL.2019.124299 
Sörengård M, Di Baldassarre G (2017) Simple vs complex rating curves: accounting for measurement uncertainty, slope ratio and sample size. Hydrological Sciences Journal 62(13):2072-2082, DOI: $10.1080 / 02626667.2017 .1367397$

Sperna Weiland F, Hegnauer M, Bouaziz L, Beersma J (2015) Implications of the KNMI'14 climate scenarios for the discharge of the Rhine and Meuse comparison with earlier scenario studies. Technical report, Deltares, Delft, Netherlands

Steenblik S, Gensen MRA, Warmink JJ, Hulscher SJMH (2020) Quantifying uncertainties in the discharge distribution over the river Rhine branches using expert elicitation. In: Uijttewaal W, Franca M, Valero D, Chavarrias V, Ylla Arbós C, Schielen R, Crosato A (Eds.) River Flow 2020; Proceedings of the 10th Conference on Fluvial Hydraulics

Steinbakk GH, Thorarinsdottir TL, Reitan T, Schlichting L, Hølleland S, Engeland K (2016) Propagation of rating curve uncertainty in design flood estimation. Water Resources Research 52(9):6897-6915, DOI: $10.1002 / 2015$ WR018516

Stouthamer E, Berendsen HJA (2001) Avulsion Frequency, Avulsion Duration, and Interavulsion Period of Holocene Channel Belts in the Rhine-Meuse Delta, The Netherlands. Journal of Sedimentary Research 71(4):589-598, DOI: $10.1306 / 112100710589$

Straatsma MW, Huthoff F (2011) Uncertainty in $2 \mathrm{D}$ hydrodynamic models from errors in roughness parameterization based on aerial images. Physics and Chemistry of the Earth 36(7-8):324-334, DOI: 10.1016/J.PCE.2011.02.009

Straatsma MW, Van der Perk M, Schipper AM, De Nooij RJW, Leuven RSEW, Huthoff F, Middelkoop H (2013) Uncertainty in hydromorphological and ecological modelling of lowland river floodplains resulting from land cover classification errors. Environmental Modelling \& $\quad$ Software 42:17-29, DOI: 10.1016/j.envsoft.2012.11.014

Ten Brinke WBM (2013) Fact Finding afvoerverdeling Rijntakken. Technical report
Ten Brinke WBM, Van Zetten R (2020) Het verhaal van de Rijntakken. Technical report, Rijkswaterstaat: PUC_633896_31

Toonen WHJ, Middelkoop H, Konijnendijk TYM, Macklin MG, Cohen KM (2016) The influence of hydroclimatic variability on flood frequency in the Lower Rhine. Earth Surface Processes and Landforms 41(9):1266-1275, DOI: 10.1002/esp.3953

Twijnstra JJ, Gensen MRA, Warmink JJ, Hulscher SJMH, Huthoff F, Horn G (2020) Water balance in the Dutch river Rhine and rating curve uncertainty. In: Uijttewaal W, Franca M, Valero D, Chavarrias V, Ylla Arbós C, Schielen R, Crosato A (Eds.) River Flow 2020; Proceedings of the 10th Conference on Fluvial Hydraulics, Delft, DOI: $10.1201 / \mathrm{b} 22619-304$

US Army Corps of Engineers (2017) Risk assessment for flood risk management studies. Technical report, Washington, D.C.

Van Bergeijk VM, Verdonk VA, Warmink JJ, Hulscher SJMH (2021) The Cross-Dike Failure Probability by Wave Overtopping over Grass-Covered and Damaged Dikes. Water 13(5):690, DOI: 10.3390/W13050690

Van Duin OJM, Hulscher SJMH, Ribberink JS, Dohmen-Janssen CM (2017) Modeling of Spatial Lag in Bed-Load Transport Processes and Its Effect on Dune Morphology. Journal of Hydraulic Engineering 143(2):04016084, DOI: 10.1061/(ASCE)HY.1943-7900.0001254

Van Rijn LC (1993) Principles of Sediment Transport in Rivers Estuaries and Coastal Areas. Aqua Publications, Blokzijl, The Netherlands

Van Vuren S, De Vriend HJ, Ouwerkerk S, Kok M (2005) Stochastic modelling of the impact of flood protection measures along the river waal in the Netherlands. Natural Hazards 36(1-2):81-102, DOI: 10.1007/s11069-0044543-x

Vanoni VA, Hwang LS (1967) Relation between bedforms and friction in streams. Journal of Hydraulics Division 93(3), DOI: 10.1061/JYCEAJ.0001607 
Walker WE, Harremoes P, Rotmans J, Van der Sluijs JP, van Asselt MBA, Janssen P, Krayer von Krauss MP (2003) A Conceptual Basis for Uncertainty Management in Model-Based Decision Support. Integrated Assessment 4(1):5-17

Warmink J, Van Der Klis H, Booij M, Hulscher S (2011) Identification and Quantification of Uncertainties in a Hydrodynamic River Model Using Expert Opinions. Water Resources Management 25:601-622, DOI: $10.1007 / \mathrm{s} 11269-010-9716-7$

Warmink JJ (2014) Dune dynamics and roughness under gradually varying flood waves, comparing flume and field observations. Advances in Geosciences 39:115-121, DOI: 10.5194/adgeo-39-1152014

Warmink JJ, Booij MJ, Van der Klis H, Hulscher SJMH (2013a) Quantification of uncertainty in design water levels due to uncertain bed form roughness in the Dutch river Waal. Hydrological Processes 27(11):1646-1663, DOI: 10.1002/hyp.9319

Warmink JJ, Straatsma MW, Huthoff F, Booij MJ, Hulscher SJMH (2013b) Uncertainty of design water levels due to combined bed form and vegetation roughness in the Dutch River Waal. Journal of Flood Risk Management 6(4):302-318, DOI: $10.1111 /$ jfr3.12014

Warmink JJ, Brugnach M, Vinke-de Kruijf J, Schielen RMJ, Augustijn DCM (2017) Coping with Uncertainty in River Management: Challenges and Ways Forward. Water Resources Management pp 4587-4600, DOI: $10.1007 /$ s11269-017-1767-6
Wilbers AWE, Ten Brinke WBM (2003) The response of subaqueous dunes to floods in sand and gravel bed reaches of the Dutch Rhine. Sedimentology 50(6):1013-1034, DOI: $10.1046 /$ j.1365-3091.2003.00585.x

Winsemius HC, Aerts JCJH, Van Beek LPH, Bierkens MFP, Bouwman A, Jongman B, Kwadijk JCJ, Ligtvoet W, Lucas PL, Van Vuuren DP, Ward PJ (2016) Global drivers of future river flood risk. Nature Climate Change 6(4):381-385, DOI: $10.1038 /$ nclimate2893

Ylla Arbós C, Blom A, Acevedo Goldaracena F, Van Vuren S, Schielen RMJ (2020a) Bed level change in the Upper Rhine Delta and Niederrhein. In: Uijttewaal W, Franca MJ, Valero D, Chavarrias V, Ylla Arbós C, Schielen RMJ, Crosato A (Eds.) River Flow 2020; Proceedings of the 10th Conference on Fluvial Hydraulics, Delft; Netherlands, pp 680-684

Ylla Arbós C, Blom A, Viparelli E, Reneerkens M, Frings RM, Schielen RMJ (2020b) River Response to Anthropogenic Modification: Channel Steepening and Gravel Front Fading in an Incising River. Geophysical Research Letters p e2020GL091338, DOI: $10.1029 / 2020 \mathrm{gl} 1091338$

Zevenbergen C, Rijke J, Van Herk S, Ludy J, Ashley R (2013) Room for the river: international relevance. Water Governance $3(2)$

Zhang W, Feng H, Hoitink AJF, Zhu Y, Gong F, Zheng J (2017) Tidal impacts on the subtidal flow division at the main bifurcation in the Yangtze River Delta. Estuarine, Coastal and Shelf Science 196:301-314, DOI: 10.1016/J.ECSS.2017.07.008 



\section{List of publications}

\section{Peer-reviewed journal papers}

Gensen, M.R.A., Warmink, J.J., Huthoff, F., Hulscher, S.J.M.H. (2020). Feedback mechanism in bifurcating river systems: the effect on water-level sensitivity. Water, 12(7), [1915]. DOI:10.3390/w12071915

Berends, K.D., Gensen, M.R.A., Warmink, J.J., Hulscher, S.J.M.H. (2021). Multidecadal analysis of an engineered river system reveals challenges for model-based design of human interventions. CivilEng, 2(3), 580-598. DOI:10.3390/civileng2030032

Gensen, M.R.A., Warmink, J.J., Huthoff, F., Hulscher, S.J.M.H. (2021). Human interventions in a bifurcating river system: numerical investigation and uncertainty assessment. Journal of Flood Risk Management. e12762. DOI:10.1111/jfr3.12762

\section{Conference papers and abstracts}

Franks, S.W., White, C.J., Gensen, M.R.A. (2015). Estimating extreme flood events assumptions, uncertainty and error. 369: 31-36. Proceedings of the International Association of Hydrological Sciences. DOI:10.5194/piahs-369-31-2015

Gensen, M.R.A., Warmink, J.J., Hulscher, S.J.M.H. (2018). Large-scale uncertainties in river water levels. 122-123. Abstract from NCR Days 2018, Delft, Netherlands.

Gensen, M.R.A., Warmink, J.J., Hulscher, S.J.M.H. (2019). Propagating main channel roughness uncertainty in the bifurcating Dutch Rhine system. 28-29. Abstract from NCR Days 2019, Utrecht, Netherlands.

Gensen, M.R.A., Warmink, J.J., Hulscher, S.J.M.H. (2019). River dune based roughness uncertainty for the Dutch Rhine branches. 101-106. Abstract from MARID VI, Marine and River Dune Dynamics 2019, Bremen, Germany.

Gensen, M.R.A., Warmink, J.J., Hulscher, S.J.M.H. (2020). Water level uncertainties due to uncertain bedform dynamics in the Dutch Rhine system. In Kalinowska, M.B., Mrokowska, M.M., Rowínski, P.M. (Eds.): Recent trends in Environmental Hydraulics: $38^{\text {th }}$ International School of Hydraulics. 
Gensen, M.R.A., Warmink, J.J., Huthoff, F., Hulscher, S.J.M.H. (2020). Uncertain amount of impact of a river intervention in a bifurcating river system. 80-81. Abstract from NCR Days 2020, Nijmegen, Netherlands.

Gensen, M.R.A., Warmink, J.J., Hulscher, S.J.M.H., Huthoff, F. (2020). Effects of a river intervention on water levels in a bifurcating river system. In Uijttewaal, W., Franca, M.J., Valero, D., Chavarrias, V., Ylla Arbos, C., Schielen, R.M.J., Crosato, A. (Eds.), River Flow 2020: Proceedings of the $10^{\text {th }}$ Conference on Fluvial Hydraulics, Delft, Netherlands. 1890-1898. CRC Press/Balkema, London, UK.

Steenblik, S., Gensen, M.R.A., Warmink, J.J., Hulscher, S.J.M.H. (2020). Quantifying uncertainties in the discharge distribution over the river Rhine branches using expert elicitation. In Uijttewaal, W., Franca, M.J., Valero, D., Chavarrias, V., Ylla Arbos, C., Schielen, R.M.J., Crosato, A. (Eds.), River Flow 2020: Proceedings of the $10^{\text {th }}$ Conference on Fluvial Hydraulics, Delft, Netherlands. 797-804. CRC Press/Balkema, London, UK.

Berends, K.D., Gensen, M.R.A., Warmink, J.J., Hulscher, S.J.M.H. (2020). Thirty-year analysis of a changing river system using Bayesian rating curves. In Uijttewaal, W., Franca, M.J., Valero, D., Chavarrias, V., Ylla Arbos, C., Schielen, R.M.J., Crosato, A. (Eds.), River Flow 2020: Proceedings of the $10^{\text {th }}$ Conference on Fluvial Hydraulics, Delft, Netherlands. 10221026. CRC Press/Balkema, London, UK.

Twijnstra, J.J., Gensen, M.R.A., Warmink, J.J., Hulscher, S.J.M.H., Huthoff, F., Horn, G. (2020). Water balance in the Dutch river Rhine and rating curve uncertainty. In Uijttewaal, W., Franca, M.J., Valero, D., Chavarrias, V., Ylla Arbos, C., Schielen, R.M.J., Crosato, A. (Eds.), River Flow 2020: Proceedings of the $10^{\text {th }}$ Conference on Fluvial Hydraulics, Delft, Netherlands. 2171-2178. CRC Press/Balkema, London, UK.

Gensen, M.R.A., Warmink, J.J., Huthoff, F., Hulscher, S.J.M.H. (2021). Compensating human interventions at a river bifurcation. 46-47. Abstract from NCR Days 2021, Enschede, Netherlands.

Gensen, M.R.A., Warmink, J.J., Berends, K.D., Huthoff, F., Hulscher, S.J.M.H. (2021). Rating curves with a closing water balance in the bifurcating Rhine River in the Netherlands. Abstract from the $4^{\text {th }}$ World's Large Rivers Conference, Moscow, Russia.

\section{Other}

Gensen, M.R.A. (2018). Large-scale uncertainties in river water levels: Literature report. CE\&M research report 2018-011/WEM-001. University of Twente, Enschede, Netherlands. 


\section{About the author}

Matthijs Gensen was born on August 16, 1993 in Apeldoorn, the Netherlands. He grew up in Emst, a small town in the Veluwe region. After finishing the secondary school at the RSG Noord-Oost Veluwe in Epe, he moved to Enschede to start a Bachelor of Sciences in Civil Engineering at the University of Twente. For his BSc thesis, he travelled to the Australian island of Tasmania to visit the University of Tasmania. There, he analyzed observed discharges of major Australian rivers to see whether climatic oscillations like the El Niño Southern Oscillation influenced them. Matthijs then moved to Delft, to start a MSc in Hydraulic engineering with a focus on river engineering. He attained the MSc degree with a thesis entitled 'Wave overtopping in harbour areas', which was the result of research he performed in collaboration with HKV Lijn in Water. In September 2017, Matthijs started a $\mathrm{PhD}$ at the University Twente in the AllRisk progam. During his $\mathrm{PhD}$, Matthijs attended the SAMO summer school and multiple national and international conferences. He also supervised several BSc and MSc graduate students.

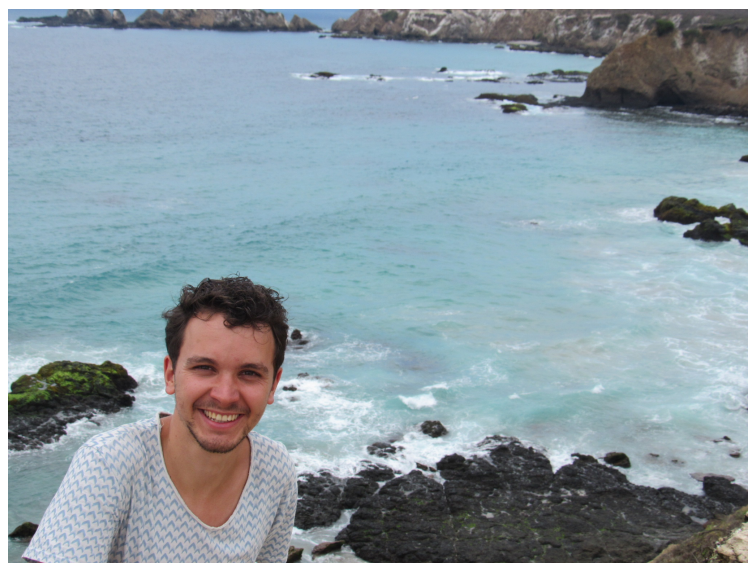

